\title{
Sandra Dalfiume
}

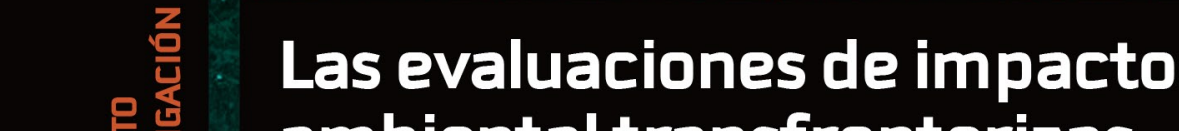 ambiental transfronterizas en el Perú:}

\section{una primera aproximación}

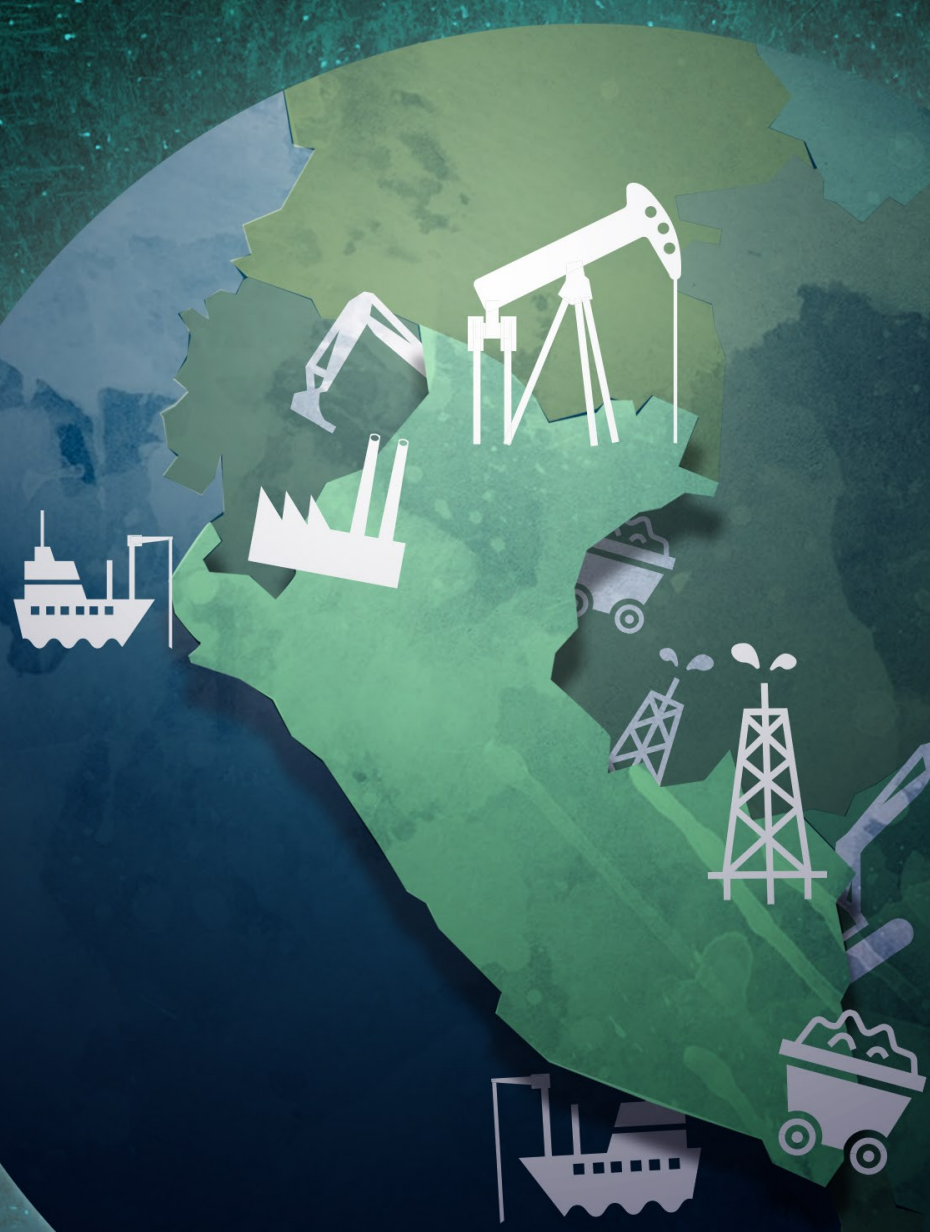




zas evaluaciones de impacto 足 ambiental transfronterizas en el Perú:

una primera aproximación 
(C) Sandra Dalfiume, 2018

De esta edición:

(C) Universidad del Pacífico

Avenida Salaverry 2020

Lima 11, Perú

www.up.edu.pe

Las evaluaciones de impacto ambiental transfronterizas en el Perú: una primera aproximación

Sandra Dalfiume

1. a edición: marzo 2018

Diseño de la carátula: Ícono Comunicadores

ISBN e-book: 978-9972-57-386-6

http://dx.doi.org/10.21678/978-9972-57-386-6

\section{BUP}

Dalfiume, Sandra.

Las evaluaciones de impacto ambiental transfronterizas en el Perú / Sandra Dalfiume. -- 1a edición. -- Lima : Universidad del Pacífico, 2018.

166 p. -- (Documento de investigación ; 9)

1. Evaluación de impacto ambiental -- Perú

2. Contaminación transfronteriza -- Perú

3. Derecho internacional público

4. Derecho ambiental internacional

I. Universidad del Pacífico (Lima)

$348.54($ SCDD)

Miembro de la Asociación Peruana de Editoriales Universitarias y de Escuelas Superiores (Apesu) y miembro de la Asociación de Editoriales Universitarias de América Latina y el Caribe (Eulac).

La Universidad del Pacífico no se solidariza necesariamente con el contenido de los trabajos que publica. Prohibida la reproducción total o parcial de este texto por cualquier medio sin permiso de la Universidad del Pacífico.

Derechos reservados conforme a Ley. 
Para Johanna, mi madre, y Sandro, mi padre. 

«Borders are meaningless[...] There's one ocean, one land, one system, which we all depend upon».

Jean-Michel Cousteau 



\section{Índice}

$\begin{array}{ll}\text { Agradecimientos } & 11\end{array}$

Lista de abreviaturas, acrónimos y siglas $\quad 13$

Introducción $\quad 17$

1. Introducción a las EA transfronterizas y la relevancia

1.1 ¿Qué son las EA transfronterizas? 23

1.2 ¿Cuáles son los impactos que deben ser considerados

1.3 ¿Por qué es importante establecer reglas de prevención para los impactos transfronterizos? 31

1.3.1 El surgimiento de la obligación de prevención $\quad 33$

1.3.2 Situación jurídica de la prevención $\quad 35$

1.3.3 Alcance de la prevención $\quad 36$

1.3.4 Las EA transfronterizas como medidas preventivas $\quad 37$

1.4 La situación del Perú $\quad 38$

1.4.1 Minería $\quad 38$

1.4.2 Hidrocarburos $\quad 43$

1.4.3 Servicio de abastecimiento de agua $\quad 45$

1.4.4 Servicios de saneamiento $\quad 46$

$\begin{array}{ll}1.4 .5 \text { Hidrovías } & 47\end{array}$

1.4.6 Hidroeléctricas 48

1.5 Conclusión $\quad 50$

2. La obligación consuetudinaria internacional de llevar a cabo

EA transfronterizas 
2.1 La costumbre internacional 53

2.1.1 Elemento objetivo $\quad 54$

2.1.2 Opinio juris 56

2.1.3 Oposición y regionalización de la costumbre $\quad 58$

2.2 La obligación consuetudinaria internacional de elaborar EA transfronterizas $\quad 58$

2.2.1 Elemento objetivo $\quad 58$

2.2.2 Opinio juris 65

2.3 Contenido de la obligación de realizar EA transfronterizas $\quad 75$

2.3.1 ¿Cuándo se debe llevar a cabo el proceso? $\quad 76$

2.3.2 La estructura procedimental y el contenido de las EA transfronterizas $\quad 77$

$\begin{array}{ll}\text { 2.3.3 Obligación de medios } & 90\end{array}$

2.4 Conclusión 91

3. El contexto nacional sobre la regulación de las EA

y los impactos transfronterizos 93

3.1 La incorporación e implementación del derecho consuetudinario en el sistema jurídico peruano 93

3.1.1 La incorporación $\quad 93$

3.1.2 La implementación $\quad 96$

3.2 La implementación del proceso de EA transfronteriza en el Perú 101

3.2.1 Implementación a nivel legislativo 101

3.2.2 La implementación a nivel administrativo $\quad 116$

3.3 Conclusión 119

4. Propuesta de implementación de las EA transfronterizas en el Perú 121

4.1 Escenario ideal: primero tratado, luego desarrollo de legislación nacional $\quad 122$

4.1.1 La importancia del tratado $\quad 122$

4.1.2 Adhesión al Convenio Espoo o elaboración de un nuevo convenio 124

4.1.3 Desarrollo de legislación a partir de un tratado $\quad 130$

4.2 Escenario real: implementación directa 130

4.2.1 Países con implementación directa 131

4.2.2 Recomendaciones para adecuar la legislación peruana a la obligación internacional de realizar EA transfronterizas 138

4.3 Conclusión

5. Conclusiones y recomendaciones 149

Referencias 155 


\section{Agradecimientos}

Elaborar un documento de investigación es un proceso que difícilmente se puede llevar a cabo si no se cuenta con un grupo de personas valiosas que a lo largo del mismo orientan, asesoran y motivan.

En esta sección, quisiera comenzar agradeciendo a Carlos J. Zelada. La publicación de este documento, y en sí todo el trabajo de investigación realizado, no hubiese sido posible sin su tiempo, paciencia, buen humor y fantástica asesoría.

En segundo lugar, quiero agradecer a mi familia, especialmente a mis abuelos Tina, Andrés, Rita y Giuliano, a mis padres, Johanna y Sandro, y a mi hermano Gianfranco, quienes han sido mi principal apoyo y motivación.

A mis amigas, amigos y colegas: Mirko, Denisse, Alexandra, Kathy, Nelson, Adela, Cecilia, Dora, Ale, Milagros, Carla, Elisa, Andrea y Borja, cuyo apoyo y palabras de aliento nunca faltaron a lo largo de todo este proceso.

$\mathrm{Al}$ profesor Lorenzo de la Puente, por introducir en una de sus clases el tema de los dańos transfronterizos.

Y, finalmente, al Dr. Eduardo Calvo Buendía, Ph. D., asesor de la Dirección General de Medio Ambiente del Ministerio de Relaciones Exteriores; al Ing. Elvis Medina Peralta, director general de la Dirección General de Asuntos Ambientales Mineros del Ministerio de Energía y Minas; al Dr. Iván Lanegra, exadjunto para el Medio Ambiente, los Servicios Públicos y Pueblos Indígenas de la Defensoría del Pueblo; a Mariana Montoya, Ph. D., directora Perú de la Wildlife Conservation Society (WCS); al Dr. Ramón Rivero, coordinador del proyecto Fortalecimiento de la Capacidad Indígena en la Resolución de 
Conflictos en la Asociación para la Conservación de la Cuenca Amazónica (ACCA); al Ing. Edmundo Roca, gerente de unidad de Minsur S. A.; y al Dr. Erick Leddy García Cerrón, especialista legal de la Unidad Técnico-Normativa del Servicio Nacional de Certificación Ambiental (Senace), por hacerse un tiempo en sus apretadas agendas y contribuir con valiosos comentarios y aportes al presente trabajo. 
Lista de abreviaturas, acrónimos y siglas

\section{Abreviatura Significado}

ACCA Asociación para la Conservación de la Cuenca Amazónica

ADI Asociación de Derecho Internacional

ANA Autoridad Nacional del Agua

Aladi Asociación Latinoamericana de Integración

BDAN Banco de Desarrollo de América del Norte

BID Banco Interamericano de Desarrollo

BM Banco Mundial

CARU Comisión Administradora del Río Uruguay

CAN Comunidad Andina

CCA Comisión para la Cooperación Ambiental de América del Norte

CDB Convenio sobre la Diversidad Biológica

CEE Comunidad Económica Europea

CEPE Comisión Económica para Europa de las Naciones Unidas (véase Unece)

CDI Comisión de Derecho Internacional de las Naciones Unidas

CIDH Corte Interamericana de Derechos Humanos

CIJ Corte Internacional de Justicia

CMARN Código de Medio Ambiente y los Recursos Naturales

CMNUCC Convención Marco de las Naciones Unidas sobre el Cambio Climático

Cocef Comisión de Cooperación Ecológica Fronteriza

Conam Consejo Nacional del Ambiente

Conama Conselho Nacional do Meio Ambiente 
Convemar Convención de las Naciones Unidas sobre el Derecho del Mar

Convenio Convenio sobre acceso a la información, participación del Aarhus público en la toma de decisiones y acceso a la justicia en materia de medio ambiente

Convenio Convenio Espoo sobre la Evaluación del Impacto AmbienEspoo tal en un Contexto Transfronterizo

DAI

Derecho Ambiental Internacional

DIA

Declaración de Impacto Ambiental

Dicapi

Dirección General de Capitanías y Guardacostas

DIP

Derecho Internacional Público

EA Evaluaciones de impacto ambiental

EA transfron- Evaluaciones de impacto ambiental transfronterizas terizas

EE. UU. Estados Unidos de América

EIA (en texto Estudio de impacto ambiental en español)

EIA (en texto Environmental impact assessment en inglés)

EIA-d Estudio de impacto ambiental detallado

EIA-s/d Estudio de impacto ambiental semidetallado

Estado(s) Estado(s) distinto(s) al Estado de origen cuyo medio afectado(s) ambiente se ve afectado por la ejecución de una actividad en el Estado de origen

Estado(s) Estado(s) que comparten frontera con el Estado de origen fronterizo(s)

Estado de Estado donde se ejecuta la actividad origen 
Ibama Instituto Brasileiro do Meio Ambiente e dos Recursos Naturais Renováveis

ILC International Law Commission of the United Nations

LGA Ley General del Ambiente

MEE Ministerio de Economía y Empleo de Finlandia

MDSMA Ministerio de Desarrollo Sostenible y Medio Ambiente de Bolivia

MEM Ministerio de Energía y Minas

Minam Ministerio del Ambiente

Mitinci Ministerio de Industria, Turismo, Integración y Negociaciones comerciales Internacionales

MRNPMB Ministerio de Recursos Naturales y Protección del Medio Ambiente de Bielorrusia

NEPA National Environmental Policy Act

Nimos National Instituut Voor Milieu \& Ontwikkeling in Suriname

OEA Organización de los Estados Americanos

OEFA Organismo de Evaluación y Fiscalización Ambiental

OI Organización internacional

OMC Organización Mundial del Comercio

OMS Organización Mundial de la Salud

ONU Organización de las Naciones Unidas

ONG Organización no gubernamental

Orpalc Oficina Regional para América Latina y el Caribe

OTCA Organización del Tratado de Cooperación Amazónica

PCM Presidencia del Consejo de Ministros

Planaa Plan Nacional de Acción Ambiental 
Pluspetrol Pluspetrol Perú Corporation S. A.

Perú

PNUMA Programa de las Naciones Unidas para el Medio Ambiente

Produce Ministerio de la Producción

RIAA Report of International Arbitral Awards

Ropme Organización Regional para la Protección del Medio Marino

RR. EE. Ministerio de Relaciones Exteriores

SEIA Sistema Nacional de Evaluación de Impacto Ambiental

SELA Sistema Económico Latinoamericano y del Caribe

Senace Servicio Nacional de Certificación Ambiental para las Inversiones Sostenibles

Sinefa Sistema Nacional de Evaluación y Fiscalización Ambiental

SNAP Sistema Nacional de Áreas Protegidas de Bolivia

SNGA Sistema Nacional de Gestión Ambiental

Sunass Superintendencia Nacional de Servicios de Saneamiento

TdR Términos de referencia

TEIA Transboundary environmental impact assessment

TI Trabajo de investigación

TLCAN Tratado de Libre Comercio para América del Norte

UE Unión Europea

UICN Unión Internacional para la Conservación de la Naturaleza

Unasur Unión de Naciones Suramericanas

Unece United Nations Economic Commission for Europe

UP Universidad del Pacífico 


\section{Introducción}

Darnos cuenta de la importancia de analizar los impactos que las actividades económicas podían generar sobre el medio ambiente nos tomó mucho tiempo, y prueba de eso es que las evaluaciones de impacto ambiental (EA) recién se comenzaron a llevar a cabo a mediados del siglo XX. Percatarnos de esta situación en el Perú nos tomó aún más tiempo, puesto que recién a comienzos de la década de 1990, con la aprobación del ya derogado Código del Medio Ambiente y los Recursos Naturales (CMARN), se consideró necesario realizar EA previas al inicio de una actividad económica.

Dar el paso de analizar el posible impacto ambiental y social que una actividad económica podía generar en nuestro entorno fue una decisión asertiva. Sin embargo, la solución fue parcialmente correcta puesto que los Estados olvidaron que el medio ambiente es un sistema integrado que no conoce de fronteras políticas y que los impactos que se generan en una parte del mundo pueden producir efectos a miles de kilómetros de distancia del lugar donde se originaron.

Esta concepción de que una actividad que se genera dentro de un Estado puede impactar el medio ambiente más allá de sus fronteras es relativamente nueva. Y mientras más vamos conociendo el funcionamiento de nuestros océanos, ríos y atmósfera, más vamos comprendiendo la frecuencia con que se pueden dar los impactos transfronterizos y, como consecuencia, la urgente necesidad de buscar prevenirlos o en todo caso minimizarlos.

La visión de que una actividad económica que se desarrolla en una parte del mundo puede producir efectos en otra parte del mundo, se comenzó a delinear por primera vez en el año 1972 en la Cumbre de Estocolmo. Desde ahí hasta su paso por la Cumbre de la Tierra, llevada a cabo en el año 1992 en Río de Janeiro, esta idea fue enriqueciéndose. Sin embargo, este concepto fue realmente asimilado como tal en diciembre de 2015, en París. En esta 
conferencia, más de 190 países se pusieron de acuerdo en un documento en el que, entre otros aspectos, asumieron que los problemas ambientales de un Estado son también los problemas ambientales de otros Estados.

En los últimos 100 años han existido varios ejemplos de actividades que se llevaron a cabo en un Estado y que generaron impactos que trascendieron sus fronteras. Uno de los primeros casos sobre los que se tiene registro es el referido a la fundición Trail. Desde el año 1896 existía, cerca de la localidad de Trail, en Canadá, aproximadamente a $17 \mathrm{~km}$ de la frontera con los Estados Unidos de América (EE. UU.), una fundición de zinc y plomo, la cual, en su proceso de producción, generaba grandes cantidades de bióxido de azufre (Gómez-Robledo, 2003, p. 351). Desde el año 1925 hasta el año 1931, se constató que las emisiones traspasaron la frontera canadiense, causando dańos en el estado de Washington, EE. UU. (p. 351). Como consecuencia de esto, ambas partes celebraron un acuerdo internacional de arbitraje (p. 352), del cual emanaron dos laudos, uno en el año 1938 y otro en el año 1941, en los cuales, entre otros aspectos, se indicó que efectivamente se había efectuado un daño a causa de la fundición, estableciéndose el pago de indemnizaciones e indicándose que «[...] ningún Estado tiene el derecho de usar o permitir el uso de su territorio de tal manera que por los humos cause dańo en otro territorio o en las propiedades o las personas que ahí se encuentren, cuando se trate de consecuencias graves y el daño sea determinado a través de pruebas claras y convincentes» ${ }^{1}$.

Un caso más reciente de impactos transfronterizos fue el que ocurrió entre Colombia y Ecuador. En el marco de su política para eliminar cultivos de coca, Colombia entre los años 2000 y 2007 realizó fumigaciones sobre los cultivos de coca, las cuales generaron dańos a cultivos ecuatorianos. Este caso, si bien fue llevado a la Corte Internacional de Justicia (CIJ), fue posteriormente resuelto por ambos países de manera diplomática, con Colombia comprometiéndose a pagar 15 millones de dólares para compensar cualquier tipo de daño que hubiera podido generar (Angarita, 2014).

Acercándonos a nuestra realidad, en 2013, 100 metros del principal oleoducto de la empresa estatal Petroecuador se rompieron, generando como consecuencia que 11.480 barriles de petróleo se vertieran en el río Coca en la Amazonía ecuatoriana. El petróleo vertido viajó hacia el Perú hasta la cuenca

\footnotetext{
${ }^{1}$ Texto original en inglés: «[...] no State has the right to use or permit the use of its territory in such a manner as to cause injury by fumes in or the territory of another of the properties or persons therein, when the case is of serious consequence and the injury is established by clear and convincing evidence" (Trail Smelter Case, 1938, 1941).
} 
del río Napo, en una zona correspondiente a la localidad de Cabo Pantoja, en el distrito de Torres Causana, provincia de Maynas, región Loreto, llegando finalmente hasta Brasil.

Asimismo, como veremos más adelante, el Perú no ha estado ajeno a cuestionamientos por generar impactos de carácter transfronterizo. Los usos y transvases hacia la ciudad de Tacna de las aguas del río Maure, a través de distintos proyectos hidráulicos en la cuenca transfronteriza del Maure-Mauri, han sido cuestionados por afectar el caudal y contaminar las aguas en el lado chileno, así como por haber afectado extensas áreas de bofedales chilenos. De igual manera, en el año 2011, diversos medios chilenos señalaron que la minera peruana Pucamarca, ubicada en la región Tacna, a un kilómetro del hito 52 de la frontera peruano-chilena, como consecuencia de sus operaciones, estaba afectando a las personas y la flora y fauna del territorio chileno ${ }^{2}$.

Es en este contexto en el cual se introduce y se puede apreciar la importancia de realizar EA transfronterizas. Estos instrumentos consisten en un proceso de toma de decisiones llevado a cabo por los Estados para evaluar los impactos que podría producir una actividad no solo sobre su medio ambiente, sino también sobre el medio ambiente de sus Estados vecinos. Llevar a cabo este proceso permite a los Estados identificar medidas para prevenir o minimizar la ocurrencia de impactos transfronterizos.

El presente trabajo busca introducir el tema de las EA transfronterizas en el Perú desde una perspectiva del derecho internacional público y el derecho interno. Para lograr esto, ha sido dividido en cuatro capítulos.

El primer capítulo busca introducir este instrumento, haciendo referencia a su origen, las actividades económicas sometidas a evaluación y su relación con el principio de prevención, pilar del derecho ambiental. Asimismo, a través de este capítulo se busca presentar la idea de que es de suma importancia para el Perú introducir lo más pronto posible este instrumento en su legislación, puesto que el país tiene una alta probabilidad de generar impactos transfronterizos.

A través del segundo capítulo, se busca demostrar que las EA transfronterizas constituyen hoy una obligación consuetudinaria del derecho internacional público. Para esto, se probará la existencia tanto del elemento objetivo como de la opinio juris, ambos elementos necesarios para determinar si una obligación consuetudinaria existe o no.

\footnotetext{
${ }^{2}$ Estos ejemplos son desarrollados con mayor detalle en el capítulo 1, subcapítulo «1.4 La situación del Perú».
} 
Habiéndose demostrado que existe una obligación internacional de realizar EA transfronterizas, en el capítulo tercero se analizarán las diversas normas e instrumentos del sector ambiental, vigentes hasta diciembre de 2016, a fin de identificar si en la legislación peruana se ha recogido la figura de EA transfronterizas. Asimismo, en este capítulo se presentará el caso de una minera peruana que evaluó los posibles impactos que sus operaciones podrían generar sobre el territorio de un país vecino.

Finalmente, en el último capítulo se presentará una propuesta de cómo el Perú podría implementar las EA transfronterizas. Para esto, se propondrán sugerencias de adopción de instrumentos a nivel internacional, así como sugerencias de modificaciones para la legislación nacional.

Ahora bien, no quisiéramos dejar de mencionar cómo surgió el interés en realizar el presente trabajo de investigación. Este se remonta al año 2013, cuando en el curso de derecho ambiental el profesor Lorenzo de la Puente hizo referencia a la posibilidad de que se demande al Perú por los daños transfronterizos que se estarían generando como consecuencia de la minería ilegal en Madre de Dios.

A partir de ese momento, surgió este interés sobre los impactos transfronterizos. Con las investigaciones realizadas -bajo la orientación del profesor, y también asesor del presente trabajo, Carlos J. Zelada-, descubrimos que en el Derecho Ambiental Internacional (DAI) no existía claridad respecto a las reglas de responsabilidad ambiental por dańos transfronterizos, pero que, en cambio, sí existía claridad en relación con las reglas de prevención. A partir de entonces, el paso a analizar las EA transfronterizas fue inmediato.

El método de trabajo usado en el presente trabajo fue principalmente el de revisión de fuentes secundarias. Realizamos la consulta bibliográfica de distintos libros, documentos de trabajo y artículos de revistas, así como también un riguroso análisis de la normativa internacional y nacional vigente sobre la materia hasta diciembre de 2016. Y a fin de tener conocimiento sobre si en el Perú se habían llevado a cabo EA transfronterizas, utilizamos el recurso de acceso a la información pública, regulado por la Ley de Transparencia y Acceso a la Información Pública, Ley 27806, para solicitar al Ministerio de Energía y Minas una copia del estudio de impacto ambiental (EIA) de un proyecto minero ubicado en la frontera con Chile. Por último, con el fin de corroborar la información obtenida de fuentes secundarias, realizamos entrevistas a distintos representantes del sector público, privado y de la sociedad civil.

Cabe señalar que todo este proceso de investigación tuvo una duración aproximada de tres ańos, marcada por dos grandes etapas. La primera etapa, 
desde el año 2013 hasta junio de 2015, estuvo enfocada en convertir las investigaciones realizadas en una tesis para obtener el título profesional de abogada. Y la segunda etapa, que abarcó los meses finales de 2015, el año 2016 y principios de 2017, estuvo enfocada en adecuar la señalada tesis al presente documento de investigación.

Por último, quisiéramos culminar esta introducción señalando la importancia de tener en cuenta que, más allá del hecho de la existencia de una obligación internacional de llevar a cabo EA, los impactos ambientales generados por los individuos no conocen y no respetan las fronteras establecidas por los Estados. Es por esto que se debe buscar analizar los impactos ambientales a través de mecanismos que vean más allá de las fronteras, que analicen el medio ambiente como un solo sistema, como es el caso de las EA transfronterizas. En ese sentido, esperamos que este documento de investigación contribuya a promover el interés en relación con este tema e impulse la realización de investigaciones adicionales a fin de que, en el menor tiempo posible, este procedimiento sea incluido en nuestro Sistema Nacional de Evaluación de Impacto Ambiental (SEIA). 



\section{Introducción a las EA transfronterizas y la relevancia de estas para el Perú}

\section{1 ¿Qué son las EA transfronterizas?}

El estudio de las EA transfronterizas se enmarca en el campo del Derecho Ambiental Internacional (DAI), y, en relación con este sistema normativo, es importante tener en cuenta que se trata de un sistema disperso que no cuenta con una organización internacional (OI) que centralice toda la producción normativa, a diferencia, por ejemplo, de las normas de salud internacional o comercio internacional, que cuentan con instituciones que centralizan la producción de normas, como la Organización Mundial de la Salud (OMS) y la Organización Mundial del Comercio (OMC) respectivamente.

En ese sentido, si bien existen diversos instrumentos del hard law y soft law que buscan esbozar una definición sobre las EA transfronterizas, no existe aún un tratado general que establezca una definición al respecto. Lo que sí existe es un tratado vigente para 45 países, denominado Convenio Espoo sobre la Evaluación del Impacto Ambiental en un Contexto Transfronterizo ${ }^{3}$, el cual constituye el único instrumento legal vigente referido únicamente a la regulación de las EA transfronterizas.

\footnotetext{
${ }^{3}$ El Convenio Espoo es hasta la fecha el único tratado referido únicamente a las EA transfronterizas. Fue adoptado en el año 1991 en Espoo, Finlandia, en el marco de la Comisión Económica para Europa de las Naciones Unidas (Unece, por sus siglas en inglés), y entró en vigor el 10 de septiembre de 1997. A la fecha, ha sido ratificado por 45 países. Este instrumento será analizado detenidamente a lo largo del presente trabajo.
} 
Si bien este instrumento no define con exactitud qué son las EA transfronterizas, su artículo 1 esboza las siguientes definiciones:

- Evaluación de impacto medioambiental: "procedimiento nacional destinado a evaluar el probable impacto que una actividad propuesta tendrá en el medio ambiente»;

- Impacto: «los efectos causados por una actividad propuesta en el medio ambiente, incluidos la salud y la seguridad de los seres humanos, la flora, la fauna, el suelo, la atmósfera, el agua, el clima, el paisaje y los monumentos históricos u otras estructuras materiales o la interacción entre esos factores; incluye asimismo las repercusiones sobre el patrimonio cultural o las condiciones socioeconómicas que se deriven de las alteraciones de esos factores»;

- Impacto transfronterizo: «todo impacto no necesariamente de naturaleza global, dentro de una zona bajo la jurisdicción de una de las Partes y que haya sido causado por una actividad propuesta cuyo origen físico esté ubicado total o parcialmente dentro de una zona situada bajo la jurisdicción de otra Parte»;

En el campo del soft law, Timo Koivurova, en su libro Las evaluaciones de impacto ambiental transfronterizas en la Unión Europea: el Convenio Espoo y el Protocolo de Kiev sobre las evaluaciones ambientales estratégicas ${ }^{4}$, esboza la siguiente definición para las EA transfronterizas:

La Evaluación de Impacto Ambiental (EA) puede ser definida -en su mínima expresión- como un procedimiento llevado a cabo por un Estado, con la participación de sus ciudadanos, para evaluar científicamente los posibles impactos ambientales que una actividad propuesta pudiese generar [...]. Las EA transfronterizas a menudo se perciben solo como un procedimiento ampliado de EA entre Estados territoriales que incluye el análisis de los impactos transfronterizos y los actores extranjeros en el proceso de EA nacional del Estado de origen 5 .

\footnotetext{
${ }^{4}$ Título original en inglés: Transboundary Environmental Impact Assessment in the European Union: The Espoo Convention and its Kiev Protocol on Strategic Environmental Assessment.

${ }^{5}$ Texto original en inglés: «Environmental Impact Assessment (EIA) can be defined -at its minimum- as a government-controlled procedure involving the public within which scientific assessments are conducted of the potential environmental impacts of a proposed activity [...]. TEIA is often perceived only as an extended EIA procedure between territorial states that includes transboundary impacts and foreign actors into the domestic EIA of the origin state» (Marsden \& Koivurova, 2011, p. 15).
} 
Tomando como referencia lo anterior, en el presente trabajo entenderemos a las EA transfronterizas como un proceso de toma de decisiones llevado a cabo por los Estados para evaluar, de manera científica y con la participación de los ciudadanos, los impactos que se podrían producir sobre su medio ambiente y el de otros Estados a causa del desarrollo de una determinada actividad, con la finalidad de identificar las medidas para prevenir, reducir y controlar dichos impactos.

El origen de las EA transfronterizas

Las EA transfronterizas, tal como las conocemos hoy, se adoptaron por primera vez como un procedimiento legal vinculante en la Directiva relativa a la evaluación de las repercusiones de determinados proyectos públicos y privados sobre el medio ambiente, de 27 de junio de 1985, Directiva 85/337/CEE. Sin embargo, la adopción de este instrumento se basó en las EA que existían a un nivel nacional y en diversos instrumentos de carácter internacional. Como destaca Koivurova: «fue la propagación de los procedimientos nacionales de Evaluación de Impacto Ambiental lo que permitió que se llegara a concluir instrumentos jurídicamente relevantes y tratados sobre Evaluaciones de Impacto Ambiental Transfronterizas ${ }^{6} »$.

La EA como proceso de toma de decisiones nacional fue desarrollada por primera vez en el año 1969 a través de una ley federal estadounidense denominada National Environmental Policy Act (NEPA). En los años siguientes, este procedimiento fue desarrollado por varios estados de los EE. UU., y, para mediados de la década de 1970, países como Canadá, Francia, Australia y Nueva Zelanda ya habían desarrollado sus propios procedimientos de EA (Craik, 2010, p. 23).

En relación con el desarrollo de este proceso en América Latina, cabe señalar que este se originó con la finalidad de satisfacer los requisitos exigidos por organismos financieros internacionales como el Banco Interamericano de Desarrollo (BID) o el Banco Mundial (BM) para conceder créditos financieros a los Estados (Wood, 2003, p. 5). La manera como se originó este proceso generó que en América Latina tuviera mayor prioridad la presentación de informes y estudios de impacto ambiental (EIA), antes que el desarrollo de un procedimiento a través del cual se pudiera mejorar el sistema de decisiones públicas (Craik, 2010, p. 43). Sin perjuicio de esto último, es importante precisar que Colombia fue el primer país latinoamericano en incorporar la

\footnotetext{
${ }^{6}$ Texto original en inglés: «It was the spread of national EIA procedures that made it possible to conclude legally relevant instruments and treaties on TEIA» (Marsden $\&$ Koivurova, 2011, p. 16).
} 
EA en su sistema legal, en el año 1973 (Espinoza, 2007, p. 29). Le siguieron México en 1978, Brasil en 1988, Perú en 1990, Venezuela en 1992, Bolivia en 1992, Paraguay en 1993, Chile en 1993, Honduras en 1993 y Uruguay en 1994 (Espinoza, 2007, p. 29).

En relación con el desarrollo de estos procedimientos, cabe destacar que «las normas relacionadas a las EA [...] no solo se propagaron horizontalmente hacia otros estados, sino también [...] se extendieron verticalmente, influenciando el desarrollo de normas sobre EA en el derecho internacional y dentro de las organizaciones internacionales» ${ }^{7}$.

Es importante hacer mención a la Convención Nórdica de Protección Ambiental ${ }^{8}$ del año 1974 , que establecía un procedimiento «embrionario» de las EA transfronterizas (Marsden \& Koivurova, 2011, p. 16); y a la resolución del Senado de los EE. UU. del año 1978, que contenía los lineamientos de una convención general sobre EA transfronterizas e instaba a otras naciones a participar en negociaciones para adoptar dichos acuerdos?

En ese sentido, tomando como base la propagación de distintos instrumentos de carácter nacional y de distintos instrumentos internacionales, en el año 1985 se adoptó el primer documento legal vinculante en hacer mención expresa a la necesidad de llevar a cabo EA transfronterizas: la Directiva 85/337/CEE. El artículo 7 establecía que los Estados que podían verse afectados significativamente por el desarrollo de proyectos en otros Estados, tenían el derecho a recibir información del proyecto, y además, si lo deseaban, podían participar en el procedimiento de toma de decisiones sobre la viabilidad ambiental de los proyectos en los Estados de origen.

Posteriormente al desarrollo de dicha Directiva, en el año 1987, el Programa de las Naciones Unidas para el Medio Ambiente (PNUMA) elaboró un instrumento no vinculante denominado «Metas y principios de las evaluaciones de impacto ambiental», en el cual, a través del principio 12, se hizo referencia a ciertos aspectos de las EA transfronterizas, como el deber de notificar a los

\footnotetext{
${ }^{7}$ Texto original en inglés: «EIA norms [...] not only spread horizontally to other states, but they [...] also spread vertically, influencing the development of EIA norms in international law and within international organizations» (Craik, 2010, p. 23).

${ }^{8}$ Nombre original en inglés: The Nordic Environmental Protection Convention.

${ }^{9}$ Es importante precisar que, adicionalmente a estos instrumentos, existían diversos tratados como el Acta de Santiago sobre Cuencas Hidrológicas de 1971, la Convención para la Protección del Mar Mediterráneo de 1976, el Convenio Regional de Kuwait sobre Cooperación para la Protección del Medio Marino contra la Contaminación de 1978, la Convención de las Naciones Unidas sobre el Derecho del Mar de 1982, y la Convención para la Protección y el Desarrollo del Medio Ambiente Marino de la Región del Gran Caribe, Cartagena de Indias, 1983, que establecían un proceso de EA transfronteriza. Sin embargo, se ha hecho únicamente mención a la NEPA y la resolución del Senado de 1978, puesto que la doctrina las considera cómo los principales instrumentos de carácter internacional que influenciaron la Directiva 85/337/CEE.
} 
Estados que puedan verse afectados por el desarrollo de ciertas actividades, el deber de transmitir a los Estados afectados información relevante de las EA y el llevar a cabo procesos de consulta (PNUMA, 1987). Adicionalmente, este instrumento "fue utilizado como modelo en las negociaciones para el Convenio Espoo ${ }^{10}$ ».

Cuatro años después, en 1991, se adoptó el primer -y hasta la fecha el único- tratado vinculante referido únicamente a las EA transfronterizas: el Convenio Espoo. Koivurova resume el convenio de la siguiente manera:

El Convenio regula las situaciones en las que es probable que se causen impactos perjudiciales transfronterizos significativos al medio ambiente de un Estado por una actividad propuesta en otro Estado contratante (el Estado de origen). Al respecto, el convenio busca que las partes cooperen entre sí antes de que se dé inicio a la actividad. A fin de que este procedimiento pueda funcionar eficazmente, el Convenio de Espoo obliga a los Estados parte a contar con procedimientos de EA nacionales y/o subnacionales que permitan la integración de los impactos y actores extranjeros ${ }^{11}$.

El Convenio Espoo fue ratificado por la Comunidad Europea. Esto trajo como consecuencia que la Comunidad Europea modifique la Directiva 85/337/CEE, ya que esta no cumplía con los requisitos establecidos en el Convenio Espoo. La adenda a la Directiva 85/337/CEE, la Directiva 97/11/EC, fue adoptada en el ańo 1997 y sus Estados miembros se vieron obligados a implementar la directiva modificada a partir del año 1999 (Bastmeijer \& Koivurova, 2008, p. 11).

Finalmente, es importante precisar que, en el año 2001, la Comisión de Derecho Internacional de las Naciones Unidas (CDI) ${ }^{12}$ adoptó un proyecto de artículos sobre «Prevención del daño transfronterizo resultante de actividades peligrosas», el cual fue reconocido por la Asamblea General de la ONU en su

\footnotetext{
${ }^{10}$ Texto original en inglés: "The principal importance of the document is that it was used as a model in the negotiations for the Espoo Convention» (Marsden \& Koivurova, 2011, p. 18).

11 Texto original en inglés: "The Convention regulates situations where a significant adverse transboundary impact is likely to be caused to a state's environment by a proposed activity in another contracting state (the origin state). It aims to manage these situations by requiring the parties to cooperate with each other before the activity is undertaken. In order for this procedure to function effectively, the Espoo Convention requires the states parties to establish national and/or subnational EIA procedures that allow for the integration of foreign impacts and foreign actors» (Marsden \& Koivurova, 2011, p. 19).

${ }^{12} \mathrm{La}$ Comisión de Derecho Internacional, creada por la Asamblea General de las Naciones Unidas, tiene como misión favorecer el desarrollo progresivo y la codificación del derecho internacional. Su trabajo consiste básicamente en redactar proyectos de artículos sobre cuestiones de derecho internacional, que pueden ser incorporados en una convención (ONU, 2012).
} 
56..$^{\circ}$ período de sesiones ${ }^{13}$. Este documento buscaba ser la base para la futura elaboración de un convenio general que regulara las actividades no prohibidas por el derecho internacional que entrañasen el riesgo de causar un daño transfronterizo sensible.

Si bien en el siguiente capítulo veremos que existen muchos más instrumentos del derecho internacional que han contenido y contienen cláusulas relacionadas con las EA transfronterizas, la presente sección buscó presentar los instrumentos internacionales más relevantes sobre la materia a fin de demostrar que si bien el proceso de llevar a cabo EA transfronterizas se basó en las EA que los Estados realizaban a nivel nacional, el impulso de realizar estas EA transfronterizas se originó en el ámbito del derecho internacional.

\section{2 ¿Cuáles son los impactos que deben ser considerados por las EA transfronterizas?}

Al igual que para el caso de las EA transfronterizas, a la fecha no existe un tratado internacional de carácter general que precise qué son los impactos transfronterizos ni tampoco uno que indique cuáles son las características generales de estos. Sin embargo, a diferencia del caso anterior, el Convenio Espoo, en su artículo 1, sí establece una definición exacta para impacto e impacto transfronterizo:

Por «impacto» se entiende los efectos causados por una actividad propuesta en el medio ambiente, incluidos la salud y la seguridad de los seres humanos, la flora, la fauna, el suelo, la atmósfera, el agua, el clima, el paisaje y los monumentos históricos u otras estructuras materiales o la interacción entre esos factores; incluye asimismo las repercusiones sobre el patrimonio cultural o las condiciones socioeconómicas que se deriven de las alteraciones de esos factores.

Y

Por «impacto transfronterizo» se entiende todo impacto no necesariamente de naturaleza global, dentro de una zona bajo la jurisdicción de una de las Partes y que haya sido causado por una actividad propuesta cuyo origen físico esté ubicado total o parcialmente dentro de una zona situada bajo la jurisdicción de otra Parte.

\footnotetext{
${ }^{13}$ Este instrumento también será analizado a lo largo del presente trabajo.
} 
Adicionalmente a lo anterior, existen diversos instrumentos que han establecido referencias a qué se puede entender como impactos transfronterizos. Con base en la definición esbozada en la presente sección y tomando como referencia la clasificación efectuada por la doctora Xue Hanqin en su libro Transboundary Damage in International Law ${ }^{14}$, el presente trabajo propone que los impactos que deben ser sometidos a EA transfronterizas son aquellos compuestos por los siguientes cinco elementos: (i) carácter negativo; (ii) generado por una actividad humana; (iii) causalidad entre la actividad y el impacto; (iv) impactos significativos; y (v) Estado transfronterizo afectado.

\section{i) Carácter negativo}

Como primer punto, es importante tener en cuenta que en principio un impacto ambiental transfronterizo puede tratarse tanto de una afectación positiva como de una negativa al medio ambiente. Como seńala Leonardo Fabio Pastorino: «[C] ualquier actividad humana puede producir un impacto en el sentido de "efecto de una actividad sobre la naturaleza". Pero estos impactos pueden no ser siempre negativos, ya que también el hombre impacta la naturaleza para mejorar el ambiente o corregir los desequilibrios que él mismo ha provocado» (2005, p. 17).

En ese sentido, un primer punto que se debe tener en cuenta es que los impactos que son analizados por las EA transfronterizas son aquellos que afectan negativamente al medio ambiente.

ii) Generado por una actividad humana

El segundo elemento que se debe considerar es que el impacto transfronterizo debe haberse generado por una actividad humana. Aquellos impactos que puedan ser generados por la misma naturaleza, como terremotos, inundaciones, erupciones volcánicas o huracanes, no son actos que generan responsabilidad por parte de los Estados (Hanqin, 2003, p. 6) y, por ende, tampoco están sometidos a la obligación de prevención. Como señala Marte Jervan, «en la literatura se indica que los efectos dañinos causados por factores ambientales no calzan dentro del alcance de la obligación, a menos que estas tengan una "relación causal relativamente próxima a una conducta humana"»"

\footnotetext{
${ }^{14} \mathrm{Si}$ bien este libro se centra en los temas de responsabilidad internacional generada por los daños transfronterizos, se han adoptado ciertos elementos y se han adaptado al aspecto de prevención de los impactos. Los elementos señalados por Xue Hanqin son: (i) the physical relationship between the activity and the damage; (ii) the requirement of human causality; (iii) the threshold criterion; (iv) the transboundary movement of harmful effects (2003, pp. 7-10)

${ }^{15}$ Texto original en inglés: «In the literature it is held that damaging effects caused by environmental factors do not fall within the scope of the obligation unless they have some "reasonably proximate causal relation to human conduct"» (Jervan, 2014, p. 4).
} 
iii) Causalidad entre la actividad y el impacto

De igual manera, no solo este impacto debe haberse generado por una actividad humana, sino que debe haber una relación de causalidad entre la actividad y el impacto generado. La doctora Xue Hanqin hace referencia a la causalidad con los siguientes ejemplos (2003, p. 6):

- La construcción de una planta nuclear en una zona de frontera que coloca en riesgo al país vecino;

- La existencia de un aeropuerto en una zona de frontera que genera molestia en un pueblo ubicado en el país vecino con los despegues y aterrizajes de los aviones;

- La existencia de industrias que emiten humos nocivos y como resultado de esto se incrementa el riesgo de que los residentes que habitan en el otro lado de la frontera sufran enfermedades en la piel o en los pulmones; $\mathrm{o}$,

- La existencia de una falla en la construcción de una carretera fronteriza que provoca un deslizamiento de tierra que termina afectando los cultivos de una granja ubicada en el país vecino.

iv) Significatividad del impacto

Asimismo, un punto importante es que los impactos que se debe tomar en cuenta son únicamente aquellos que tienen cierto grado de significatividad. Günther Handl, al respecto, precisa lo siguiente: «es aceptado de manera general que los Estados están solo exhortados a no causar un daño transfronterizo que sea "grave", "significativo", "sustancial", "apreciable" o alguna calificación similar»" ${ }^{16}$. Si bien la necesidad del criterio de "significatividad" nunca se ha puesto en duda ni en la teoría ni en la práctica, su significado sí ha sido largamente debatido (Hanqin, 2003, p. 7). El desarrollo de su significado se ha analizado de manera detallada en la sección «2.3.2.1 Screening». Sin embargo, sin perjuicio de esto último, es importante tener en cuenta que "para ser legalmente relevante, el daño debería ser al menos "mayor que la mera molestia o mayor que el dańo insignificante normalmente tolerado" ${ }^{18}$.

\footnotetext{
${ }^{16}$ Este grado de necesidad de severidad del impacto es llamado de diferentes maneras por los diferentes instrumentos legales existentes. En el presente trabajo utilizaremos el término de impacto «significativo». ${ }^{17}$ Texto original en inglés: «it is generally agreed that states are enjoined only from causing transboundary harm that is 'serious', 'significant', 'substantial', 'appreciable', or similarly qualified» (Handl, 2007, p. 535).

${ }^{18}$ Texto original en inglés: «To be legally relevant, damage should be at least "greater than the mere nuisance or insignificant harm which is normally tolerated”" (Hanqin, 2003, p. 8).
} 
v) Estado transfronterizo afectado

Finalmente, el quinto requisito es que debe existir al menos un Estado que se vea afectado por los impactos, distinto al Estado donde se originaron estos. En relación con esto, Xue Hanqin señala:

Es el acto de cruzar las fronteras lo que genera que el daño efectuado sea sometido a soluciones internacionales e implique la subsecuente aplicación de normas de carácter internacional. Un dańo transfronterizo puede ser el resultado de movimientos transfronterizo a través de varias fronteras que genere consecuencias perjudiciales en varios Estados; o, también, puede tomar la forma de un acto que causa daño dentro de una jurisdicción nacional, pero también más allá del control de esta como, por ejemplo, la contaminación marina en alta mar generada por causas terrestres ${ }^{19}$.

Habiendo establecido lo anterior, cabe precisar que cuando el presente trabajo haga referencia a «impactos transfronterizos», deberá entenderse estos como toda afectación negativa física significativa sobre el medio ambiente generada por una actividad humana en un Estado cuyos efectos no solo se dan en el Estado de origen, sino que además trascienden las fronteras hacia otros Estados.

Es importante tener siempre presente que el DAI no busca prevenir la ocurrencia de todos los impactos que se puedan generar, sino únicamente de aquellos que, entre otras características, sean negativos y reúnan cierto grado de «significatividad $»^{20}$.

\section{3 ¿Por qué es importante establecer reglas de prevención para los impactos transfronterizos?}

Hasta el momento ya hemos señalado qué son las EA transfronterizas y cuáles son los impactos ambientales que ameritan la realización de estos procesos.

\footnotetext{
${ }^{19}$ Texto original en inglés: «It is the act of boundary-crossing which subjects the consequent damage to international remedy and initiates the application of international rules. Moreover, a "transboundary" harm may result from transboundary movements across several boundaries that causes detrimental effects in several States. A transboundary act may also take the form of an act which causes harm in and beyond national jurisdiction of control, such as marine pollution of the high seas from land-based sources» (Hanqin, 2003, p. 9). ${ }^{20}$ Es importante notar que en la presente sección no se ha identificado si los impactos por ser sometidos a las EA son aquellos que aparte del medio ambiente incluyen las personas o el medio físico. De igual manera, tampoco se ha establecido si se incluyen también los impactos socioeconómicos sobre el medio ambiente. $\mathrm{Al}$ respecto, de acuerdo a la sentencia de las Plantas de Celulosa, se indica que el contenido de las EA debe dejarse al derecho interno de los Estados. Como consecuencia de esto, consideramos que esto es algo que depende del derecho interno de los Estados y que debe ser definido por ello. Sobre esto volveremos en la sección «2.3.2.2 Alcance y contenido de las EA transfronterizas», del capítulo 2.
} 
La presente sección lo que busca es precisar por qué es importante que estos impactos transfronterizos sean prevenidos, cómo surgió la obligación de prevención, su situación jurídica actual, su alcance y, finalmente, cuáles son los mecanismos que existen para concretar esta obligación.

Es importante comenzar señalando que la prevención es, hoy, la política principal por seguir en el DAI. Se considera que el medio ambiente se protege mejor a través de acciones para prevenir los daños que a través de medidas de reparación, procedimientos que pueden ser sumamente costosos y a veces hasta imposibles de lograr (Duvic-Paoli, 2014). Como destacó el Tribunal Arbitral en el caso Rin de Hierro: «hoy, en el derecho ambiental internacional, se está poniendo cada vez más énfasis en el deber de prevención $»^{21}$.

De igual manera, en relación con la importancia de la prevención, es importante destacar los comentarios generales aprobados por la CDI en su $53 .^{\circ}$ período de sesiones, sobre el proyecto de artículos sobre «Prevención del daño transfronterizo resultante de actividades peligrosas» (CDI, 2001a, p. 417):

1) [...]. La prevención en este sentido, como procedimiento o como obligación, se refiere a la fase anterior a la situación en que ya se ha producido efectivamente un daño o perjuicio sensible que requiere que los Estados interesados apliquen medidas correctivas o de indemnización, y que a menudo comprende cuestiones relativas a la responsabilidad.

2) El concepto de prevención ha adquirido gran importancia e interés en la actualidad. Se hace hincapié en la obligación de prevenir, por oposición a la obligación de reparar, remediar o indemnizar, y esto tiene varios aspectos importantes. La política preferida debe ser la prevención, ya que en el caso de daño la indemnización por lo general no restablece la situación que existía antes de producirse el suceso o accidente. El cumplimiento de la obligación de prevenir o aplicar la debida diligencia es todavía más necesario a medida que aumentan constantemente los conocimientos sobre las actividades peligrosas, los materiales utilizados y su administración y los riesgos que suponen. Desde un punto de vista jurídico, como ha aumentado la capacidad para determinar la relación de causalidad, es decir, la vinculación física entre la causa (actividad) y el efecto (daño), e

\footnotetext{
${ }^{21}$ Texto original en inglés: "Today, in international environmental law, a growing emphasis is being put on the duty of prevention" (Iron Rhine Arbitration, 2005, párr. 59, 222).
} 
incluso las diversas etapas intermedias de ese vínculo causal, es también imperativo que quienes realizan actividades peligrosas adopten todas las medidas necesarias para prevenir el daño. En todo caso, en cuanto política, prevenir es mejor que curar.

\subsubsection{El surgimiento de la obligación de prevención}

Desde inicios del siglo XX, como consecuencia del laudo emitido en el ańo 1941 por el Tribunal Arbitral en relación con el caso Trail Smelter ${ }^{22}$, se estableció la obligación general de que los Estados estaban prohibidos de usar su territorio de tal manera que afecte el territorio de los demás Estados:

[...] ningún Estado tiene el derecho de usar o permitir el uso de su territorio de tal manera que por los humos cause daño en otro territorio o en las propiedades o las personas que ahí se encuentren, cuando se trate de consecuencias graves y el daño sea determinado a través de pruebas claras y convincentes ${ }^{23}$.

Esta regla general fue posteriormente desarrollada en la sentencia del caso del Canal de Corfú, en la cual la CIJ indicó que dicha obligación general podía ser quebrantada a través de actos u omisiones (C. I. J. Corfu Channel Case, 1949, párr. 22). Posteriormente, en el año 1996, a través de la opinión consultiva en Cuestión de la Legalidad de la Amenaza o el Empleo de Armas Nucleares, la CIJ reconoció la existencia de esta obligación en el campo del derecho ambiental:

La existencia de la obligación general de que los Estados velen por que las actividades realizadas dentro de su jurisdicción o bajo su control no dañen el medio ambiente de otros Estados o zonas que estén fuera de su jurisdicción nacional forma parte ya del corpus de normas internacionales en materia de medio ambiente. (C. I. J. Legality of the Threat of Use of Nuclear Weapons, Advisory Opinion, 1996)

\footnotetext{
${ }^{22}$ Desde el año 1896, existía, cerca de la localidad de Trail, en Canadá, aproximadamente a $17 \mathrm{~km}$ de la frontera con EE. UU., una fundición de zinc y plomo, la cual, en su proceso de producción, generaba grandes cantidades de bióxido de azufre. Desde el año 1925 hasta el año 1931, se constató que las emisiones traspasaron la frontera canadiense, causando dańos en el estado de Washington, EE. UU. Como consecuencia de esto, ambas partes celebraron un acuerdo internacional de arbitraje, del cual emanaron dos laudos, uno en el año 1938 y otro en el ańo 1941 (Gómez-Robledo, 2003, pp. 351-352).

${ }^{23}$ Texto original en inglés: «[...] no State has the right to use or permit the use of its territory in such a manner as to cause injury by fumes in or the territory of another of the properties or persons therein, when the case is of serious consequence and the injury is established by clear and convincing evidence» (Trail Smelter Case, 1938, 1941).
} 
Esta obligación de no afectar el medio ambiente de los otros Estados fue confirmada por la CIJ en el ańo 1997, a través de la sentencia relacionada con el proyecto Gabcikovo-Nagymaros y, en 2010, a través de la sentencia de las Plantas de Celulosa. De igual manera, esta obligación fue recogida en el principio 21 de la Declaración de Estocolmo de 1972, en el principio 2 de la Declaración de Río de 1992 y en el proyecto de artículos sobre «Prevención del daño transfronterizo resultante de actividades peligrosas».

La respuesta del derecho internacional a los impactos transfronterizos y a cumplir con la obligación de no afectar el medio ambiente de los otros Estados, fue imponer reglas de responsabilidad al Estado culpable de causar el daño, exigiéndole abstenerse de la conducta que causaba daño y a conceder una reparación adecuada al Estado lesionado (Jervan, 2014, p. 3), ya que, como señalan Sands et al., las normas de responsabilidad cumplen diversos propósitos:

Las normas de responsabilidad pueden ser una forma de instrumento económico que sirva como incentivo para fomentar el cumplimiento de las obligaciones ambientales. También pueden ser utilizadas para imponer sanciones por conductas incorrectas o para solicitar medidas correctivas que permitan la restauración de la situación del medio ambiente a su estado inicial. Finalmente, también pueden servir como técnica para que los costos ambientales y sociales sean internalizados en los procesos de producción y demás actividades, en cumplimiento del principio contaminador-pagador ${ }^{24}$.

Sin embargo, a pesar de que los Estados han reconocido -y reconocen- el importante rol de las normas de responsabilidad, hasta la fecha, en el campo del DAI, no existe un instrumento específico que establezca normas de responsabilidad internacional. Como destacan nuevamente Sands et al.:

En el campo del derecho ambiental no existe ningún instrumento que establezca las normas internacionales de aplicación general sobre responsabilidad. El Proyecto de Artículos sobre

\footnotetext{
${ }^{24}$ Texto original en inglés: «They [Liability rules] may be a form of economic instrument that provides an incentive to encourage compliance with environmental obligations. They may also be used to impose sanctions for wrongful conduct, or require corrective measures to restore a given environmental asset to its pre-damage condition. Finally, they may provide a technique for internalizing environmental and other social cost into production processes and other activities in implementation of the polluter pays principle» (Sands et al., 2012, p. 700).
} 
Responsabilidad del Estado de la $\mathrm{CDI}^{25}$ reúne las normas generales del derecho internacional y estas se aplican (en la medida en que reflejan el derecho consuetudinario) en conjunto con las normas ambientales establecidas por los tratados y otras nomas de aplicación internacional ${ }^{2627}$.

Ahora bien, el problema con las reglas de responsabilidad es que a lo largo de la historia estas no han sido necesariamente aplicadas o activadas por los Estados. Un ejemplo de esto último es el relacionado con el caso Chernobyl de 1986, "donde no se interpusieron demandas a pesar de tratarse de un caso relativamente evidente en el cual se hubiese podido interponer una demanda por responsabilidad internacional ${ }^{28}$ ".

En consecuencia, a pesar de la existencia de reglas de responsabilidad, estas no han sido aplicadas por los Estados afectados. De esta manera, no solo los actos no eran cesados, ni se efectuaban las reparaciones respectivas, sino que, además, se generaban daños irreparables en el medio ambiente, impidiendo que este vuelva a su situación inicial. Como consecuencia de esto, la comunidad internacional determinó que en los casos en que era posible que ocurra un impacto ambiental significativo, se propicien e impulsen medidas de prevención.

\subsubsection{Situación jurídica de la prevención}

La prevención ha alcanzado tal nivel de importancia en el DAI, que a la fecha no solo ha sido recogida en distintos instrumentos del soft law y el hard law ${ }^{29}$,

\footnotetext{
${ }^{25}$ El autor se está refiriendo al proyecto de artículos sobre responsabilidad del Estado para actos prohibidos por el derecho internacional elaborados por la CDI en el año 2001.

${ }^{26}$ Texto original en inglés: «In the environmental field, no single instrument sets forth the generally applicable international rules governing responsibility and liability. The ILC's Articles on State Responsibility bring together the rules of general international law, and they are applicable (to the extent they reflect customary law) with environmental rules established by treaties and other internationally applicable rules» (Sands et al., 2012, p. 704).

${ }^{27}$ Es importante precisar que aparte del proyecto de artículos sobre Responsabilidad del Estado para Actos Prohibidos por el Derecho Internacional señalado por Sands et al., la CDI también desarrolló un proyecto de artículos sobre Responsabilidad Internacional por las Consecuencias Perjudiciales de Actos No Prohibidos por el Derecho Internacional. Sin embargo, a diferencia del proyecto de artículos sobre actos prohibidos (ya considerado norma de derecho consuetudinario), a la fecha todavía se cuestiona el carácter vinculante de este último proyecto de artículos sobre Responsabilidad Internacional por las Consecuencias Perjudiciales de Actos No Prohibidos por el Derecho Internacional.

${ }^{28}$ Texto original en inglés: «which no claims were made, even though it provided a relatively clear cut case on which an international liability claim could be made» (Sands et al., 2012, p. 701).

${ }^{29}$ El principio de prevención se encuentra reconocido en distintos instrumentos internacionales, como en los principios 6, 7, 15, 18, 21 y 24 de la Declaración de Estocolmo; los principios 2, 11 y 14 de la Declaración de Río; y, explícitamente, en el artículo 3 del Proyecto de Artículos de «Prevención del Daño Transfronterizo Resultante de Actividades Peligrosas» de la Comisión de Derecho Internacional (CDI). De igual manera, este principio ha sido invocado o respaldado en un gran número de tratados relativos a distintos asuntos ambientales, como, por ejemplo: el artículo 194.1 de la Convemar, el artículo 5 y anexo II
} 
sino que, incluso, hoy es considerada la piedra angular del DAI (Duvic-Paoli, 2014) y constituye una obligación consuetudinaria del derecho internacional. Es decir, actualmente, todos los Estados se encuentran jurídicamente vinculados a tomar medidas preventivas para minimizar los posibles impactos que las actividades que se llevan a cabo en su territorio puedan generar.

Esto ha sido confirmado por la CIJ tanto en la opinión consultiva sobre la legalidad del uso o de la amenaza del uso de armas nucleares de 1996, al declarar que ya formaba parte del corpus de normas de derecho internacional (CDI, 2001b), como, recientemente, en la sentencia del caso de las Papeleras de Celulosa entre Argentina y Uruguay del año 2010: «[...] el principio de prevención, en tanto norma consuetudinaria, tiene sus orígenes en la diligencia debida que es requerida a un Estado en su territorio» ${ }^{30}$.

\subsubsection{Alcance de la prevención}

La prevención lo que busca es prevenir, reducir, limitar, controlar y cooperar en relación con las actividades que puedan generar un impacto en el ambiente. $\mathrm{Al}$ respecto, Fitzmaurice destaca: «[...] la acción preventiva [...] incluye la obligación de cooperar con respecto al daño ambiental transfronterizo [...] para prevenir, reducir, limitar o controlar tal daño» ${ }^{31}$.

Es importante precisar que la prevención a nivel internacional no busca impedir que ocurran impactos en el ambiente, sino minimizar el impacto que las actividades puedan generar. La CDI en los comentarios al artículo 3 del proyecto de artículos sobre «Prevención del Daño Transfronterizo Resultante de Actividades Peligrosas», destacó lo siguiente:

[L]a obligación [...] no pretende garantizar la prevención total de daños sensibles, cuando no es posible lograrla. [...] el Estado de origen deberá esforzarse cuanto pueda por minimizar el riesgo. En ese sentido, esta obligación no garantiza que el daño no se produzca. (CDI, 2001b)

\footnotetext{
del Acuerdo de las Naciones Unidas sobre Peces Transzonales y Altamente Migratorios, el preámbulo de la CDB, los artículos III y V de la Convención sobre la Conservación de las Especies Migratorias de Animales Silvestres, el Convenio Internacional para Prevenir la Contaminación por Buques, y los artículos 4 y 9 del Convenio de Basilea sobre el Control de los Movimientos Transfronterizos de los Desechos Peligrosos y su Eliminación.

${ }^{30}$ Texto original en inglés: «the principle of prevention, as a customary rule, has its origins in the due diligence that is required of a State in its territory» (C. I. J. Pulp Mills, 2010, párr. 101).

${ }_{31}$ Texto original en inglés: «[...] preventive action [...] includes an obligation to co-operate with regard to transboundary environmental damage [...] to prevent, to reduce, limit or control such damage» (Fitzmaurice, 2001, p. 267).
} 
En consecuencia, como es fácilmente deducible, la prevención requiere que se tomen acciones en una fase temprana, antes de que los impactos se generen (Sands et al., 2012, p. 201).

De otro lado, es importante destacar que la prevención no está referida únicamente a prevenir aquellos impactos que tienen una alta probabilidad de ocurrencia, sino que también comprende a aquellos impactos que tienen una baja probabilidad de ocurrencia, pero que, de ocurrir, podrían tener serias consecuencias (Handl, 2007, p. 539).

Esta idea de los tipos de riesgo que cubre el principio de prevención, ha sido recogida en los artículos 1 y 2(a) del proyecto de artículos sobre «Prevención del Daño Transfronterizo Resultante de Actividades Peligrosas» de la CDI:

\section{Artículo 1}

\section{Alcance}

Los presentes artículos se aplicarán a las actividades no prohibidas por el derecho internacional que entrañen el riesgo de causar, por sus consecuencias físicas, un daño transfronterizo sensible.

\section{$[\ldots]$}

\section{Artículo 2}

\section{Términos empleados}

A los efectos de los presentes artículos:

El «riesgo de causar dańo transfronterizo sensible» abarca los riesgos que se presentan como una alta probabilidad de causar daño transfronterizo sensible y una baja probabilidad de causar un daño transfronterizo catastrófico.

\subsubsection{Las EA transfronterizas como medidas preventivas}

Los encargados de cumplir con la obligación de prevención y, por ende, con las respectivas medidas preventivas son los Estados a través de sus distintos órganos legislativos, administrativos y judiciales. Por otro lado, se puede dar cumplimiento a la obligación de prevención a través de distintas medidas preventivas. Ejemplo de esto son los procedimientos de otorgamiento de autorizaciones, la adopción de estándares ambientales nacionales e internacionales, el establecimiento de sanciones y la realización de EA transfronterizas (Sands et al., 2012, pp. 201-202). 
Las EA transfronterizas son uno de los mecanismos centrales utilizados por los Estados para dar cumplimiento a su obligación de prevención; pero, como veremos en el siguiente capítulo, estas se tienen que realizar obligatoriamente cuando se está frente a actividades con posibilidad de generar impactos con las características señaladas en la presente sección, puesto que actualmente la realización de EA transfronterizas constituye una obligación consuetudinaria del derecho internacional.

En consecuencia, no solo existe una obligación internacional para los Estados de no dañar el medio ambiente de los otros Estados y de tomar medidas de prevención para evitar estos impactos ${ }^{32}$, sino que también, actualmente, llevar a cabo EA transfronterizas constituye una obligación consuetudinaria del derecho internacional.

Ahora bien, sin perjuicio de lo anterior, es importante precisar que llevar a cabo únicamente EA transfronterizas no necesariamente implica que el Estado esté cumpliendo con su obligación de prevención (Craik, 2010, p. 64); sin embargo, es obligatoria su realización para las actividades que puedan causar un impacto trasfronterizo significativo en el medio ambiente.

\subsection{La situación del Perú}

En el Perú existe un gran número de actividades que se realizan en zonas fronterizas, así como sobre recursos naturales compartidos, como ríos y lagos, que tienen un gran potencial de generar impactos transfronterizos con las características señaladas en la sección 1.2. Al respecto, es importante resaltar que el Perú no solo tiene el potencial de generarlos, sino que, incluso, ya ha generado impactos que han sido materia de reclamo por los países vecinos, como veremos a continuación.

\subsubsection{Minería}

Para comenzar, actualmente existen en el sector minero más de 100 derechos mineros titulados en zonas fronterizas con Ecuador, Bolivia y Chile, los cuales en un futuro podrían convertirse en proyectos de explotación con un alto potencial de causar impactos transfronterizos significativos.

Como se podrá apreciar, el mapa 1 muestra en color azul todos los derechos mineros titulados que existían en el Perú a diciembre de 2016. Adicionalmente, los mapas 2, 3 y 4 muestran un acercamiento a las áreas de frontera, a fin de

\footnotetext{
${ }^{32}$ Asimismo, es importante destacar que Günther Handl señala que la obligación de prevención se presenta también como un aspecto esencial de la obligación de no causar daño significativo al medio ambiente más allá de la jurisdicción o control nacional (2007, p. 539).
} 
que se pueda apreciar de mejor manera la gran cantidad de derechos mineros titulados que existen en dichas zonas, ergo el gran riesgo que tiene el Perú de generar impactos transfronterizos.

Mapa 1.1. Catastro minero, diciembre de 2016

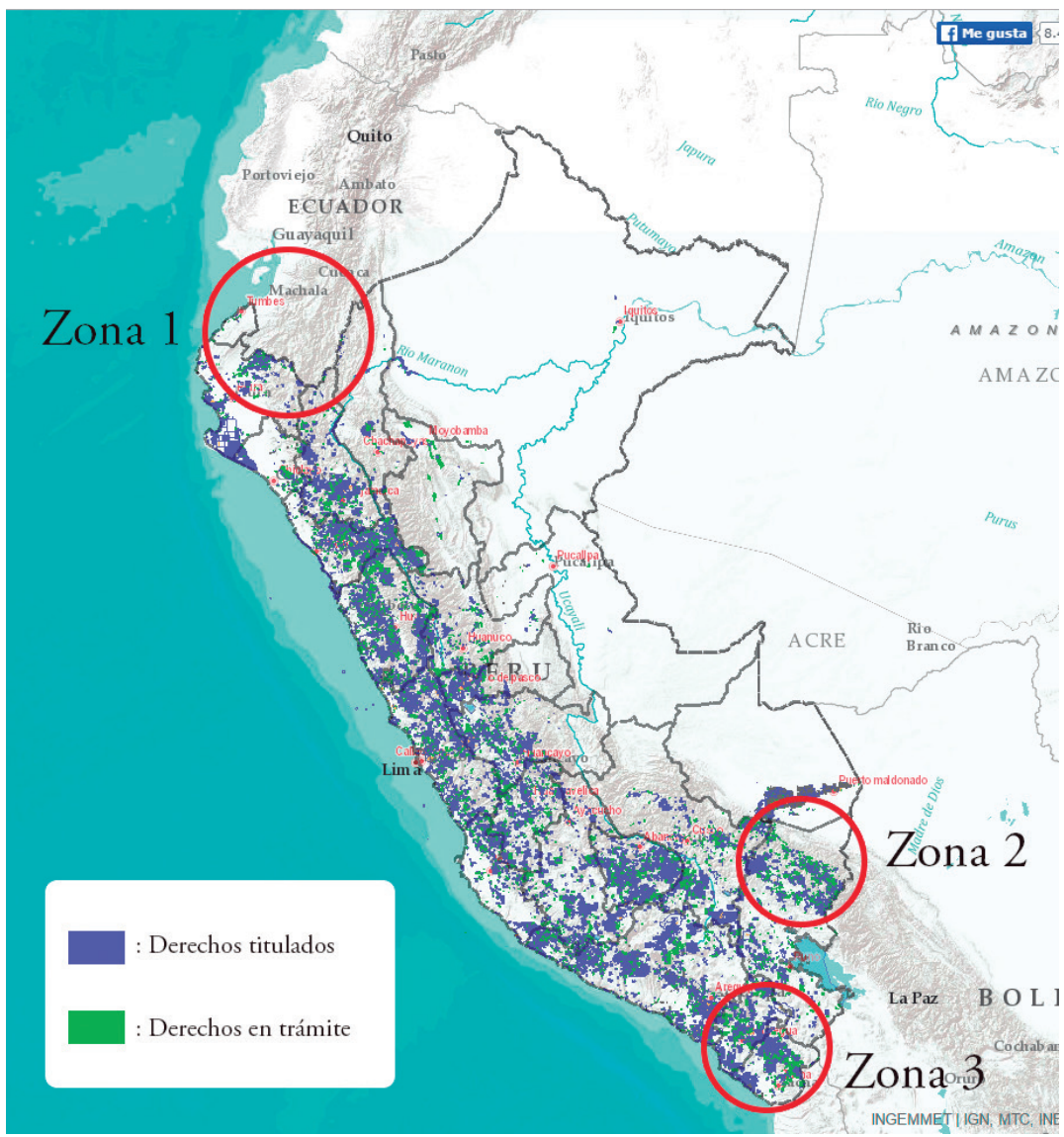

Elaboración: mapa elaborado por la autora a partir de la información proporcionada por el programa Geocatmin del Ingemmet en diciembre de 2016. 


\section{Mapa 1.2. Zoom zona 1 - frontera con Ecuador}

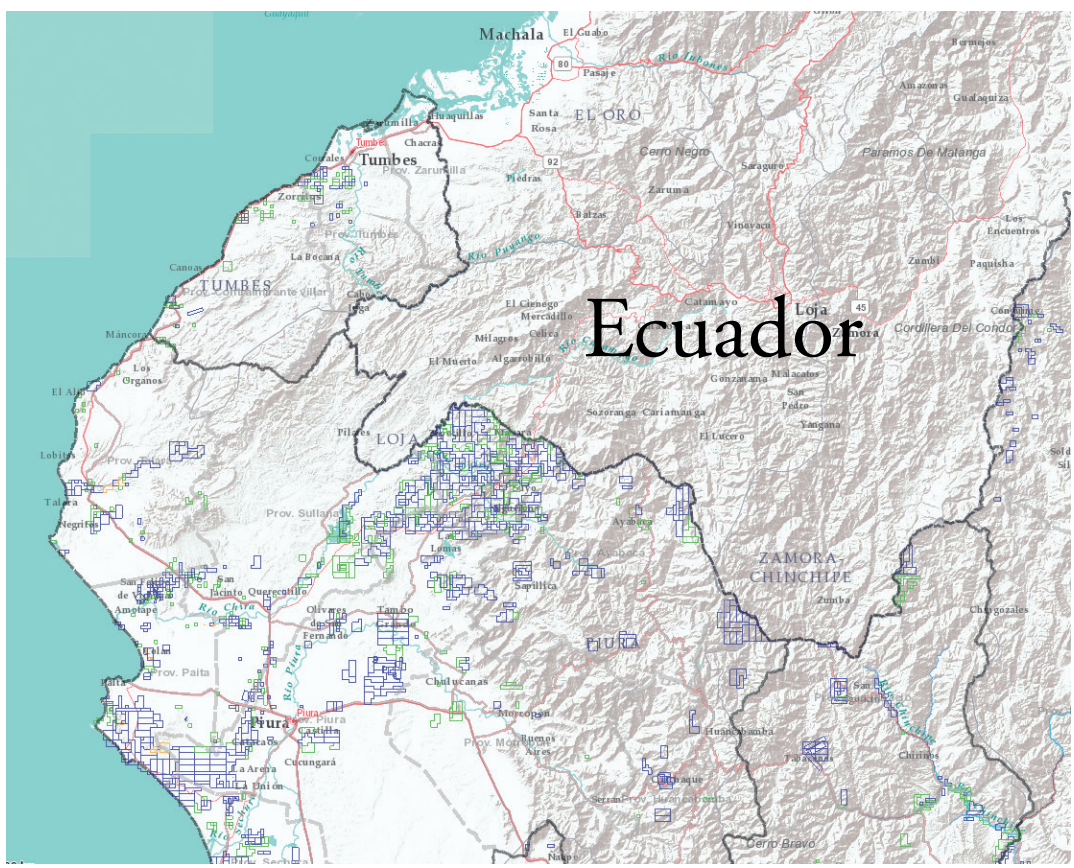

Elaboración: mapa elaborado por la autora a partir de la información proporcionada por el programa Geocatmin del Ingemmet en diciembre de 2016. 
Mapa 1.3. Zoom zona 2 - frontera con Bolivia

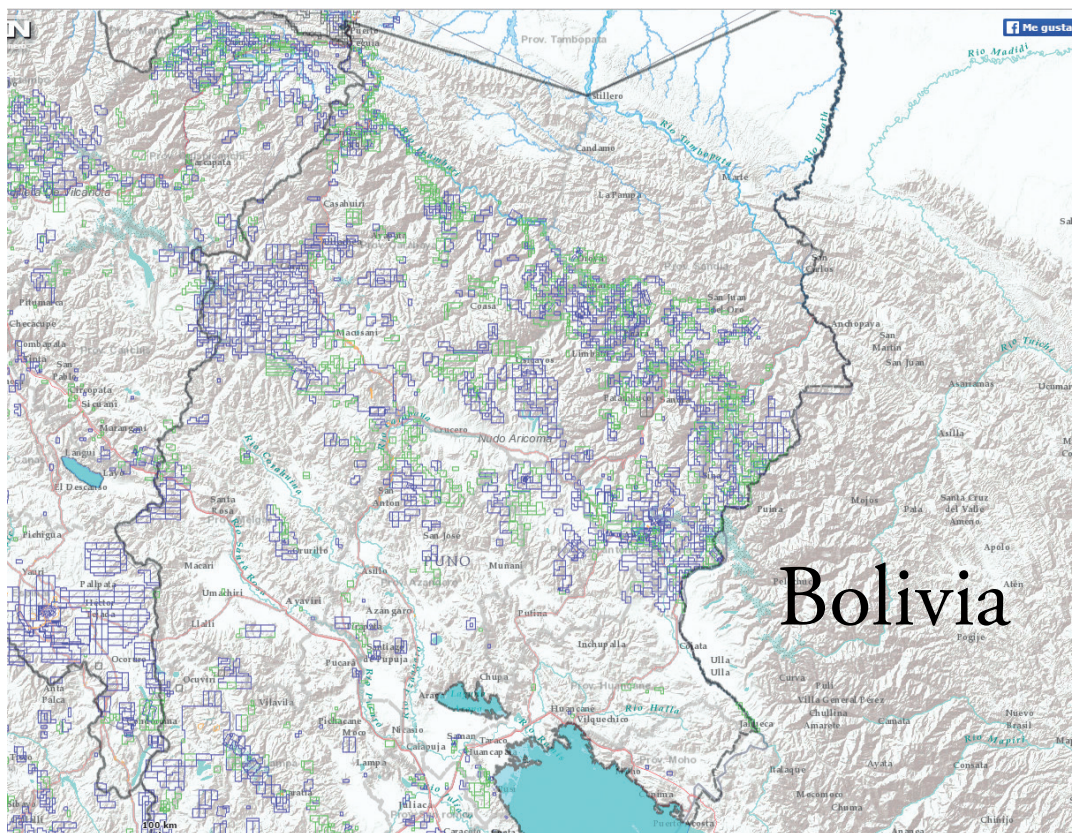

Elaboración: mapa elaborado por la autora a partir de la información proporcionada por el programa Geocatmin del Ingemmet en diciembre de 2016. 
Mapa 1.4. Zoom zona 3 - frontera con Chile

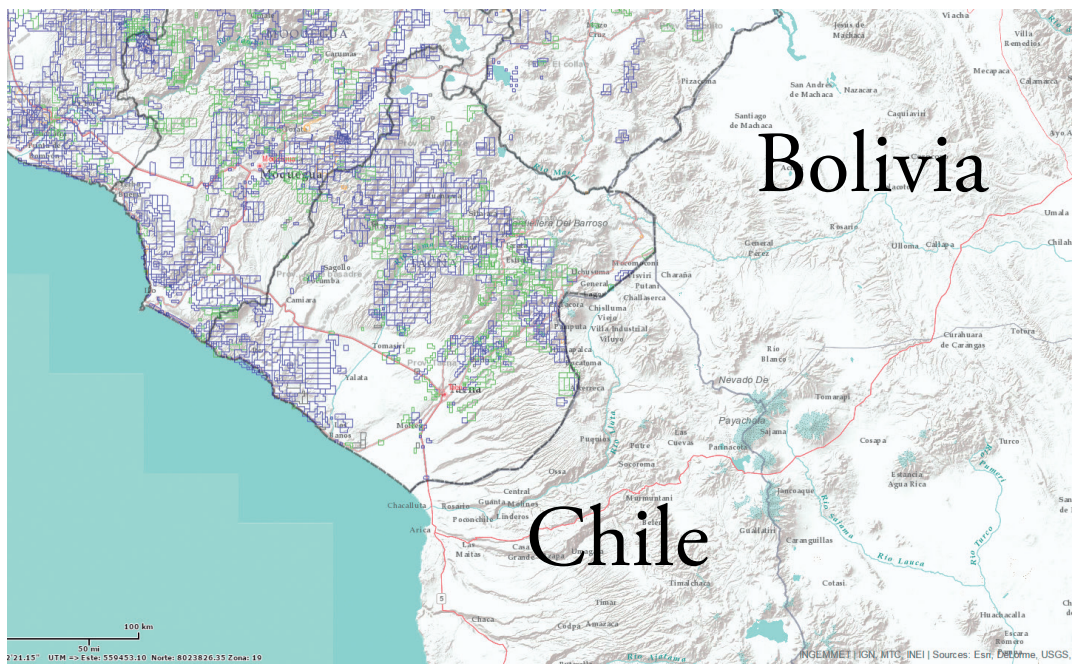

Elaboración: mapa elaborado por la autora a partir de la información proporcionada por el programa Geocatmin del Ingemmet en diciembre de 2016.

\subsubsection{Proyecto minero Río Blanco}

Un ejemplo de un proyecto minero en frontera que tiene gran potencial de generar estos tipos de impactos es Río Blanco, propiedad de la minera Rio Blanco Copper. Este abarca 6.473 ha y se encuentra ubicado en las provincias de Ayabaca y Huancabamba, en la región Piura, muy cerca de la frontera con Ecuador. El proyecto minero cuenta con una reserva estimada de 8 millones de toneladas de contenido de cobre, y es considerado uno de los mayores depósitos de cobre sin desarrollar en el mundo (Gestión, 2016). Debido a la magnitud de este proyecto y su cercanía a la frontera ecuatoriana, existe una clara posibilidad de que, al explotarse el yacimiento, se generen impactos transfronterizos, por lo que en la EA de este proyecto estos impactos deberían ser considerados, a fin de analizar como poder prevenirlos o minimizarlos.

\subsubsection{Mina Pucamarca}

Adicionalmente al proyecto antes mencionado, que podría estar en la posición de generar impactos sobre los países vecinos, cabe hacer referencia a un proyecto que fue cuestionado por los medios de prensa de haber generado impactos sobre el territorio chileno: la mina de oro Pucamarca. 
La mina de oro Pucamarca, propiedad de la empresa Minsur S. A., es un yacimiento aurífero a tajo abierto ubicado en Cerro Checocollo, distrito de Palca, en la región Tacna, a 200 metros de la frontera con Chile (AMEC, 2007, p. 1). Desde la fase de exploración, el proyecto fue materia de preocupación en el país vecino, lo que generó que la empresa realice, en el año 2007, una EA del proyecto sobre territorio chileno ${ }^{33}$. Posteriormente, en diciembre del año 2011, comunidades aimaras del altiplano chileno realizaron una protesta contra Pucamarca, puesto que seńalaban que las tronaduras que realizaba la mina en territorio peruano, formaban brumas que se trasladaban con el viento al territorio chileno afectando a las personas, la flora y la fauna de la zona (Radio Uno, 2012). Asimismo, indicaban que el agua subterránea utilizada para la operación minera estaba generando deterioro y desaparición de los bofedales (El Morrocotudo, 2011). De acuerdo a lo conversado con el representante de la empresa Minsur S. A. (Minsur) en respuesta a estas protestas, periódicamente la mina realiza monitoreos sobre el medio ambiente chileno para corroborar su estado, resultados que son enviados al gobierno chileno, a través de la cancillería peruana, a fin de mantener a la población chilena informada al respecto. Estas acciones han contribuido, según lo precisado por el representante, a que en los últimos dos años $(2015$ - 2016) no se haya tenido reportes de ninguna protesta en el territorio del país vecino.

\subsubsection{Hidrocarburos}

Otro sector que tiene un gran potencial de generar impactos transfronterizos es el de hidrocarburos. Al respecto, a diferencia del sector minero, en el sector hidrocarburos ya existe más de un proyecto petrolero que se ha ejecutado en frontera. Ejemplo de esto último es el Lote 192 (ex 1-AB) ubicado en Andoas, Loreto, y que hasta el 29 de agosto de 2015 fue explotado por Pluspetrol Perú Corporation S. A. (Pluspetrol Perú). De igual manera, como se puede apreciar en el mapa 5, a la fecha existen varios lotes en frontera sobre los que ya se han firmado contratos y otros que a la fecha se encuentran en proceso de licitación.

33 Este tema es tratado en profundidad en la sección «3.2.2 La implementación a nivel administrativo», del capítulo 3 . 
Mapa 1.5. Lotes de hidrocarburos

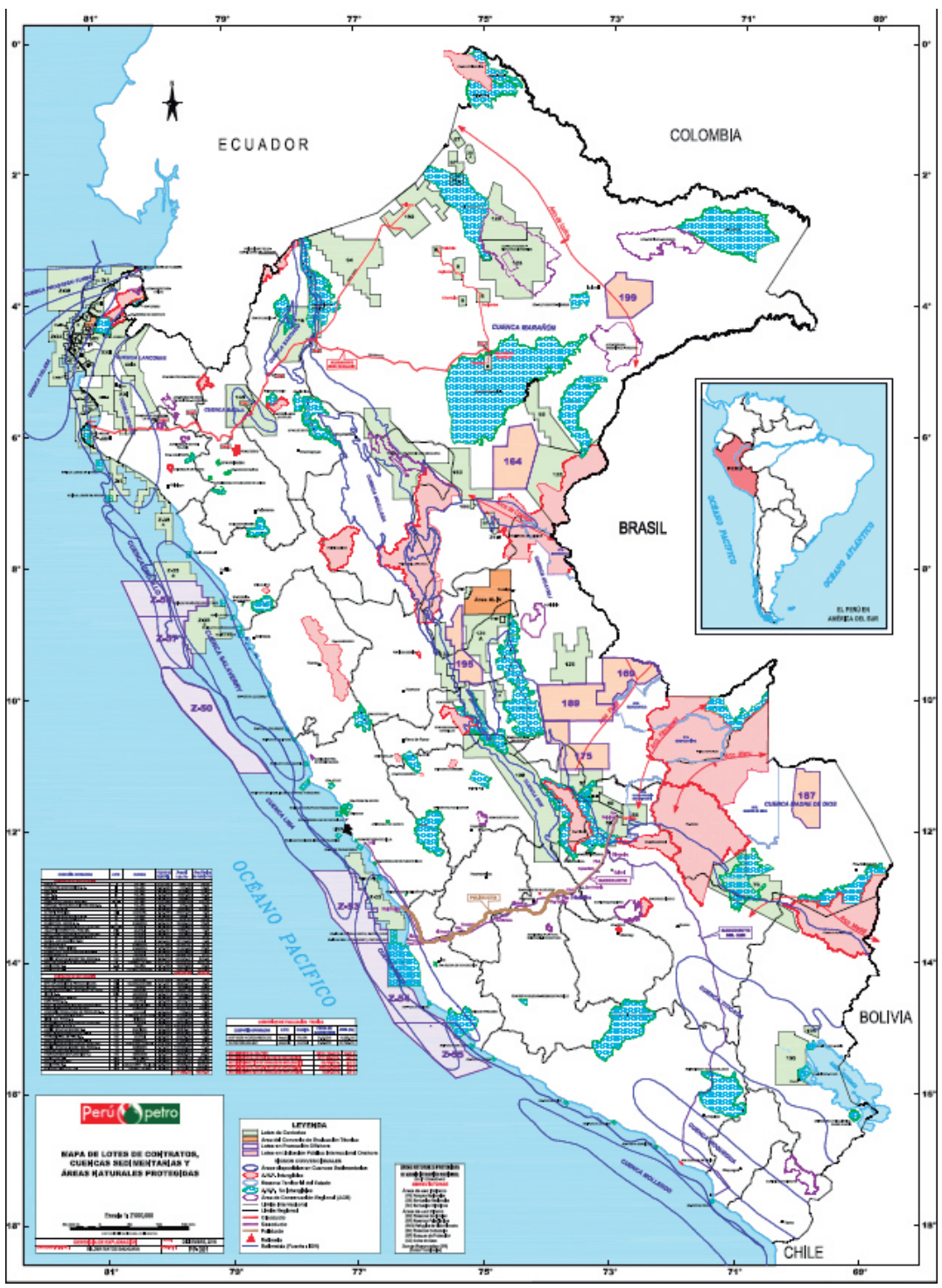

Fuente: Perú Petro, diciembre de 2016. 
En relación con esta expansión de lotes de hidrocarburos, Percy Summers destaca lo siguiente: «con la expansión de la explotación de hidrocarburos [...] aumenta también la probabilidad de problemas transfronterizos asociados a la contaminación de las aguas debido a derrames, vertimiento de aguas producidas, rompimiento de oleoductos, entre otros» (2014, p. 31). En consecuencia, como se podrá deducir, existe más de un caso en el que es posible la ocurrencia de impactos transfronterizos en el sector hidrocarburos.

\subsubsection{Servicio de abastecimiento de agua}

Ahora bien, más allá de los impactos transfronterizos que pudieran ocasionar las industrias extractivas, es importante destacar que también se pueden generar impactos transfronterizos $-\mathrm{y}$ ya se han producido impactos- por otro tipo de actividades, como por ejemplo los servicios de abastecimiento de agua.

Desde hace varios años, la región Tacna tiene problemas de escasez hídrica. Como consecuencia de esto, desde hace varias décadas se han llevado a cabo obras hidráulicas en la cuenca transfronteriza del Maure-Mauri ${ }^{34}$ para desviar el agua hacia Tacna: la bocatoma Uchusuma, el canal Patapujo, el túnel Kovire (ANA, 2015, p. 7) y los pozos El Ayro (Cuadema, 2009).

Puesto que el $70 \%$ de los recursos hídricos de la cuenca se encuentran en territorio boliviano, las infraestructuras construidas en el lado peruano para desviar el agua, de acuerdo a diversos medios bolivianos ${ }^{35}$, han generado severos impactos en el país vecino:

- Disminución del caudal del río Mauri-Maure, de sus afluentes y del río Desaguadero (Cuadema, 2009);

- Deterioro de la calidad del agua de los ríos Mauri-Maure y Caquena (Cuadema, 2009);

- Secado de 600 hectáreas de bofedales en territorio boliviano, como consecuencia de los pozos perforados en él (Cuadema, 2009);

- Desaparición de 800 hectáreas de bofedales en territorio boliviano, como consecuencia del trasvase del río (Cuadema, 2009);

\footnotetext{
34 La cuenca transfronteriza del Maure-Mauri tiene una superficie de $9.810,57 \mathrm{~km}^{2}$ y abarca tres países: Perú $(20 \%)$, Bolivia (70\%) y Chile (10\%). La mayor disponibilidad hídrica se encuentra en territorio boliviano (ANA, 2015, pp. 6, 9).

${ }_{35}$ Medios virtuales consultados: Eju (2011), Cuadema (2009), Tarija (2010), La Razón - Bolivia (2010), Página Siete (2014), RPP (2009), Luksic (2010), ALT (2007), Bolpress (2010).
} 
- Aumento considerable de la contaminación de las aguas con boro (30mg/l) y arsénico (5mg/l) (Cuadema, 2009), como consecuencia del desvío del río en Kovire, en el Perú;

Además de lo anterior, existe un proyecto adicional de transvase denominado Vilavilani que busca derivar el río Mauri-Maure en la sección Villachaullani (ANA, 2015, p. 178), también para abastecer la demanda hídrica de Tacna. Si bien este proyecto fue desestimado en el año 2010 por los diversos cuestionamientos del país vecino (Bolpress, 2010), durante el primer semestre del año 2016 se hicieron diversas declaraciones en Tacna acerca de retomar el proyecto de transvase (La República, 2016; Radio Uno, 2016). En ese sentido, es de suma relevancia, conociendo los antecedentes de las obras hidráulicas pasadas, que se analicen los posibles impactos ambientales transfronterizos que la obra pueda generar sobre los países vecinos.

\subsubsection{Servicios de saneamiento}

En línea con lo anterior, otra actividad que también es susceptible de generar impactos transfronterizos es la referida a los vertidos de aguas residuales. Las aguas residuales son un tipo de agua procedente de la actividad nacional, comercial e industrial que contiene desechos fisiológicos provenientes de la actividad humana. Son una consecuencia inevitable de las actividades humanas (Summers, 2014, p. 40); sin embargo, requieren de un sistema de tratamiento antes de ser vertidas a los cuerpos de aguas naturales (ríos, mares y lagos), debido a su alto grado de contaminación. Según un diagnóstico situacional de la Superintendencia Nacional de Servicios de Saneamiento (Sunass) del año 2008, hacia finales del año 2007 solo el 29\% de las aguas residuales en el Perú pasaban por un sistema de tratamiento de aguas residuales antes de ser vertidas a los cuerpos de aguas naturales, sistemas de tratamiento que asimismo tenían serias deficiencias en su operación (Summers, 2014, p. 39). De igual manera, en la región amazónica peruana, región que comparte varios recursos naturales con otros países, en la mayoría de los casos los desechos tienden a ir directamente al agua (Summers, 2014, p. 40).

En consecuencia, el incremento demográfico, la migración hacia las ciudades, el crecimiento económico, y la falta de planificación en los procesos de urbanización, son factores que generarán un aumento del vertimiento de aguas residuales en los cuerpos de aguas; vertimientos que, sin el respectivo tratamiento, pueden no solo impactar en la salud y el ambiente de las poblaciones locales, sino también en las fronteras más allá del territorio peruano. 


\subsubsection{Hidrovías}

En años recientes, el transporte fluvial ha sido visto como la solución ideal al transporte en la selva (Dourojeanni, 2010). Como consecuencia de esto, ha existido un interés del gobierno peruano por transformar los principales ríos de la Amazonía peruana en hidrovías (Dourojeanni, 2010):

Tabla 1.1. Propuesta de hidrovías en la Amazonía peruana

\begin{tabular}{c|c|c|c}
\hline Hidrovía & Desde & Hasta & $\mathrm{km}$ \\
\hline Napo & Cabo Pantoja & Río Amazonas & 564 \\
Putumayo & Güeppí & Santa Sofía & 1.173 \\
Huallaga & Yurimaguas & Río Marańón & 211 \\
Marańón & Saramiriza & Río Amazonas & 632 \\
Ucayali & Pucallpa & Río Amazonas & 1.032 \\
Ucayali & Pucallpa & Atalaya & 517 \\
Urubamba & Atalaya & Malvinas & 293 \\
Amazonas & Comienzo del Amazonas & Santa Rosa & 601 \\
Madre de Dios & Puerto Maldonado & Frontera & n. d. \\
\hline Total & \multicolumn{2}{c}{} & 5.023 \\
\hline
\end{tabular}

Fuentes: MTC (2009), Dourojeanni et al. (2010) y BID (2010), citados en Dourojeanni (2010).

Si bien los costos ambientales derivados del transporte fluvial son mínimos en comparación con otros tipos de transporte (aéreo, ferroviario, carreteras), la transformación de los ríos amazónicos plantea problemas ambientales inéditos no solo para el Perú (Dourojeanni, 2010), sino también para sus países vecinos.

Los dragados, la rectificación de los meandros de los ríos, el aumento del transporte fluvial, necesarios para la construcción de las hidrovías, pueden generar los siguientes impactos: remoción de sedimentos, cambios en la calidad del agua, impactos sobre los ecosistemas y hábitats acuáticos (por ejemplo, afectaciones a la migración de los peces), contaminación de las aguas por sustancias tóxicas, por mencionar algunos (Dourojeanni, 2010). Estas afectaciones, que en un comienzo se darían en el lado peruano, necesariamente terminarían afectando a los países vecinos con los que se comparten los recursos hídricos, por lo que es de suma importancia que se proceda a evaluar los posibles impactos de estas hidrovías. 


\subsubsection{Hidroeléctricas}

La expansión de la economía brasileña ha generado una fuerte demanda de electricidad en dicho país (Little, 2014, p. 35). En el marco de este crecimiento de demanda de energía, el gobierno brasileño se embarcó en un ambicioso programa de construcción de represas hidroeléctricas en la Amazonía (Little, 2014, p. 35). Junto con esto, en los últimos años, el Perú también ha estado mirando a la Amazonía como parte de su estrategia para generar energía a través de la construcción de represas. Esta situación originó que Brasil y el Perú firmaran un acuerdo energético en 2010.

Este acuerdo proponía la producción de más de 7.200 MW de hidroelectricidad para consumo nacional y exportación a Brasil por los próximos 50 años (Little, 2014, p. 35). De haberse implementado este acuerdo, esto hubiese resultado en la construcción de 15 represas en las cabeceras de la cuenca amazónica (Little, 2014, p. 35). Esto hubiese generado diversos impactos socioambientales en el Perú, pero también en los países vecinos: inundaciones, alteraciones en los regímenes hidrológicos y de sedimentos, y afectaciones a los flujos migratorios de los peces ${ }^{36}$, por mencionar algunos (WCS, 2016, p. 23).

\section{Propuesta de la central hidroeléctrica Inambari}

La propuesta de la central hidroeléctrica de Inambari fue una de las propuestas de represa que surgieron de las negociaciones entre el gobierno peruano y el brasileño. Este proyecto hidroeléctrico quedó paralizado por la desaprobación del EIA presentado, y si bien nuestro actual presidente, Pedro Pablo Kuczynski, ha descartado su realización, siempre existe la posibilidad de que las negociaciones puedan reiniciarse (WCS, s. f. [a]).

La ubicación de la represa Inambari está propuesta en las inmediaciones de la confluencia de los ríos Inambari y Araza (WCS, s. f. [a]). El proyecto, que incluye un reservorio de aproximadamente $380 \mathrm{~km}^{2}$, abarcaría zonas de las regiones Madre de Dios, Puno y Cusco (WCS, s. f. [a]), pero además podría tener impactos sobre Brasil y Bolivia. Esto último como consecuencia de que la cuenca del río Inambari forma parte del sistema mayor Madre de Dios Madeira - Amazonas (WCS, 2016), que abarca dichos países. En ese sentido, los diferentes impactos que se puedan producir sobre la cuenca del Inambari pueden alterar no solo los regímenes hidrológicos, de sedimentos, movimiento de peces y otros organismos migratorios de esa cuenca (WCS, 2016, p. 23),

\footnotetext{
${ }^{36}$ A continuación, algunos artículos, páginas web y referencias bibliográficas que describen la afectación a los ciclos migratorios de los peces: Salisbury (2016), WCS (s. f. [a]), WCS (s. f. [b]), Finer y Jenkins (2012).
} 
sino que también pueden impactar al sistema mayor de cuencas que van más allá del territorio peruano. Por ello, en caso de llevarse a cabo nuevamente un EIA de este proyecto, sería recomendable que no solo se busque identificar los posibles impactos de esta actividad en el lado peruano, sino que además se evalúen las posibles afectaciones a los países vecinos.

\section{Proyecto de la central hidroeléctrica Pongo de Manseriche}

El pongo de Manseriche se encuentra en el distrito de Santa María de Nieva, provincia de Condorcanqui, región Amazonas. Este es atravesado por el río Marañón y permite que este pueda confluir con el río Ucayali, permitiéndole finalmente abastecer al Amazonas. Desde la década de 1950, el pongo de Manseriche es considerado como el más grande recurso hidroenergético del país. Se ha identificado que la construcción de una represa en esta zona podría generar una capacidad de $8.370 \mathrm{MW}$. De construirse, esta sería 10 veces más grande que la actual mayor central hidroeléctrica del país: el Mantaro. Una hidroeléctrica en el pongo de Manseriche podría cubrir toda la demanda energética nacional.

Al igual que para el caso de la hidroeléctrica en el Inambari, pero con efectos potenciados, esta central podría generar severas consecuencias ambientales. Se podría afectar enormemente el ciclo migratorio de los peces que viajan hasta Brasil, pero también se considera que el embalse podría afectar el territorio ecuatoriano. En ese sentido, de iniciarse este proyecto, sería recomendable que el EIA pudiera identificar potenciales efectos de las hidroeléctricas en los países vecinos.

Tanto para el caso de las hidrovías como para el de las hidroeléctricas, vale hacer mención a lo señalado por Marc Dourojeanni, Alberto Barandiarán y Diego Dourojeanni. Ellos destacan que las construcciones de obras en la Amazonía peruana son motivo de preocupación no solo del Perú, sino también de nuestros países vecinos, principalmente de Brasil:

La Amazonía brasileña, a través de millones de años, fue formada y transformada por los Andes. Todo lo que se haga en la cuenca alta amazónica de la que el Perú tiene la mayor parte, repercute directa e ineludiblemente en esa región del Brasil. Los Andes, a pesar de representar tan solo el 13\% de la cuenca, han dado su forma actual a la Amazonía brasileña a través de 10 millones de años de influencia, especialmente aportando sedimentos y nutrientes minerales que mantienen la vida en las partes bajas. 
Los ríos andino-amazónicos han creado los corredores productivos donde se desarrolla su mejor agricultura (las «várzeas») y donde está establecida la mayor parte de su población que, asimismo, depende del agua fértil de sus ríos para mantener la pesca. La mayoría de las más importantes especies de peces de esa región dependen totalmente de los aportes andinos, que también regulan sus migraciones y que redistribuyen los nutrientes de las fértiles partes altas a los mucho menos productivos sistemas acuáticos de las partes bajas (McClain \& Naiman, 2008). Lo que esto significa, en buena cuenta, es que el Brasil está lejos de ser inmune al mal manejo de los recursos naturales de los Andes y de la parta alta de la Amazonía y que el futuro de su vasta región amazónica está estrechamente ligado a lo que se haga en Perú, Bolivia y Ecuador. Dicho sea de paso, eso ya es bien conocido allí cada vez que se producen periodos de inundaciones que casi siempre tienen su origen en los Andes que, debido a la deforestación, retienen cada vez menos el agua. (Dourojeanni, Barandiarán, \& Dourojeanni, 2009, pp. 118-119).

Como se ha podido apreciar a lo largo de esta sección, sí es posible que el Perú, a través del desarrollo de distintas actividades económicas en zonas de frontera o sobre recursos naturales compartidos, genere impactos negativos transfronterizos de carácter significativo. Ante esto, el Perú ya debería estar llevando a cabo EA transfronterizas. Sin embargo, como veremos a lo largo del presente trabajo, el país aún no está tomando las precauciones del caso. En ese sentido, no solo está incumpliendo con una obligación internacional, sino que, además, está poniendo en peligro al medio ambiente, y se podría llegar al punto de generar tal afectación a este, que no se tenga cómo remediar el daño.

\subsection{Conclusión}

En el presente capítulo presentamos qué son las EA transfronterizas, cuáles son los impactos transfronterizos que acarrean la necesidad de llevar a cabo estos procesos, por qué es importante prevenir la ocurrencia de estos tipos de impactos y, finalmente, cuál es la situación del Perú como generador de estos tipos de impactos.

Tomando como referencia lo señalado por distintos expertos en la materia y los distintos instrumentos del derecho internacional, se definió a las EA transfronterizas como un proceso de toma de decisiones, llevado a cabo por los Estados, para evaluar, de manera científica y con la participación de los 
ciudadanos, los impactos que un determinado proyecto podría producir sobre su medio ambiente y el de otros Estados, con la finalidad de identificar las medidas para prevenir, reducir y controlar dichos impactos.

Para identificar cuáles son los impactos ambientales transfronterizos que deberían ser analizados por las EA transfronterizas, tomamos como referencia principal lo señalado por el Convenio Espoo. Y, además, completamos el análisis con la revisión de diversos instrumentos. Como consecuencia de lo anterior, se determinó que los impactos ambientales transfronterizos sometidos a obligaciones de prevención reunían los siguientes cinco elementos: (i) impacto negativo; (ii) causalidad entre la actividad y el impacto; (iii) generado por una actividad humana; (iv) significatividad del impacto; y (v) Estado transfronterizo afectado.

Habiendo definido las EA transfronterizas y los impactos que acarreaban la necesidad de llevar a cabo estos procesos, en la tercera sección del capítulo se indicó la importancia de establecer reglas de prevención para los impactos transfronterizos. Al respecto, se señaló que el medio ambiente se protege mejor a través de acciones de prevención que a través de medidas de reparación, ya que, entre otras razones, la indemnización por lo general no restablece la situación que existía antes de producirse la afectación, y en ocasiones se generan daños irreparables al medio ambiente.

Es por eso que, actualmente, la prevención es la política principal por seguir en el DAI. Y tal es el nivel de importancia de esta en el DAI que, a la fecha, es considerada una obligación consuetudinaria del derecho internacional.

Uno de los mecanismos centrales utilizados por los Estados para dar cumplimiento a sus obligaciones de prevención son las EA transfronterizas. Y, como se analizará en el siguiente capítulo, si bien las EA transfronterizas son una de las maneras que los Estados tienen para dar cumplimiento a su obligación de prevención, estas se tienen que realizar obligatoriamente cuando se está frente a actividades que pueden generar un impacto transfronterizo significativo en el medio ambiente, pues, actualmente, la realización de EA transfronterizas constituye también una obligación consuetudinaria del derecho internacional.

En la última sección de este capítulo, se demostró que el Perú no es un Estado ajeno a la generación de los tipos de impactos descritos. Se señaló que existe un gran número de actividades que se realizan en zonas fronterizas -hidrocarburos, minería-, así como sobre recursos naturales compartidos como ríos y lagos -hidrovías e hidroeléctricas-, que tienen una alta probabilidad de generar impactos transfronterizos. A fin de prevenir cualquier impacto al medio ambiente de nuestros Estados vecinos, el Perú ya debería estar llevando a cabo 
EA transfronterizas. Sin embargo, como veremos más adelante, esta situación no se está dando, lo que coloca al Perú en una situación de incumplimiento de la normativa internacional, pero además en una posición de alto riesgo de afectar el medio ambiente más allá de sus fronteras políticas. 


\section{La obligación consuetudinaria internacional de llevar a cabo EA transfronterizas}

El presente capítulo tiene como objetivo demostrar que las EA transfronterizas definidas en el capítulo 1 son consideradas, actualmente, una obligación consuetudinaria del DAI. Es decir, que necesariamente deben ser llevadas a cabo por los Estados. Para probar esto, primero explicaremos qué es una costumbre del derecho internacional y cuáles son los requisitos que deben existir para que esta se configure. Acto seguido, con base en lo anterior, procederemos a probar la existencia de la obligación consuetudinaria de realizar EA transfronterizas; y, finalmente, en la tercera sección del presente capítulo, indicaremos cuál es el procedimiento y el contenido de esta obligación.

\subsection{La costumbre internacional ${ }^{1}$}

La costumbre es una de las fuentes formales del Derecho Internacional Público (DIP) que crea, modifica y extingue derechos y obligaciones entre los distintos sujetos del derecho internacional ${ }^{2}$.

Para poder entender la costumbre, es necesario recurrir a distintos instrumentos del derecho internacional, ya que, a diferencia de los tratados -otra fuente del DIP que se encuentra regulada por la Convención de Viena de

\footnotetext{
${ }^{1}$ Esta sección presentará algunos lineamientos básicos sobre la costumbre internacional necesarios para la comprensión del presente trabajo. En caso se desee profundizar más al respecto, se recomienda la lectura de las obras de Lepard (2010) y Thirlway (2014).

${ }^{2}$ El proceso de creación de la costumbre en el DAI es análogo al proceso de creación de costumbre en el DIP, por lo que es válido aproximarse a este tema a través del análisis de la costumbre como fuente de derecho del DIP (Dupuy, 2007, p. 454).
} 
1969-, la costumbre no tiene un tratado marco que establezca una definición, ni los elementos que deba reunir, ni que mencione si es vinculante para los sujetos del derecho internacional o no.

A la fecha, existe una posición mayoritaria en la doctrina (Cancado, 2005, p. 151), que reconoce que la costumbre «comprende a las normas del derecho que se derivan de la conducta consecuente de los Estados quienes actúan bajo la creencia que el derecho requiere que actúen de esa manera ${ }^{3}$. De igual manera, el artículo 38, inciso $1 \mathrm{~b}$, del Estatuto de la CIJ define a la costumbre como «[la] prueba de una práctica generalmente aceptada como derecho».

Como se puede apreciar, la costumbre se trata de una norma del derecho que se genera por la existencia de dos elementos: la práctica de los Estados -elemento objetivo-y el convencimiento de que se tiene que actuar de cierta manera-opinio juris.

Si bien la necesidad de coexistencia de estos dos elementos para la conformación de la costumbre ha sido cuestionada por diversos autores -especialmente Kelsen- a lo largo de la historia, la posición mayoritaria ha sido que ambos elementos deben coexistir (Cancado, 2005, pp. 150-152). Esta idea ha sido confirmada por la CIJ a través de distintas sentencias como la del Caso Lotus, el Caso de la Plataforma Continental del Mar del Norte de 1969, el Caso de la Plataforma Continental entre Libia y Malta de 1985, el Caso de Nicaragua contra los Estados Unidos de 1986 y la Opinión Consultiva del Uso de Armas Nucleares de 1996 (Cancado, 2005, p. 154).

A continuación, pasaremos a analizar estos dos elementos con mayor detenimiento.

\subsubsection{Elemento objetivo}

En relación con el elemento objetivo, es una opinión aceptada que la costumbre debe ser una práctica de los Estados en sus relaciones internacionales (Rosenne, 2001, p. 57) que: (i) tenga continuidad en el tiempo, (ii) muestre intensidad y coherencia, y (iii) sea generalizada 4 .

En relación con el primer elemento, es importante dejar en claro que, si bien se requiere que la práctica haya tenido cierta continuidad en el tiempo, actualmente no se requiere para la formación de la costumbre que haya transcurrido un largo período de tiempo (Rosenne, 2001, p. 58).

\footnotetext{
${ }^{3}$ Texto original en inglés: "comprises the rules of law derived from the consistent conduct of States acting in the belief that the law requires them to act in that way" (Rosenne, 2001, p. 57).

${ }^{4}$ La separación en estos tres puntos la he realizado a partir de la lectura de diversos autores que comentan los requisitos del elemento objetivo: Rosenne (2001), Barboza (2008), Thirlway (2014), Marińo (2005), Barberis (1994) y Gonzales et al. (2008).
} 
Sin embargo, lo que sí se exige -y este es el segundo elemento- es que "durante el período de formación la práctica haya tenido cierta intensidad y coherencia» (Barboza, 2008, p. 98). Thirlway destaca: «de hecho, es más relevante la consistencia y la repetición de la práctica, que la duración de esta» 5 .

Asimismo, la práctica de los Estados tiene que ser uniforme o tener coherencia, como algunos autores le llaman. Esto significa que «las conductas [...] deben tener un significado semejante y de ellas, de modo inequívoco, debe poder extraerse una regla de comportamiento determinada» (Marińo, 2005, p. 259).

$\mathrm{Al}$ respecto, es relevante hacer referencia al fallo en el asunto de las pesquerías anglo-noruegas, en el cual la CIJ indicó que la norma materia de discusión, que fijaba las 10 millas para el cierre de las bahías, «ha sido aceptada por ciertos Estados [...] otros Estados han adoptado un límite diferente. En consecuencia, la regla de las 10 millas no ha adquirido la autoridad de una regla general del derecho internacional $»^{6}$.

Sin perjuicio de esto último, es importante destacar lo que señala Barberis al respecto: «los actos [...] no deben ser necesariamente idénticos entre sí. Es suficiente que se trate de actos que, si bien difieren en algunos aspectos, guardan una semejanza entre ellos» (Barberis, 1994, p. 86).

Finalmente, el tercer requisito se refiere a que la costumbre debe ser, además, generalizada. Esto significa que la actuación de un solo Estado no es suficiente para el establecimiento de la costumbre, sino que se requiere la actuación de más de un Estado (Rosenne, 2001, p. 58). Ahora bien, «la práctica requerida para que se establezca una norma consuetudinaria no tiene que tratarse de una práctica llevada a cabo por todos los Estados del mundo [...]», lo que se requiere es que sea una práctica llevada a cabo por los Estados cuyos intereses se encuentran especialmente afectados (Thirlway, 2014, pp. 64-65). Siguiendo a Gonzales Campos et al.: "pueden considerarse como "Estados interesados" aquellos que han tenido ocasión de comportarse en el sentido de la norma que se invoca, contribuyendo mediante su condura (precedentes) a la formación de la práctica» (2008, p. 201).

\footnotetext{
${ }^{5}$ Texto original en inglés.: «It is in fact the consistency and repetition rather than the duration of the practice that carries the most weigh" (Thirlway, 2014, p. 64).

${ }^{6}$ Texto original en inglés: «[...] has been adopted by certain States [...] other States have adopted a different limit. Consequently, the ten-mile rule has no acquired the authority of a general rule of international law» (Fisheries case, 1951, p. 131).

${ }^{7}$ Texto original en inglés: «the settled practice required to establish a rule of customary law does not need to be the practice of every single State of the world [...]» (Thirlway, 2014, p. 67).
} 


\subsubsection{La prueba de la práctica de los Estados}

Debido a que la costumbre que estamos analizando es la costumbre como fuente del DIP -y este regula esencialmente las relaciones entre los Estados-, la práctica que es relevante para el establecimiento de una norma consuetudinaria es, justamente, aquella referida a la acción o inacción de los Estados (Thirlway, 2014, p. 63). En ese sentido, la principal evidencia de la práctica consuetudinaria es la conducta de los Estados (Thirlway, 2014, p. 63). Y esta puede ser deducida del comportamiento de cualquiera de los órganos del Estado, incluyendo los judiciales (Rosenne, 2001, p. 58).

Asimismo, los actos pueden ocurrir tanto en el plano normativo: «la conclusión de tratados, el dictado de leyes, decretos o actos administrativos internos, resoluciones de organizaciones internacionales» (Barberis, 1994, p. 84), como también en el plano de los hechos: «el ejercicio de un bloqueo, ciertos actos de guerra, o la toma de posesión de un territorio» (Barberis, 1994, p. 84). Como señala Barberis: «una costumbre puede ser creada por cualquiera de las dos categorías de actos» (Barberis, 1994, p. 84).

De igual manera, es relevante hacer referencia al Reporte de la Asociación de Derecho Internacional (ADI) ${ }^{8}$ sobre la Formación de la Costumbre en el Derecho Internacional del año 2000, donde se precisó que: (i) los actos verbales, y no solo los físicos, cuentan como práctica de los Estados; (ii) los actos que no son públicos no cuentan; y (iii) en ciertas circunstancias, la omisión también cuenta como práctica (ADI, 2000, pp. 14-15).

\subsubsection{Opinio juris}

La práctica de los Estados, por sí sola, independientemente de la cantidad de Estados que la hayan practicado, no puede establecer una norma consuetudinaria internacional (Rosenne, 2001, p. 58). Adicionalmente al elemento material, la doctrina y la jurisprudencia destacan la necesidad de la existencia de la opinio juris: «se ha indicado que los Estados o los otros actores internacionales deben de comportarse de una manera en particular para conformar una práctica equivalente a una costumbre general, pero, además, deben hacerlo bajo la creencia de que la están conformando»" Como seńala Oppenheim: «hay costumbre internacional cuando se ha desarrollado un definido y continuo

\footnotetext{
${ }^{8}$ Organización sin fines de lucro que promueve el estudio, clarificación y desarrollo del derecho internacional.

${ }^{9}$ Texto original en inglés: «States or other international actors, it is said, must behave in a particular way in order to conform to, and in the belief that they are conforming to, and established practice amounting to a general custom» (Thirlway, 2014, p. 72).
} 
hábito de llevar a cabo ciertos actos con la convicción de que, con arreglo al derecho internacional, son obligatorios o justos» (1961, p. 27).

\subsubsection{La prueba de la opinio juris}

Existen tres tipos de evidencia que se pueden utilizar para probar la opinio juris. El primer tipo de evidencia -al igual que para el caso de la prueba en el elemento material- se refiere al comportamiento de los distintos órganos del Estado. Ahora bien, adicionalmente a lo que hemos seńalado para el punto anterior, es importante tener en cuenta que como estos órganos de por sí no son individuos y, por ende, no pueden tener "convicciones», en el derecho internacional se considera que los actos de los representantes de estos órganos -presidentes, congresistas, jueces-son actos del Estado (Lepard, 2010, p. 171).

A fin de comprobar estas "convicciones» de los Estados, se puede hacer referencia a una gran variedad comportamientos y declaraciones de dichos representantes (Lepard, 2010, p. 172). Por ejemplo, se pueden considerar la aprobación de tratados u otros acuerdos internacionales, la adopción de legislación que regule aspectos de asuntos internacionales, la realización de actos administrativos vinculados a asuntos internacionales, la jurisprudencia nacional que haga referencia a asuntos internacionales y, en general, cualquier acto realizado por representantes del poder ejecutivo, legislativo o judicial que haga referencia a la relación con otros Estados (Lepard, 2010, p. 172).

No solo los actos de los Estados o de sus representantes sirven para probar la existencia de la opinio juris. Las resoluciones de las OI son el segundo tipo de evidencia y estas también cumplen un rol relevante al respecto. Sin embargo, la relevancia de estas es menor que la de los comportamientos de los Estados, debido a que es justamente la forma de actuar de los Estados la que forma la opinio juris (Lepard, 2010, p. 180). Sin perjuicio de esto último, «los actos de las organizaciones internacionales y sus agentes pueden proporcionar evidencia indirecta de estas actitudes de los Estados» ${ }^{10}$.

Adicionalmente a los dos tipos de evidencia antes señalados, existen otras fuentes de evidencia de opinio juris, como las opiniones de los expertos y de ONG (Lepard, 2010, p. 185). En la sección 2.2 haremos referencia a cada uno de estos tres grupos de evidencia con mayor detalle.

\footnotetext{
10 Texto original en inglés: "[ $\mathrm{t}]$ he acts of international organizations and their agents may provide indirect evidence of these state attitudes" (Lepard, 2010, p. 172).
} 


\subsubsection{Oposición y regionalización de la costumbre}

Un punto adicional que se debe tener en cuenta es que, si bien en la formación de la costumbre no es necesaria la participación de todos los Estados, una vez consolidada, esta se aplica a todos los sujetos del DIP, incluso a aquellos que no participaron en el proceso formativo y no expresaron su parecer al respecto (Thirlway, 2014, p. 54). No obstante, esta regla tiene dos excepciones.

La primera excepción se denomina el objetor persistente y está referida a los casos en que los Estados muestran su oposición o protesta durante el período de formación de la costumbre (Rosenne, 2001, p. 58). En caso de demostrarse que un Estado efectivamente ha mostrado su oposición a la formación de la costumbre, esta no se aplica al Estado opositor; sin embargo, la existencia de un objetor persistente no impide la formación de la regla consuetudinaria.

De otro lado, la segunda excepción está referida a las costumbres locales. Thirlway las define de la siguiente manera: «[...] existen normas de derecho consuetudinario de carácter especial o local que son aplicables solo a un grupo determinado de Estados [...] ${ }^{11}$. Sin embargo, es importante tener en cuenta que para que un Estado de la región pueda decir que dicha costumbre se le aplica tiene que brindar su consentimiento. Es decir, «el consentimiento es la condición necesaria para la existencia de una costumbre regional» (Barboza, 2008, p. 101).

\subsection{La obligación consuetudinaria internacional de elaborar EA transfronterizas}

Habiendo señalado los puntos más importantes en relación con la teoría sobre la costumbre como fuente del DIP, la presente sección busca evidenciar la existencia de una obligación consuetudinaria internacional de realizar EA transfronterizas. A continuación, pasaremos a demostrar la existencia de tal obligación consuetudinaria probando la existencia tanto del elemento objetivo como de la opinio juris.

\subsubsection{Elemento objetivo}

Como señalamos al inicio de este capítulo, la costumbre debe tratarse de una práctica que se haya realizado de manera intensa y coherente, generalizada y durante un cierto período de tiempo.

Para probar que nos encontramos frente a una práctica que cumple tales condiciones es importante también recordar que las prácticas que son relevantes

\footnotetext{
${ }^{11}$ Texto original en inglés: «[...] there exist rules of special or local customary law, which are applicable only within a defined group of States [...]" (Thirlway, 2014, p. 56).
} 
son aquellas referidas a la acción y/o inacción de los Estados, las cuales pueden ser deducidas del comportamiento de cualquiera de los órganos del Estado, tanto en el plano normativo como en el plano de los hechos.

En ese sentido, a continuación, pasaremos a hacer referencia a distintas conductas seguidas por los Estados durante los últimos ańos, a fin de demostrar que la práctica de llevar a cabo EA transfronterizas cumple con todos los requisitos antes señalados.

\subsubsection{Plano normativo}

Como seńala Julio Barberis, los actos que pueden servir como prueba en el plano normativo son los tratados, la promulgación de leyes, decretos o actos administrativos internos y las resoluciones de organizaciones internacionales (Barberis, 1994, p. 84). Como se podrá ver a continuación, existe una serie de actos normativos llevados a cabo por los Estados desde la década de 1970 que coadyuvan a demostrar la existencia de este primer elemento:

\subsection{Tratados}

- Acta de Santiago sobre Cuencas Hidrológicas, 1971, artículos 5 y 6;

- Convención Nórdica de Protección Ambiental, 1974, todos los artículos;

- Estatuto del Río Uruguay, 1975, artículos 7-13, 30;

- Convención para la Protección del Mar Mediterráneo, Barcelona, 1976, artículo 4;

- Convenio Regional de Kuwait sobre Cooperación para la Protección del Medio Marino contra la Contaminación, 1978, artículo XI;

- Tratado de Cooperación Amazónica, 1978, artículo XV'12;

- Acuerdo entre Colombia y Perú para la conservación de la flora y de la fauna en la Amazonía, 1979, artículo 15;

- Convención de las Naciones Unidas sobre el Derecho del Mar (Convemar), 1982, artículos 204, 205 y 206;

- Convención para la Protección y el Desarrollo del Medio Ambiente Marino de la Región del Gran Caribe, Cartagena de Indias, 1983, artículo 12;

\footnotetext{
${ }^{12}$ Este tratado fue firmado el 3/7/1978, ratificado por el Perú el 27/8/1979 y entró en vigencia el 2/8/1980.
} 
- Convención para la Protección de los Recursos Naturales y el Medio Ambiente en el Pacífico Sur-Convención de Noumea-, 1986, artículo 16;

- Convenio Espoo, 1991, todos los artículos;

- Protocolo sobre asuntos de transporte a la Convención Alpina de 1991, Lucerna, artículo 8;

- Tratado entre Chile y Argentina sobre medio ambiente, 1991, artículo 3;

- Convenio de Diversidad Biológica, 1992, artículo 14³;

- Convenio sobre la protección y uso de los cursos de agua transfronterizos y los lagos internacionales -Convenio de Helsinki-, 1992, artículo 3, inciso $1 \mathrm{~h}$;

- Convención para la Protección del Medio Ambiente Marino del Océano Báltico, Helsinki, 1992, artículo 7;

- Acuerdo para la Cooperación Ambiental de Norteamérica, 1993, artículo 10.7, 10.8, 10.9;

- Convención de las Naciones Unidas sobre el derecho de los usos de los cursos de agua internacionales para fines distintos de la navegación, 1997, artículo 12;

- Tratado sobre integración y complementación minera entre Chile y Argentina, 2000, artículo 12;

- Convenio de Cooperación para la Protección y el Desarrollo Sostenible de las Zonas Marinas y Costeras del Pacífico Noroeste, Antigua, 2002, artículo 5;

- Convenio marco para la protección del medio marino del Mar Caspio -Convenio de Teherán-, 2003, artículo 17;

- Convención Marco sobre la Protección y el Desarrollo Sostenible de los Cárpatos, Kiev, 2003, artículo 12;

- Convenio de Cooperación en Materia de Cambio Climático, Conservación de la Diversidad Biológica y Desarrollo Ambiental entre la República de Ecuador y la República del Perú, 2011, cláusula tercera ${ }^{14}$;

\footnotetext{
${ }^{13}$ Este Convenio fue adoptado el 5/6/1992, ratificado el 24/5/1993 y entró en vigor para el Perú el 7/9/1993.

${ }^{14}$ Este convenio fue ratificado por el Perú el 7/11/2011.
} 
- Declaración de la Isla Esteves Perú-Bolivia, 2015, artículo 9.

2.2.1.1.2 Declaraciones de los Estados (véase la sección 2.2.2.2)

- Solicitud de Opinión Consultiva a la CIJ realizada en 1995 por Nueva Zelanda;

- Declaración de Costa Rica a Nicaragua realizada el 14 de julio de 2014;

- Resolución del Senado de los EE. UU. del año 1978, que proponía lineamientos para la realización de una convención sobre EA transfronterizas, y alentaba a los países a elaborar una Convención al respecto;

- Actuación de las Partes en el caso del Proyecto Gabcikovo-Nagymaros, 1993;

- Declaración de Uruguay en el Caso de Plantas de Celulosa, 2010.

\subsection{Legislación nacional}

- Colombia: Decreto 2811 de 1974, parte II;

- Bolivia: Ley 1333, Ley del Medio Ambiente de 1992, capítulo VIII;

- Bolivia: anexo 2 del Decreto Supremo 24176, Reglamento de Prevención y Control Ambiental, artículos 167 y 168;

- Paraguay: Ley 294/1993, Evaluación de Impacto Ambiental y su modificatoria Ley 345/1994, capítulo VIII;

- Guatemala: Reglamento de Evaluación, Control y Seguimiento Ambiental, Acuerdo Gubernativo 23-2003, artículos 7, inciso i), y 72;

- Costa Rica: Reglamento General sobre los Procedimientos de Evaluación de Impacto Ambiental de Costa Rica, N.o 31849-Minae-SMOPT-MAG-MEIC, artículo 70;

- Brasil: Resolución Conselho Nacional do Meio Ambiente (Conama) 237/97.

2.2.1.1.4 Instrumentos de organizaciones internacionales

- Directiva relativa a la evaluación de las repercusiones de determinados proyectos públicos y privados sobre el medio ambiente -Directiva 85/337/CEE- de 1985, modificada por Directiva 97/11/EC de 1997, artículo 7 ; 
- Metas y principios del PNUMA sobre evaluaciones de impacto ambiental, 1987, principios 11 y 12 ;

- Declaración de Río sobre el Medio Ambiente y el Desarrollo -Declaración de Río-, 1992, principio 19;

- Proyecto de artículos sobre «Prevención del Daño Transfronterizo Resultante de Actividades Peligrosas» adoptado por la CDI en su 53. período de sesiones, 2001;

- Principios sobre la conservación y la utilización armoniosa de los recursos naturales compartidos por dos o más Estados, desarrollados por el PNUMA en 1978, principio 4;

- Carta Mundial de la Naturaleza preparada por la Unión Internacional para la Conservación de la Naturaleza (UICN) y adoptada por la Asamblea General de la ONU, por la Resolución 37/7(1982), 1982, artículos 11c y 16 .

\subsubsection{Plano táctico}

En relación con el plano táctico o plano de los hechos, resulta de singular complejidad determinar todas las EA transfronterizas llevadas a cabo en el marco de los distintos tratados y/o en el marco de las distintas legislaciones nacionales, sobre todo por el hecho de que no existe una obligación de llevar a cabo un registro de las EA transfronterizas realizadas en el marco de todos los tratados, ni tampoco en los países que realizan estos procedimientos.

La Comisión Económica para Europa de las Naciones Unidas (Unece, por sus siglas en inglés) $)^{15}$-organismo bajo el cual se llevó a cabo el Convenio Espoo- es una de las pocas organizaciones que tiene un registro -no oficial- de las EA transfronterizas que han llevado a cabo los países miembros del Convenio Espoo desde su entrada en vigencia. En la página web de la Unece ${ }^{16}$ se puede apreciar una lista no oficial de todos los proyectos que han requerido llevar a cabo una EA transfronteriza entre 1997 y 2011. En ella se puede apreciar que en un período aproximado de 14 años se han llevado a cabo más de 200 EA transfronterizas.

\footnotetext{
${ }^{15}$ La abreviatura en español es CEPE.

${ }^{16}$ http://www.unece.org/fileadmin/DAM/env/eia/documents/database/Listing_of_transboundary_EIA_ procedures_July_2011.pdf
} 
$\mathrm{Al}$ respecto, algunos ejemplos de EA transfronterizas llevadas a cabo en el marco del Convenio Espoo son las siguientes ${ }^{17}$ :

- EA transfronteriza de la planta de energía hidráulica del río Neman, entre Bielorrusia y Lituania. El Ministerio de Recursos Naturales y Protección del Medio Ambiente de Bielorrusia (MRNPMB) tenía como objetivo construir una planta de energía hidráulica sobre el río Neman a $11 \mathrm{~km}$ de la frontera con Lituania. A fin de construir esta planta, Bielorrusia llevó a cabo una EA transfronteriza para analizar los posibles impactos que esta planta podría tener en Lituania. En ese sentido, el 1 de julio de 2009, Bielorrusia envió el primer borrador del EIA en inglés y ruso a Lituania. En relación con este borrador, Lituania efectuó comentarios, luego Bielorrusia absolvió los comentarios y, posteriormente, llevó a cabo una audiencia pública tanto en Lituania como en Bielorrusia. Después de realizados estos actos, el 6 de julio de 2010, los expertos ecológicos de Bielorrusia emitieron una resolución positiva del proyecto, la cual fue notificada a Lituania el 5 de noviembre de 2010. El proceso de elaboración de la EA transfronteriza demoró 1 año y 4 meses $^{18}$ (Bonvoisin, 2011).

- EA transfronteriza de la carretera Thonon-Annemasse en Francia, cerca de la frontera con Suiza. Con la finalidad de construir una carretera que una la ciudad de Annemasse y Thonon en Francia, este país, signatario del Convenio Espoo, notificó el 2 de diciembre de 2004

\footnotetext{
${ }^{17}$ De las 200 EA transfronterizas recogidas en la lista no oficial de la Unece se seleccionaron estos tres ejemplos porque: (i) en la página de la Unece había boletines de información de estos casos (no existe información detallada de todos los casos); (ii) la EA transfronteriza de la planta de energía hidráulica del río Neman y la EA transfronteriza de la carretera Thonon-Annemasse en Francia son ejemplos de proyectos que también se podrían llevar a cabo en el Perú; y (iii) la EA transfronteriza de las Plantas Nucleares en Finlandia es un ejemplo de un caso que demuestra que a pesar de la complejidad de este (se notificó a más de un país en el proceso, más de un país decidió formar parte del proceso y el EIA tuvo que ser traducido a varios idiomas), la EA igual se pudo llevar a cabo sin haber generado demoras excesivas en la ejecución del proyecto. ${ }^{18}$ El proceso más detallado fue así: El 1 de julio de 2009, Bielorrusia envió el primer borrador del EIA en inglés y ruso a Lituania y Rusia y les consultó si deseaban participar del proceso. Lituania respondió positivamente a la notificación y el 7 de agosto de 2009 envió sus comentarios al EIA en inglés. Rusia no respondió a la notificación. El 17 de agosto de 2009, los comentarios emitidos por Lituania fueron enviados a todas las instituciones interesadas en Bielorrusia. Un mes después, el 21 de septiembre de 2009, el Ministerio de Recursos Naturales de Bielorrusia, envió los comentarios absueltos a Lituania. Cuatro días después, el 25 de septiembre, se llevó a cabo la Audiencia Pública en Lituania con representantes de instituciones educativas, ONG, compañías de ingeniería civil, representantes del Estado de Lituania y representes del gobierno de Bielorrusia encargados de hacer el proyecto. Los comentarios del proceso participativo fueron recolectados hasta el 9 de octubre de 2009. Posteriormente, el 24 de febrero de 2010, los representantes de Lituania y Bielorrusia se reunieron en Bielorrusia para intercambiar los resultados de la audiencia pública, el 10 de marzo de 2010 se llevó a cabo la audiencia pública con los ciudadanos de Bielorrusia y el 6 de julio de 2010 se emitió la resolución positiva de los expertos ecológicos. El 5 de noviembre de 2010 se presentó a Lituania la decisión final.
} 
a Suiza, también parte de dicho convenio, sobre la construcción de este proyecto. El 14 y 17 de enero de 2005, el servicio de EIA del cantón de Ginebra de Suiza y la Oficina para el medio ambiente del Gobierno Federal Suizo confirmaron a Francia su voluntad de participar en la EA transfronteriza y de realizar una audiencia para obtener comentarios sobre el proyecto. El proceso participativo en Ginebra se llevó a cabo entre el 19 de enero y el 2 de marzo de 2005. De igual manera, las autoridades suizas realizaron una evaluación sobre los impactos que podría generar el proyecto y la remitieron el 16 de marzo de 2005 a Francia, a fin de que fueran tomados en cuenta en el momento de evaluar la viabilidad ambiental del proyecto ${ }^{19}$ (Unece, 2006). Como se puede apreciar, en el presente caso, el gobierno francés remitió el borrador del EIA a Suiza y, a partir del envío del estudio, el proceso participativo con el gobierno suizo demoró alrededor de 3 meses.

- EA transfronteriza de la planta de energía nuclear Olkiluoto 3 en Finlandia. En el año 1998, Finlandia inició el proceso de elaboración de la EA transfronteriza de la central nuclear Olkiluoto 3, ubicada en la isla de Olkiluoto, a la orilla del golfo de Botnia, al oeste de Finlandia. Para iniciar la elaboración de la $\mathrm{EA}^{20}$, Finlandia envió a Austria, Dinamarca, Estonia, Alemania, Letonia, Lituania, Noruega, Polonia y Suecia un programa del posible contenido del EIA, para lo cual se tradujo este programa a cada uno de los idiomas de los países antes señalados. Todos los países señalados, menos Dinamarca y Letonia, decidieron participar del proceso y enviaron sus comentarios al programa del EIA. Con base en los comentarios recibidos, Finlandia procedió a la elaboración del EIA y en el año 1999 remitió a todos los países la primera versión del EIA ${ }^{21}$. Todo el EIA estuvo disponible en finés, sueco e inglés, y el resumen del EIA fue traducido a los idiomas de cada una de las partes. Con base en esta propuesta, se volvió a recibir comentarios; y, con base en los comentarios recibidos, se ajustó el EIA

\footnotetext{
${ }^{19}$ El cantón de Ginebra dio su visto bueno al proyecto, pero pidió al gobierno francés que tomara en cuenta sus sugerencias (incremento del tráfico, incremento de las emisiones de gases, la conservación de corredores de fauna, la protección de los cursos de agua y los humedales). En relación con los comentarios realizados por las autoridades suizas, el proponente del proyecto se comprometió a mantener un diálogo continuo con ellos.

${ }^{20}$ Nótese que, a diferencia de los dos casos anteriores, en los que el proceso de elaboración de la EA transfronteriza se dio una vez elaborado el primer borrador del EIA, en este caso el proceso participativo con los posibles Estados afectados se dio antes de la elaboración del primer borrador del EIA.

${ }^{21}$ Como se puede apreciar, para el caso finlandés el proceso participativo se da en dos momentos: (i) antes de la elaboración del EIA y (ii) después de la elaboración del primer borrador.
} 
y se envió al Ministerio de Economía y Empleo de Finlandia (MEE) ${ }^{22}$ para su aprobación. El 17 de enero de 2002 el MEE aprobó el EIA ${ }^{23}$. En este caso, el proceso de elaboración de la EA transfronteriza tomó alrededor de 4 años (Unece, 2009).

\subsubsection{Opinio juris}

Como hemos precisado en más de una ocasión, para que pueda existir una costumbre es necesario que los Estados lleven a cabo los actos con la convicción de que estos son obligatorios de acuerdo al DIP.

En las siguientes líneas, procederemos a probar la existencia de la opinio juris. Como elementos de prueba de este segundo requisito se pueden considerar los actos realizados por representantes del poder ejecutivo, legislativo o judicial que hagan referencia a la relación con otros Estados, las resoluciones de las OI y las opiniones de expertos y ONG.

Como se podrá percibir, ciertas evidencias mostradas en la sección anterior también sirven para probar este segundo requisito.

\subsubsection{Los tratados como evidencia de opinio juris}

Los tratados son una de las evidencias más fuertes para probar la existencia de opinio juris, debido, entre otros aspectos, al carácter vinculante de estos.

Es importante comenzar precisando que existen ciertos tratados que tienen una función codificadora de las normas consuetudinarias; otros que tienen una función cristalizadora; así como también, de otro lado, existen tratados que son generadores, es decir, que contribuyen al desarrollo de la costumbre. Los tratados seńalados en la sección anterior y que sirven también como evidencia de opinio juris, no han sido tratados codificadores ni cristalizadores, sino más bien tratados que han contribuido con el desarrollo de esta obligación. En relación con esto, la CIJ en más de una sentencia ha reconocido que los tratados, aunque no crean derecho consuetudinario per se, pueden contribuir a su desarrollo, así como también pueden constituir una importante evidencia de opinio juris.

Ejemplos de lo anterior son el caso de la Plataforma Continental del Mar del Norte del año 1969, donde la CIJ señaló lo siguiente: “"no hay duda” de que una norma que fue originalmente incluida en un tratado puede pasar a

\footnotetext{
${ }^{22}$ El MEE es la autoridad competente para aprobar los EIA en Finlandia.

${ }^{23}$ Es importante tener en cuenta que, de acuerdo a la legislación finlandesa, luego de que el EIA es aprobado por el MEE, esta decisión debe ser ratificada por el Parlamento. En el presente caso, el 24 de mayo de 2002 el Parlamento ratificó la decisión del MEE.
} 
formar parte del corpus del derecho internacional consuetudinario» ${ }^{24}$; y el caso de la Plataforma Continental, donde la CIJ en el ańo 1985 indicó que: «las convenciones multilaterales pueden desempeñar un papel importante en plasmar y definir normas derivadas de la costumbre o incluso pueden cumplir un papel importante en desarrollarlas» ${ }^{25}$.

En consecuencia, todos los tratados señalados en la sección 2.2.1.1.1 han contribuido al desarrollo de la obligación consuetudinaria de llevar a cabo EA transfronterizas, al servir tanto como evidencia del elemento objetivo como evidencia de la opinio juris. Ahora bien, sin lugar a dudas, de todos los tratados señalados, el Convenio Espoo es el más relevante: es el único instrumento vinculante aplicable a más de 40 países tanto de Europa, como de Asia y América que desarrolla de manera específica cómo llevar a cabo este procedimiento, el contenido mínimo de la obligación y las actividades sujetas a esta.

\subsubsection{Declaraciones de los Estados como evidencia de opinio juris}

Junto a los tratados, otra de las evidencias del plano normativo señaladas en la sección anterior, que sirven también como una importante evidencia de opinio juris, son las declaraciones expresas que realizan los Estados. Estas son de singular importancia pues muestran la aceptación por parte de los países de una práctica como derecho consuetudinario. En relación con la evidencia de las declaraciones de los Estados como opinio juris, Brian Lepard señala: «el impacto inmediato de una declaración es obligar únicamente al Estado declarante; sin embargo, una declaración con características particulares puede también afirmar o implicar que un Estado considera que otros Estados deben asumir obligaciones legales similares, lo que luego permitirá proporcionar evidencia de Opinio iuris» ${ }^{26}$.

Con base en lo expresado en la sección anterior, a continuación presentaremos tres casos de suma relevancia, en los que los Estados afirman estar frente a una obligación del derecho consuetudinario.

\footnotetext{
${ }^{24}$ Texto original en inglés: «there is 'no doubt' that a rule that was originally embodied in a treaty can pass into the corpus of customary international law» (C. I. J. North Sea Continental Shelf, 1969, párr. 71).

${ }^{25}$ Texto original en inglés: «Multilateral conventions may have an important role to play in recording and defining rules deriving from custom, or indeed in developing them» (C. I. J. Continental Shelf, 1985, párr. 27).

${ }^{26}$ Texto original en inglés: «the immediate impact of such a declaration is to bind only the declaring state, but a particular declaration may also affirm or imply that the state believes that other states should undertake similar legal obligations, which would then provide evidence of Opinio iuris» (Lepard, 2010, p. 190).
} 


\subsection{Opinión consultiva solicitada por Nueva Zelanda a la CIJ}

El primer caso está referido al sustento de un pedido realizado por Nueva Zelanda a la CIJ. En el año 1995, Nueva Zelanda solicitó a la Corte que declare: (i) que los nuevos ensayos nucleares propuestos por Francia constituirían una violación a los derechos correspondientes a Nueva Zelanda; y que además, o como alternativa, declare: (ii) que es ilegal que Francia lleve a cabo ensayos nucleares sin antes haber realizado una evaluación de los efectos en el medio ambiente conforme a las normas internacionales aceptadas.

Para sustentar sus pedidos, entre otros aspectos, Nueva Zelanda indicó que la realización de EA transfronterizas no estaba supeditada a la existencia de un tratado de por medio, sino que esta constituía una obligación consuetudinaria del derecho internacional (Handl, 2007, p. 541):

35. Considerando que Nueva Zelanda reiteró en sus declaraciones orales que el artículo 12 de la Convención de Noumea requiere que Francia «tome todas las medidas apropiadas para prevenir, reducir y controlar la contaminación en la zona del Convenio que pudiera derivarse de las pruebas de los dispositivos nucleares»; que el artículo 16 de dicha Convención requería la realización de una evaluación de impacto ambiental antes de que se inicie cualquier proyecto importante «que pudiera afectar el medio ambiente marino»; que una obligación similar existía bajo el derecho consuetudinario; que, por otra parte, dicha obligación no estaba sujeta a ninguna excepción reconocida del derecho internacional relativa a la seguridad nacional; que el principio de precaución implicaba que Francia lleve a cabo una evaluación como condición previa para la realización de actividades, así como para demostrar que no había ningún riesgo asociado con ellas; y que el fracaso de Francia de cumplir con estas obligaciones había afectado a la base del fallo de $1974{ }^{27}$.

\footnotetext{
${ }^{27}$ Texto original en inglés: «35. Whereas New Zealand reiterated in its oral statements that Article 12 of the Noumea Convention required France to 'take all appropriate measures to prevent, reduce and control pollution in the Convention Area which might result from the testing of nuclear devices'; that Article 16 of that Convention required the carrying out of an environmental impact assessment before any major project "which might affect the marine environment" was embarked upon; that a similar obligation existed under customary law; that, moreover, such obligation was not subject to any exception recognized in international law concerning national security; that the Precautionary Principle required France to carry out such an assessment as a precondition for undertaking the activities, and to demonstrate that there was no risk associated with them; and that France's failure to comply with these obligations had affected the basis of the 1974 Judgment» (C. I. J. Request for an Examination of the Situation in accordance with Paragraph 63 of the Court S Judgment of 20 December 1974 in the Nuclear Tests 1995, párr. 35).
} 
Es importante resaltar que no solo Nueva Zelanda declaró que realizar EA transfronterizas ya constituía una obligación consuetudinaria, sino que además Francia no negó su existencia como tal, sino que la interpretó como "conceder a los Estados un "margen de apreciación" en la determinación de cómo van a prevenir el daño»"

En consecuencia, estos actos ponen en evidencia que, desde el año 1995, para ciertos países, realizar una EA transfronteriza ya constituía una obligación consuetudinaria del derecho internacional.

\subsection{Costa Rica exige a Nicaragua información ambiental sobre el Gran Canal}

El segundo caso está referido a una declaración realizada por Costa Rica a Nicaragua en el marco de la construcción un Canal de $278 \mathrm{~km}$ de longitud que cruzará Nicaragua con la finalidad de unir el océano Pacífico con el mar Caribe $^{29}$.

Con fecha 14 de julio de 2014, el ministro de Relaciones Exteriores de Costa Rica envió a su colega nicaragüense una nota en la cual le indicaba que «respeta la decisión de Nicaragua de construir obras de infraestructura en su territorio que conduzcan al desarrollo social y económico de todos los nicaragüenses», pero que «la construcción de un canal interoceánico debe cumplir con las obligaciones internacionales que Nicaragua tiene, en este caso con Costa Rica, de conformidad con los instrumentos que gobiernan nuestras relaciones» (Ministerio de Relaciones Exteriores de Costa Rica, 2014).

En relación con la obligación internacional, la nota añade que «Costa Rica espera que Nicaragua le transmita, antes de iniciar cualquier obra, el estudio de impacto ambiental transfronterizo y cualquier otro estudio técnico pertinente, que acredite que no se afectará a Costa Rica» (Ministerio de Relaciones Exteriores de Costa Rica, 2014).

Además, el texto agrega que «Costa Rica espera que en el estudio de impacto ambiental transfronterizo que seguramente Nicaragua ha realizado o realizará, se estimen los potenciales aportes de sedimento que el río Colorado recibiría con ocasión del dragado masivo que -según la información disponible- se haría en el Lago de Nicaragua» (Ministerio de Relaciones Exteriores de Costa Rica, 2014).

\footnotetext{
${ }^{28}$ Texto original en inglés: «as allowing states a "margin of appreciation" in determining how they will prevent harm» (Craik, 2010, p. 112).

${ }^{29}$ Este proyecto incluye dos puertos, un aeropuerto, una zona de libre comercio, un complejo turístico, carreteras, un lago artificial y fábricas de cemento y acero (El Nuevo Diario, 2014).
} 
Finalmente, la nota indica que «mi país [Costa Rica] estima que Nicaragua dará una buena señal sobre su deseo de cumplir con los más altos estándares internacionales de protección ambiental, así como de su genuino compromiso por observar escrupulosamente sus obligaciones internacionales [...]» (Ministerio de Relaciones Exteriores de Costa Rica, 2014).

Esta nota es particularmente importante porque, en primer lugar, resalta el respeto a la soberanía de los Estados sobre sus recursos naturales y, en segundo lugar, establece explícitamente que realizar EA transfronterizas y notificar los resultados de estas, constituyen obligaciones del derecho internacional.

\subsection{Actuación de Uruguay en el caso de las plantas de celulosa}

En el año 2006, Argentina demandó a Uruguay ante la CIJ por un supuesto incumplimiento de sus obligaciones bajo el Estatuto del Río Uruguay, al supuestamente haber otorgado certificados para el inicio de operaciones a dos compañías papeleras sin haber efectuado las respectivas consultas con la Comisión Administradora del Río Uruguay (CARU) y con Argentina.

Uruguay, al contestar la demanda, entre otros aspectos, procedió a resaltar la existencia de una obligación de realizar estudios de impacto ambiental transfronterizos:

Uruguay acepta que, de acuerdo con la práctica internacional, un estudio de impacto ambiental de la planta Orion (Botnia) era necesario [...]. De acuerdo con Uruguay, los únicos requisitos que el derecho internacional impone son que debe haber estudios de los potenciales efectos nocivos transfronterizos del proyecto sobre la población, la propiedad y el medio ambiente de otros Estados, como lo requiere la práctica estatal y el borrador de artículos de la Comisión de Derecho Internacional sobre Prevención de Daños Transfronterizos de 2001, sin que haya necesidad de evaluar los riesgos remotos o puramente especulativos ${ }^{30}$.

Esta declaración es de singular importancia, pues el Estatuto del Río Uruguay no establecía una necesidad de llevar a cabo la EA, pero Uruguay

\footnotetext{
${ }^{30}$ Texto original en inglés: «Uruguay accepts that, in accordance with international practice, an environmental impact assessment of the Orion (Botnia) mill was necessary [...]. According to Uruguay, the only requirements international law imposes on it are that there must be assessments of the project's potential harmful transboundary effects on people, property and the environment of other States, as required by State practice and the International Law Commission 2001 draft Articles on Prevention of Transboundary Harm from Hazardous Activities, without there being any need to assess remote or purely speculative risks» (C. I. J. Pulp Mills, 2010, párr. 203).
} 
en su defensa indicó que en el derecho internacional existía una obligación de llevar a cabo esta EA y que había cumplido con realizarla.

\subsubsection{Decisiones de tribunales internacionales y cortes como evidencia de opinio juris}

Las decisiones de las cortes internacionales y tribunales internacionales -en un grado menor que las de los tratados y declaraciones de los Estados- también cumplen un rol importante en la comprobación de la existencia de la opinio juris. Al respecto, es importante recordar que el artículo 38 del estatuto de la CIJ establece que la misma Corte deberá aplicar las decisiones judiciales como medio auxiliar para la determinación de las reglas de derecho, reglas que, por supuesto, también incluyen al derecho consuetudinario (Lepard, 2010, pp. 183-184). En relación con la importancia de las decisiones judiciales en la formación de la costumbre, Theodor Meron señala: «acumulativamente, la práctica de los órganos judiciales, cuasi judiciales y de supervisión tienen un rol significativo en la generación de las normas consuetudinarias» ${ }^{31}$.

A lo largo de los ańos, han existido varios pronunciamientos sobre las EA. Sin embargo, son muy pocos casos los que han efectuado referencia a la existencia de una norma consuetudinaria de realizar EA transfronterizas, ya que la mayoría de pronunciamientos han estado enfocados en interpretar la obligación en el marco de un tratado ${ }^{32}$ (Craik, 2010, p. 111). El primer caso que hizo referencia a la obligación consuetudinaria de realizar EA transfronterizas fue el referido a las plantas de celulosa sobre el río Uruguay (López, 2012). La CIJ en dicho caso estableció lo siguiente:

[...] la obligación de proteger y preservar, bajo el artículo 41 (a) del Estatuto, debe ser interpretada de acuerdo con una práctica, que en años recientes ha ganado mucha aceptación entre los Estados, que ahora puede ser considerada un requisito bajo el derecho internacional general de llevar a cabo un estudio de impacto ambiental donde existe un riesgo de que la actividad industrial propuesta pueda tener un impacto adverso significativo ambiental en un contexto transfronterizo, en particular, en un recurso compartido. Asimismo, la diligencia debida, y el deber de vigilancia y de prevención que implica,

\footnotetext{
${ }^{31}$ Texto original en inglés: «cumulatively, the practice of judicial, quasi-judicial, and supervisory organs has a significant role in generating customary rules" (Meron, 1991, p. 100).

32 C. I. J. Gabcikovo-Nagymaros Project. Separate Opinion, 1997; The MOX Plant Case, 2001; C. I. J. Sovereignty over Pedra Branca / Pulau Batu Puteh, 2008, p. 12; C. I. J. Pulp Mills, 2010, p. 14.
} 
podría considerarse que no fue ejercida, si la parte que planea obras susceptibles de afectar el régimen del río o la calidad de sus aguas no realizó un estudio de impacto ambiental de los potenciales efectos de aquellas obras ${ }^{33}$.

[...] La Corte también considera que un estudio de impacto ambiental debe ser llevado a cabo antes de la puesta en funcionamiento de un proyecto. Además, una vez que las operaciones han comenzado y, cuando sea necesario, a lo largo de la vida del proyecto, se debe llevar a cabo un monitoreo continuo de sus efectos sobre el medio ambiente ${ }^{34}$.

Un año después, el Tribunal Internacional del Derecho del Mar, en la opinión consultiva sobre «Responsabilidades y obligaciones de los Estados al patrocinar a personas y entidades a realizar actividades en el área», reafirmó la naturaleza consuetudinaria de esta obligación, al señalar que la obligación de realizar EA transfronterizas no solo se trataba de una obligación que emanaba del artículo 206 de la Convemar, sino que, además, se trataba de una obligación consuetudinaria del derecho internacional (2011).

\subsubsection{Resoluciones de otras OI como evidencia de opinio juris}

Las resoluciones, decisiones y declaraciones adoptadas por otras organizaciones internacionales distintas a la CIJ, también se consideran evidencia de opinio juris, al ser estas evidencia indirecta del comportamiento de los Estados. En la sección anterior, en el plano normativo de las evidencias del elemento objetivo, citamos a varios instrumentos que hacían referencia a la necesidad de llevar a cabo EA transfronterizas, todas ellas instrumentos que también sirven como evidencia de opinio juris. De todos ellos, nos centraremos en el

\footnotetext{
${ }^{33}$ Texto original en inglés: « [...] the obligation to protect and preserve, under Article 41 (a) of the Statute, has to be interpreted in accordance with a practice, which in recent years has gained so much acceptance among States that it may now be considered a requirement under general international law to undertake an environmental impact assessment where there is a risk that the proposed industrial activity may have a significant adverse impact in a transboundary context, in particular, on a shared resource. Moreover, due diligence, and the duty of vigilance and prevention which it implies, would not be considered to have been exercised, if a party planning works liable to affect the régime of the river or the quality of its waters did not undertake an environmental impact assessment on the potential effects of such works» (C. I. J. Pulp Mills, 2010, párr. 204).

${ }^{34}$ Texto original en inglés: "[...] The Court also considers that an environmental impact assessment must be conducted prior to the implementation of a project. Moreover, once operations have started and, where necessary, throughout the life of the project, continuous monitoring of its effects on the environment shall be undertaken» (C. I. J. Pulp Mills, 2010, párr. 205).
} 
proyecto de artículos sobre «Prevención del daño transfronterizo resultante de actividades peligrosas $»^{35}$.

Este proyecto, compuesto por 19 artículos, busca regular las obligaciones de los Estados en relación con la prevención de la ocurrencia de daños transfronterizos, que se puedan generar al llevar a cabo actividades no prohibidas por el derecho internacional. En el artículo 7 de este proyecto de artículos se establece:

\section{Artículo 7 \\ Evaluación del riesgo}

Cualquier decisión con respecto a la autorización de una actividad comprendida en el ámbito de aplicación de los presentes artículos deberá basarse, en particular, en una evaluación del daño transfronterizo que pueda causar esa actividad, incluida la evaluación del impacto ambiental.

Adicionalmente al hecho de que este proyecto de artículos establece la necesidad de llevar a cabo EA previamente a la autorización de una actividad que pueda generar dańos transfronterizos, es importante precisar que este documento también hace referencia al principio de soberanía sobre los recursos naturales y la responsabilidad de no causar daños trasfronterizos ambientales, el principio de prevención y el principio de cooperación. Estas referencias son de singular importancia, pues en un solo documento, el cual posee el visto bueno de la Asamblea General de la ONU, se muestra la estrecha coordinación entre los distintos principios antes señalados.

Asimismo, es importante precisar que la doctrina y la CIJ han precisado en distintas ocasiones la importancia que tienen las Resoluciones de la Asamblea General de la ONU como evidencia de la existencia de una nueva costumbre. Por ejemplo, la CIJ en la Opinión Consultiva emitida el 8 de julio de 1996, respecto a la Cuestión de la Legalidad de la Amenaza o el Empleo de Armas Nucleares, comentó lo siguiente al respecto:

La Corte observa que las resoluciones de la Asamblea General, aunque no son vinculantes, pueden a veces tener valor normativo. En ciertas circunstancias pueden proporcionar pruebas importantes para determinar la existencia de una norma o la

\footnotetext{
${ }^{35}$ Nos centraremos en estos artículos debido a que: (i) están enfocados justamente en la prevención de daños transfronterizos y (ii) porque además se trata de artículos que han sido aprobados por la Asamblea General, lo cual es considerado como importante evidencia de opinio juris, como se mostrará líneas abajo.
} 
aparición de una opinio juris. Para saber si una determinada resolución de la Asamblea General cumple ese recaudo, hay que examinar su contenido y las condiciones en que se aprobó; también hay que ver si existe una opinio juris en cuanto a su carácter normativo. Puede ocurrir asimismo que una serie de resoluciones muestre la evolución gradual de la opinio juris necesaria para el establecimiento de una nueva norma ${ }^{36}$.

\subsubsection{Las opiniones de expertos y de ONG como evidencia de opinio juris}

En relación con las demás fuentes de evidencia, las opiniones de los expertos y de las ONG tienen un menor grado de importancia; sin embargo, estas igual contribuyen como un importante medio auxiliar para la determinación de las reglas de derecho.

En relación con la importancia de las opiniones de expertos, Lepard señala lo siguiente: «las opiniones de los especialistas legales pueden llevar a que los Estados cambien sus puntos de vista sobre la conveniencia de instituir determinadas normas legales, ahora o en un futuro cercano y, así, impulsar la formación de nuevas normas consuetudinarias» ${ }^{37}$.

Y, de igual manera, en relación con la importancia de las opiniones de las ONG, el mismo autor precisa lo siguiente:

[...]Las investigaciones llevadas a cabo por las ONG sobre la práctica y las creencias de los Estados pueden proporcionar importantes pruebas de opinio juris. Además, las reacciones de los Estados a estas investigaciones o a las normas propuestas por estas organizaciones, pueden constituir sin duda opinio juris. En resumen, las ONG pueden ser vistas como comprometidas en establecer diálogos dinámicos con los Estados sobre la actual opinio juris y sobre la conveniencia de reconocer nuevas normas del derecho internacional ${ }^{38}$.

\footnotetext{
${ }^{36}$ Texto original en inglés: «General Assembly resolutions, even if they are not binding, may sometimes have normative value. They can, in certain circumstances, provide evidence important for establishing the existence of a rule or the emergence of opinio juris. To establish whether this is true of a given General Assembly resolution, it is necessary to look at its content and the conditions of its adoption; it is also necessary to see whether an opinio juris exists as to its normative character. Or a series of resolutions may show the gradual evolution of the opinio juris required for the establishment of a new rule» (C. I. J. Legality of the Threat of Use of Nuclear Weapons, Advisory Opinion, 1996, párr. 70).

${ }^{37}$ Texto original en inglés: «(the) opinions of legal specialists may lead states to change their views about the desirability of instituting particular legal norms now or in the near future and thus nurture the formation of new customary norms» (Lepard, 2010, p. 186).

${ }^{38}$ Texto original en inglés: «[...] [NGOs'] factual investigations into state practice and beliefs can pro-
} 
En relación con este tipo de evidencia, es relevante referirnos a las Reglas de Berlín sobre los Recursos Hídricos, elaboradas por la ADI en el año 2004, cuyo propósito general fue recopilar todo el cuerpo de derecho consuetudinario internacional relacionado con el manejo de aguas (Smets, 2006, p. 87). Y si bien este documento está únicamente referido a los recursos hídricos, estos artículos «específicamente aprueban las obligaciones de procedimiento de evaluar (artículo 29), notificar (artículos 56-7) y consultar (artículo 58) como parte del derecho internacional consuetudinario ${ }^{39}$.

De igual manera, en los comentarios realizados por el grupo de expertos al artículo 29 que establece la obligación de llevar a cabo EA, se indica lo siguiente:

La evaluación de los impactos ambientales de los proyectos propuestos hoy en día ha cobrado «singular importancia tanto en las legislaciones nacionales como en el derecho ambiental internacional». Muchos Estados requieren hoy en día la realización de dichas evaluaciones, así como también un gran número de acuerdos internacionales, comenzando (de manera embrionaria) con el artículo 2 de la Convención General Relacionada con el Desarrollo de Energía Hidroeléctrica que Afecta a Más de un Estado. El más importante de dichos acuerdos es el Convenio Espoo preparado por la Comisión Económica para Europa de las Naciones Unidas. La asociación de derecho internacional reconoce que tal práctica se ha cristalizado en una norma de derecho consuetudinario internacional, al menos en lo que se refiere a los efectos transfronterizos $[\ldots]^{40}$.

Las obligaciones de preservar y proteger la integridad de los ecosistemas y de asegurar el desarrollo sostenible son hoy en

vide important evidence of opinio juris. Furthermore, states' reactions to the investigations, or to norms advocated by these organizations, can definitely constitute opinio juris. In short, NGOs can be viewed as engaged in dynamic dialogue with states about current opinio juris and about the desirability of recognizing new norms of international law» (Lepard, 2010, p. 187).

${ }^{39}$ Texto original en inglés: «specifically endorse procedural obligations to assess (article 29), notify (articles 56-7), and consult (article 58) as part of customary international law» (Handl, 2007, p. 542).

${ }_{40}$ Texto original en inglés: "The assessment of the environmental impacts of proposed projects has now become 'singularly important in both domestic and international environmental law'. Most States now require such assessments, and as do a growing number of international agreements, beginning (in embryonic form) with the General Convention Relating to the Development of Hydraulic Power Affecting More Than One State, art. 2. The most important such international agreement is the Espoo Convention prepared by the UN Economic Commission for Europe. The International Law Association recognized that the practice has crystallized into a rule of customary international law, at least insofar as transboundary effects are concerned [...]». 
día consideradas obligaciones del derecho internacional dentro de un Estado, así como en contextos transfronterizos. Sin la evaluación previa y permanente de los posibles impactos de los programas, proyectos y actividades, ningún Estado puede pretender cumplir con sus obligaciones de una buena gestión del medio ambiente. Esto es igualmente cierto para los proyectos sin impactos transfronterizos inmediatos como para los proyectos que puedan tener efectos transfronterizos inmediatos ${ }^{41} »$.

De otro lado, una evidencia adicional de las ONG en relación con las EA transfronterizas está relacionada con lo seńalado por Greenpeace en septiembre de 2014. Esta organización efectuó una denuncia ante la Secretaría del Convenio de Aarhus, la Comisión de Aplicación del Convenio de Espoo en la CEE y la Dirección General de Medio Ambiente de la Comisión Europea, debido a que Espańa y Nuclenos S. A. no efectuaron un EIA transfronterizo en el caso de la ampliación de la vida útil de la central nuclear de Santa María de Garoña en Burgos (Greenpeace España, 2014).

Como ha sido posible apreciar a lo largo de toda esta sección, se ha mostrado que existe una gran cantidad de evidencia tanto en relación con el elemento objetivo como con la opinio juris. En ese sentido, es posible afirmar que hoy en día nos encontramos frente a una obligación de llevar a cabo EA transfronterizas en los casos en los que las actividades pueden generar impactos que cumplen con las características señaladas en el capítulo 1.

\subsection{Contenido de la obligación de realizar EA transfronterizas}

Si bien ya se puede decir que existe una obligación consuetudinaria de realizar EA transfronterizas, aún no es del todo claro cuál es el procedimiento que se debe seguir y qué es exactamente lo que se debe evaluar a través de este proceso, es decir, cuál es el contenido de esta obligación. Al respecto, cuando hacemos referencia al procedimiento de la obligación, nos estamos refiriendo a los pasos que se deberían llevar a cabo para cumplir con esta: identificación de actividades por ser sometidas, proceso de evaluación, proceso de notificación, proceso de consulta y monitoreo posterior.

\footnotetext{
${ }^{41}$ Texto original en inglés: «The obligations to preserve and protect the integrity of ecosystems and to assure sustainable development are now general obligations of international law within a State as well as in transboundary contexts. Without prior and on-going assessment of the likely impacts of all programs, projects, and activities, no State can hope to fulfill its obligations of sound environmental management. This is equally true for projects without immediate transboundary impacts as for projects likely to cause immediate transboundary impacts».
} 
En relación con dichos pasos, aún no existe claridad sobre si todos estos deben formar parte del proceso de EA transfronteriza. Sin embargo, lo que sí es claro es que el proceso de EA no se limita únicamente al proceso de evaluación, como lo indicó el juez Weeramantry en una opinión separada de la sentencia Gabcikovo-Nagymaros: «la evaluación de impacto ambiental no solo implica realizar una evaluación antes del inicio de un proyecto [...] $\gg^{42}$.

De otro lado, cuando hacemos referencia al contenido, nos referimos a qué es lo que el proceso de EA transfronteriza debe evaluar. Si bien en el capítulo 1 ya hicimos un primer adelanto en relación con esto, en el presente capítulo profundizaremos más al respecto.

Habiendo señalado lo anterior, lo que haremos en esta sección será mostrar de qué manera los distintos instrumentos del hard law y soft law-principalmente el Convenio Espoo- han regulado tanto la cuestión procedimental como la cuestión de contenido de la obligación de llevar a cabo EA transfronterizas.

\subsection{1 ¿Cuándo se debe llevar a cabo el proceso?}

Uno de los primeros puntos en relación con las EA transfronterizas consiste en determinar en qué momento se deben realizar estas.

El Convenio Espoo, en el artículo 2, inciso 3, indica lo siguiente al respecto:

La Parte de origen velará por que, conforme a lo dispuesto en el presente Convenio, se realice una evaluación del impacto medioambiental antes de que se adopte una decisión con respecto a la autorización o la ejecución de una de las actividades propuestas susceptibles de causar un impacto transfronterizo de carácter perjudicial y magnitud apreciable que se menciona en el apéndice I.

El principio 1 de las Metas y Principios de la Evaluación e Impacto Ambiental del PNUMA señala:

Los Estados (incluidas sus autoridades competentes) no deberían emprender o autorizar actividades sin un análisis previo, en una etapa temprana, de los efectos ambientales de estas. Cuando el alcance, la naturaleza o ubicación de una actividad propuesta es tal que pueda afectar significativamente el medio

\footnotetext{
${ }^{42}$ Texto original en inglés: «environmental impact assessment means not merely an assessment prior to the commencement of the Project [...]” (C. I. J. Gabcikovo-Nagymaros Project. Separate Opinion, 1997, p. 111).
} 
ambiente, se debería llevar a cabo una evaluación de impacto ambiental exhaustiva $[\ldots]^{43}$.

De igual manera, la CIJ, en el caso de las Plantas de Celulosa, precisó lo siguiente:

La Corte también considera que un estudio de impacto ambiental debe ser llevado a cabo antes de la ejecución de un proyecto. Además, una vez que las operaciones han comenzado y, cuando sea necesario, a lo largo de la vida del proyecto, debe llevarse a cabo un monitoreo continuo de sus efectos sobre el medio ambiente ${ }^{44}$.

Con base en lo anterior, podemos interpretar que la EA transfronteriza se tiene que realizar antes de que se autorice un proyecto y como máximo antes de la puesta en funcionamiento del proyecto, pero no después de que este haya comenzado sus operaciones.

\subsubsection{La estructura procedimental y el contenido de las EA transfronterizas}

A continuación, lo que haremos será presentar una estructura procedimental general de la obligación de llevar a cabo EA transfronterizas, basándonos en los distintos instrumentos internacionales que regulan esta obligación, pero principalmente guiándonos de lo establecido por el Convenio Espoo. En ese sentido, la estructura está compuesta por los siguientes pasos:

\footnotetext{
${ }^{43}$ Texto original en inglés: «States (including their competent authorities) should not undertake or authorize activities without prior consideration, at an early stage, of their environmental effects. Where the extent, nature or location of a proposed activity is such that it is likely to significantly affect the environment, a comprehensive environmental impact assessment should be undertaken in accordance with the following principles».

${ }_{44}$ Texto original en inglés: "The Court also considers that an environmental impact assessment must be conducted prior to the implementation of a project. Moreover, once operations have started and, where necessary, throughout the life of the project, continuous monitoring of its effects on the environment shall be undertaken» (C. I. J. Pulp Mills, 2010, párr. 205).
} 
Figura 2.1 Flujograma del proceso bajo el Convenio Espoo

\section{Procedimiento}

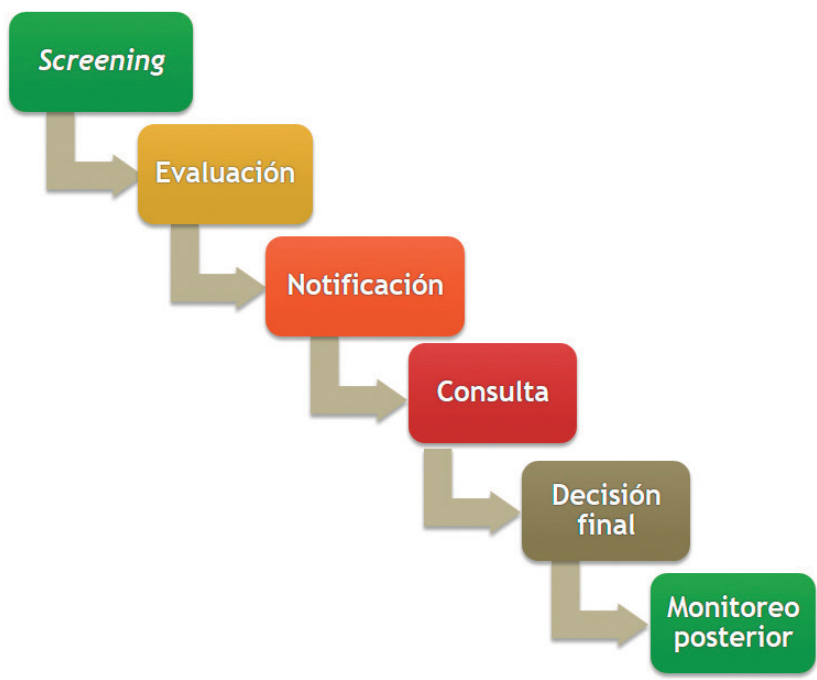

Elaboración propia.

El contenido de las EA transfronterizas lo analizaremos en el paso 2, denominado «Evaluación».

\subsubsection{Screening}

La primera consideración que se debe tomar en cuenta en cualquier sistema de EA es determinar qué actividades deberían ser sometidas al proceso de evaluación (Craik, 2010, p. 27). Al respecto, como señalamos en el primer capítulo, se debe tratar de actividades que: (i) generen impactos negativos; (ii) sean generadas por actividades humanas; (iii) en las que exista causalidad entre la actividad y los impactos; (iv) sean de carácter significativo; y (v) puedan generar consecuencias en un Estado transfronterizo.

En la presente sección nos centraremos en el requisito de "carácter significativo del impacto». El criterio que utilizan la mayoría de los instrumentos internacionales es que no solo se trate de una actividad que pueda causar un impacto negativo en el medio ambiente, sino que además este impacto sea significativo o considerable o sensible. Como se verá a continuación, el término utilizado varía dependiendo del instrumento. 
Para comenzar, el Convenio Espoo, en diversos artículos a lo largo del documento, indica lo siguiente en relación con los tipos de impacto: «impacto medioambiental transfronterizo de carácter perjudicial y magnitud apreciable» (artículos 2, 3, 5, 6).

Continuando, el principio 17 de la Declaración de Río establece:

Deberá emprenderse una evaluación del impacto ambiental, en calidad de instrumento nacional, respecto de cualquier actividad propuesta que probablemente haya de producir un impacto negativo considerable en el medio ambiente y que esté sujeta a la decisión de una autoridad nacional competente.

Por su parte, el proyecto de artículos sobre «Prevención del daño transfronterizo resultante de actividades peligrosas» elaborado por la CDI indica, en su artículo 1, que las EA se deberán realizar a las actividades no prohibidas por el derecho internacional que entrañen el riesgo de causar, por sus consecuencias físicas, un daño transfronterizo sensible.

En el caso de las Plantas de Celulosa, la CIJ hizo referencia a esto en diversas partes de la sentencia. En primer lugar, indicó lo siguiente:

La Corte nota que los estudios de impacto ambiental que son necesarios para tomar una decisión sobre cualquier plan que podría causar un daño significativo transfronterizo a otro Estado deberán ser notificados por la parte interesada a la otra parte $[\ldots]^{45}$.

Asimismo, más adelante en la sentencia la Corte señaló:

En ese sentido, la obligación de proteger y preservar [...] debe ser interpretada de acuerdo con la práctica, que en años recientes ha ganado mucha aceptación entre los Estados, que puede ser considerada un requisito bajo el derecho internacional general de emprender un estudio de impacto ambiental donde hay un riesgo de que la actividad industrial propuesta pueda tener un impacto ambiental significativo adverso en un contexto transfronterizo, en particular, en un recurso compartido ${ }^{46}$.

\footnotetext{
${ }^{45}$ Texto original en inglés: «The Court notes that the environmental impact assessments which are necessary to reach a decision on any plan that is liable to cause significant transboundary harm to another State must be notified by the party concerned to the other party [...]» (C. I. J. Pulp Mills, 2010, párr. 119).

${ }^{46}$ Texto original en inglés: «In this sense, the obligation to protect and preserve [...] has to be interpreted in accordance with a practice, which in recent years has gained so much acceptance among States that it may
} 
En consecuencia, de lo expuesto anteriormente se desprende que para llevar a cabo EA transfronterizas es necesario que exista una posible «afectación negativa significativa» en el medio ambiente, no solo del Estado de origen, sino también de sus Estados fronterizos (Craik, 2010, p. 133). Ahora, la siguiente cuestión por resolver es determinar qué se entiende por «afectación significativa».

$\mathrm{Al}$ respecto, existen pocos intentos que han buscado definir su significado en abstracto. Los «Principios sobre la conservación y la utilización armoniosa de los recursos naturales compartidos por dos o más Estados», desarrollados por el PNUMA, son uno de los pocos instrumentos que se han atrevido a darle una definición al señalar que se trata de "cualquier efecto apreciable sobre un recurso natural compartido excluyendo los efectos mínimos» ${ }^{47}$.

Sin perjuicio de esto último, la tendencia en los distintos instrumentos internacionales - y en la mayoría de las legislaciones nacionales sobre EA- no ha sido definir dicho concepto, sino más bien hacer una lista de las posibles actividades que puedan tener un impacto significativo. Ejemplo de esto último es el Convenio Espoo, que en su apéndice 1 establece una lista de las actividades que necesariamente deben ser sometidas a una EA transfronteriza.

Si bien el Convenio Espoo simplifica este primer paso para los países que lo han ratificado, es válido efectuar la pregunta sobre qué sucedería con aquellos países como el Perú, que se encuentran en obligación de llevar a cabo estas evaluaciones pero no poseen lineamientos claros que seguir.

Ante la ausencia de un instrumento internacional que regule las actividades que deberían ser sometidas a una EA transfronteriza, lo que al Estado de origen le correspondería aplicar sería el principio de no discriminación, es decir, no discriminar entre los posibles impactos nacionales o impactos transfronterizos que un proyecto podría tener, para proceder a realizar una EA (Craik, 2010, p. 133). En otras palabras, se debería recurrir a la legislación nacional para comprender qué entiende el país de origen por «impacto significativo» y para esos mismos proyectos -cuando estos tengan el riesgo de causar impactos transfronterizos- llevar a cabo las EA transfronterizas. Al respecto, como señala Neil Craik, «adoptar los mismos criterios que se utilizan para la aplicación de los EIA a un nivel nacional facilita la implementación de las obligaciones

now be considered a requirement under general international law to undertake an environmental impact assessment where there is a risk that the proposed industrial activity may have a significant adverse impact in a transboundary context, in particular, on a shared resource» (C. I. J. Pulp Mills, 2010, párr. 204).

${ }^{47}$ Texto original en inglés: "any appreciable effects on a shared natural resource and excludes "de minimis" effects» (PNUMA, 1978). 
internacionales de llevar a cabo los EIA, ya que no requerirá considerar un estándar internacional separado para la activación del EIA ${ }^{48}$.

\subsubsection{Alcance y contenido de las EA transfronterizas}

Una vez que se ha determinado qué actividades deben ser sometidas al proceso, el siguiente paso consiste en establecer qué debería evaluar toda EA transfronteriza o en todo caso cuál debería ser el contenido mínimo que toda EA transfronteriza debería analizar. En el caso de las Plantas de Celulosa, la CIJ estableció que no se había determinado un contenido mínimo a nivel internacional, sino que este estaba relegado a la legislación nacional de los Estados:

[...] es la visión de la Corte que corresponde a cada Estado determinar en su legislación nacional o en el proceso de autorización para el proyecto, el contenido específico del estudio de impacto ambiental requerido en cada caso, teniendo en cuenta la naturaleza y la magnitud del desarrollo propuesto y su posible impacto adverso sobre el medio ambiente, así como la necesidad de ejercer la debida diligencia en la realización de tal evaluación ${ }^{49}$.

Si bien autores como Sands et al. señalan, en relación con este fallo, que «sin duda ha perdido una oportunidad para aclarar también cuáles son los requisitos mínimos que una evaluación de ese tipo debería considerar»(2012), otros, como Boyle, tienen una postura mucho más positiva al respecto.

Según Boyle, a partir de dicho párrafo se desprenden dos ideas importantes. La primera está referida a que para la CIJ la obligación de llevar a cabo una EA transfronteriza no solo se origina en una norma, sino que también puede originarse al ser solicitada como un requisito de un proceso para autorizar un proyecto (Boyle, s. f., pp. 4-5). La segunda idea está referida al contenido específico de las EA. De acuerdo con Boyle (pp. 4-5), en esta sentencia, la Corte no está diciendo que todo el contenido de las EA debe ser dejado a la sola discreción de los Estados, sino que, más bien, se está haciendo alusión

\footnotetext{
${ }^{48}$ Texto original en inglés: "[a]dopting the same threshold as domestic EIA requirements facilitates the implementation of international EIA obligations as it will not require the consideration of a separate, international standard for triggering EIA» (Craik, 2010, p. 133).

${ }^{49}$ Texto original en inglés: " [...] it is the view of the Court that it is for each State to determine in its domestic legislation or in the authorization process for the project, the specific content of the environmental impact assessment required in each case, having regard to the nature and magnitude of the proposed development and its likely adverse impact on the environment as well as to the need to exercise due diligence in conducting such an assessment» (C. I. J. Pulp Mills, 2010, párr. 205).
} 
a los comentarios oficiales del artículo 7 de los artículos sobre prevención de daños transfronterizos elaborados por la CDI en el año 2001:

7) La determinación detallada del contenido de la evaluación se deja al derecho interno del Estado que la efectúe. A los fines del artículo 7, sin embargo, esa evaluación debería contener por lo menos una estimación de las posibles consecuencias transfronterizas perjudiciales de la actividad. Para que los Estados que puedan resultar afectados estén en condiciones de evaluar el riesgo a que están expuestos tienen que saber qué efectos perjudiciales puede tener la actividad para ello.

8) La evaluación incluirá los efectos de la actividad, no solo sobre las personas y los bienes, sino también sobre el medio ambiente de otros Estados. Se reconoce claramente la necesidad y la importancia de la protección del medio ambiente, independientemente de cualquier daño que puedan sufrir los seres humanos o los bienes.

En ese sentido, según Boyle (s. f., pp. 4-5), lo que la CIJ ha pretendido establecer con su sentencia es que más allá de los requisitos que establezcan los Estados en su legislación nacional sobre el contenido de las EA, el DIP requiere que las EA evalúen, al menos, los posibles impactos que se puedan generar sobre los seres humanos, bienes y el medio ambiente de otros Estados ${ }^{50}$.

Sin perjuicio de esta interpretación realizada por Boyle, es importante destacar que hubiese sido positivo para países que no están adheridos a ningún tratado sobre la materia, que la CIJ, en el caso de las Plantas de Celulosa, establezca algunos lineamientos claros sobre el contenido mínimo que las EA deberían tener.

De otro lado, cabe precisar que el Convenio Espoo sí ha establecido ciertos requisitos mínimos que todo proceso de EA transfronteriza debería observar -los cuales de acuerdo a la CIJ aún no tienen carácter consuetudinario-. Dicho Convenio ha buscado proveer una serie de requisitos mínimos a sus Estados miembros, a fin de asegurar la reciprocidad entre ellos (Craik, 2010,

\footnotetext{
${ }^{50}$ Cabe resaltar que Uruguay ante la CIJ por el caso de las Plantas de Celulosa precisó lo siguiente: «De acuerdo con Uruguay, los únicos requisitos que impone el derecho internacional son que debe haber estudios de los potenciales efectos significativos transfronterizos del proyecto sobre la población, la propiedad y el medio ambiente de otros Estados, como requieren la práctica estatal y el borrador de la Comisión de Derecho Internacional sobre Prevención de Daños Transfronterizos del año 2001, sin que haya necesidad de evaluar los riesgos remotos o puramente especulativos» (C. I. J. Pulp Mills, 2010, párr. 152).
} 
p. 104). El apéndice II del Convenio Espoo reúne los requisitos mínimos solicitados por este:

\section{Contenido de la documentación para la evaluación del im- pacto medioambiental}

De conformidad con el artículo 4, la documentación para la evaluación del impacto medioambiental incluirá al menos lo siguiente:

a) La descripción de la actividad propuesta y su finalidad;

b) La descripción, si procede, de las alternativas razonables de la actividad propuesta (en cuanto al emplazamiento o la tecnología, por ejemplo), incluida la alternativa de no realizar la actividad;

c) La descripción del medio ambiente al que la actividad propuesta y sus alternativas pueden afectar de manera apreciable;

d) La descripción del posible impacto medioambiental de la actividad propuesta y sus alternativas y la evaluación de su magnitud;

e) La descripción de las medidas paliativas para reducir al mínimo el impacto medioambiental de carácter perjudicial;

f) La indicación expresa de los métodos de predicción, las hipótesis fundamentales y los datos ambientales pertinentes utilizados;

g) La relación de las lagunas de conocimiento y dudas surgidas al recopilar la información necesaria;

h) Si procede, el esbozo de los programas de supervisión y gestión y de todo plan de análisis de proyectos a posteriori; e

i) Un resumen de carácter no técnico que incluya una presentación visual apropiada (mapas, gráficos, etc.).

En relación con el contenido esbozado por el Convenio Espoo, es importante detenerse en el punto (b) sobre "[L]a descripción, si procede, de las alternativas razonables de la actividad propuesta». De acuerdo con el análisis realizado por Neil Craik sobre el Convenio Espoo, se entiende que este Convenio ha relegado en los Estados de origen la facultad de establecer cuándo debe llevarse a cabo un análisis de las alternativas de la actividad propuesta (Craik, 2010, pp. 139-140). En otras palabras, según el Convenio Espoo, «el análisis de las alternativas razonables de la actividad propuesta» debe realizarse 
«si procede», y es facultad de los Estados de origen, de acuerdo a su legislación nacional, determinar cuándo procede realizar este análisis.

En el contexto internacional es muy importante el análisis de las alternativas del proyecto, pues al no existir estándares mínimos generales sobre el contenido de una EA transfronteriza ni existir para el Estado afectado un poder de veto, el análisis de las alternativas de un proyecto representa para los Estados afectados una de las mejores formas de expresión sobre la evaluación de los potenciales impactos sobre su territorio (Craik, 2010, p. 140).

Adicionalmente a los lineamientos mínimos sobre el contenido de una EA transfronteriza establecidos por el Convenio Espoo, sería importante, según Neil Craik, que las EA evalúen los impactos acumulativos de las actividades propuestas. Esta evaluación implicaría que el proponente de un proyecto considere no solo los impactos de su proyecto, sino también cómo los impactos de su proyecto, combinados con los impactos de otros proyectos, podrían afectar el medio ambiente.

\subsubsection{Notificación}

Un siguiente aspecto por tomar en cuenta dentro de esta estructura procedimental es el referido al deber de notificar. Y este, junto al deber de consultar, resulta ser uno de los más complicados de poner en práctica debido a las distintas interrogantes que surgen al respecto: ¿cuál es el momento preciso en que la obligación de notificar surge?, ¿qué Estados deben ser notificados?, ¿qué información debe ser notificada? (Hanqin, 2003, pp. 170-172).

En relación con el deber de notificar, el Convenio Espoo, en su artículo 3 , señala que el Estado de origen se encuentra en la obligación de notificar «[s]iempre que exista la probabilidad de que una actividad propuesta de las que se enumeran en el apéndice I cause un impacto transfronterizo de carácter perjudicial y de magnitud apreciable [...]».

Una vez que nace la obligación de notificar, el mismo instrumento, en el mismo artículo, precisa: «la Parte de origen, a fin de que se celebren consultas apropiadas y efectivas [...], cursará una notificación a toda Parte que considere pueda ser Parte afectada lo antes posible y a más tardar cuando haya informado a su propio público acerca de dicha actividad propuesta».

A fin de sobrellevar cualquier dificultad que un Estado de origen pueda enfrentar al tratar de identificar la autoridad pública apropiada a la cual notificar, la Decisión 1/3 de la reunión de las Partes del Convenio Espoo estableció que cada parte designe puntos de contacto (Unece, 1998). De igual manera, en la Decisión 1/4 de este Convenio se adoptó un formato estándar para transmitir las notificaciones. 
Asimismo, de acuerdo con el Convenio Espoo, la notificación, entre otros aspectos, debe contener información relacionada con la actividad propuesta y sus potenciales impactos transfronterizos, la naturaleza de la posible decisión y el plazo de respuesta razonable (Unece, 1991, artículo 3, inciso 2). Respecto a esto último, el Estado afectado deberá responder, dentro del plazo establecido en la notificación, la indicación de haberla recibido y si tiene la intención de participar o no en el procedimiento de evaluación ambiental (Unece, 1991, artículo 3, inciso 3). Bajo el Convenio Espoo, se da la facultad a la parte afectada de decidir si involucrarse en el proceso o no, y si decide no involucrarse, el Estado de origen no tiene que realizar ninguna actividad adicional con el posible Estado afectado.

Por el contrario, en caso de darse una respuesta afirmativa por parte del Estado afectado, el Estado de origen le proporcionará -en caso no lo haya hecho antes- la siguiente información: (i) información relevante sobre cómo es el procedimiento de EA dentro de su jurisdicción y (ii) información pertinente sobre la actividad propuesta y sus posibles impactos transfronterizos (Unece, 1991, artículo 3, inciso 5).

Adicionalmente, el Estado afectado tiene el deber -en caso el Estado de origen se lo solicite- de transmitirle la información que razonablemente se pueda obtener sobre el medio ambiente de su jurisdicción que potencialmente se pueda ver afectado. El Estado de origen normalmente pedirá esta información cuando esta sea necesaria para preparar la documentación con destino a la EA (Unece, 1991, artículo 3, inciso 6).

Finalmente, cabe destacar que el proceso de notificación, al operar principalmente en un nivel de Estado a Estado (Craik, 2010, p. 142), también requiere que el público del Estado afectado, que se pueda ver afectado, sea informado sobre la actividad propuesta y tenga la oportunidad de formular observaciones y/o plantear objeciones con respecto a la actividad propuesta. Este derecho incluye el hecho de que sus comentarios y objeciones puedan ser transmitidos, directa o indirectamente, a la autoridad competente del Estado de origen (Unece, 1991, artículo 3, inciso 8).

Como se puede apreciar, el deber de notificar involucra una gran cantidad de interacción entre el Estado de origen y el Estado afectado, por lo que la regulación de este aspecto no puede ser relegada únicamente al Estado de origen -como sí puede suceder con la fase de screening y de contenido de la obligación-. El proceso de notificación -y, como se verá más adelante, el de consulta- requiere necesariamente de normas internacionales que establezcan una guía clara sobre cómo llevar a cabo estas obligaciones (Craik, 2010, p. 141). 
En ese sentido, para los países que no están adheridos a ningún instrumento internacional sobre la materia, sería necesario que: (i) se adhieran a un tratado como el de Espoo que permite ser ratificado por cualquier país o (ii) negocien tratados bilaterales o multirregionales.

Finalmente, en relación con lo anteriormente expuesto, es importante hacer referencia a lo señalado por Xue Hanqin: «si bien la obligación de notificar está ganando aceptación por parte de los Estados, la naturaleza y el alcance de esta obligación tienen que ser todavía definidos de manera más concreta y precisa en disposiciones de tratados adicionales $»^{51}$.

\subsubsection{Consulta ${ }^{52}$}

Aparte del deber de notificar al Estado afectado, el Estado de origen tiene la obligación de consultarle sobre el proyecto planificado (Hanqin, 2003, p. 173). La importancia de este proceso es que puede ayudar a identificar una apropiada gama de alternativas de proyectos y de fuentes adicionales de información ambiental (Craik, 2010, p. 143). Sin embargo, al igual que para la fase de notificación, existen serios problemas prácticos sobre el momento y la manera en que esta obligación se debería llevar a cabo (Craik, 2010, p. 31).

Haciendo nuevamente referencia al Convenio Espoo, en este el deber de consultar surge después de enviar toda la documentación necesaria a los posibles Estados afectados y, además, luego de que esta haya sido distribuida a las autoridades competentes y al público en general.

Una vez que la información ha sido remitida, el Estado de origen debe celebrar, sin excesiva demora, consultas con el Estado afectado, respecto, entre otras cosas, del posible impacto transfronterizo de la actividad propuesta, las posibles alternativas a la actividad propuesta, las posibles medidas para reducir o suprimir dicho impacto, las posibles medidas para vigilar los efectos de las medidas adoptadas y, en general, cualquier asunto que tenga que ver con la actividad propuesta (Unece, 1991, artículo 5).

Como se puede apreciar, de acuerdo al Convenio Espoo, la obligación de consultar con los Estados afectados se da en el momento de haber completado todo el contenido necesario de la $\mathrm{EA}$. Al respecto, no existe una obligación para el Estado de origen de consultar con los Estados afectados durante la etapa de

\footnotetext{
51 Texto original en inglés: «[w]hile the obligation to notify is gaining acceptance by States, the nature and scope of the duty needs to be more concretely and precisely defined in further treaty provisions» (Hanqin, 2003, p. 173).

${ }^{52}$ En este contexto, la consulta no está referida al derecho de consulta previa recogido por el Convenio 169, sino al proceso de participación ciudadana.
} 
la determinación del alcance de la obligación ni la etapa de elaboración del reporte (Craik, 2010, pp. 142-143).

A diferencia de lo establecido por el Convenio Espoo, el proyecto de artículos sobre «Prevención del daño transfronterizo resultante de actividades peligrosas» de la CDI tiene una visión más amplia del derecho de consulta. De acuerdo a estos artículos, el proceso de consulta puede darse incluso para consultar las actividades que deberían incluirse como posibles causantes de impactos transfronterizos, es decir, la consulta se podría dar incluso antes del momento de remitir toda la documentación al Estado afectado.

Por otro lado, un punto importante por tener en cuenta, y sobre el cual el Convenio de Espoo no hace referencia, es el relacionado con la existencia de un derecho de veto o no por parte del Estado afectado sobre el proyecto. $\mathrm{Al}$ respecto, es importante dejar en claro que no existe un derecho de veto. Si las partes en un proceso de consulta, llevado de buena fe, no pueden llegar a un acuerdo satisfactorio, el Estado de origen puede igual proceder con el proyecto (Craik, 2010, p. 72). El principio de cooperación, del cual se deriva la obligación procedimental de realizar consultas, no necesariamente brinda al Estado afectado el derecho de vetar proyectos con impactos transfronterizos significativos (Craik, 2010, p. 73).

Sin embargo, es importante destacar que el Estado de origen no puede obviar los puntos de vista de los otros Estados. Un Estado que ignora o no da suficiente peso a las consideraciones dadas por el Estado afectado, no se puede decir que ha actuado de buena fe (Craik, 2010, p. 74) y, por ende, no se podría afirmar que ha cumplido con su obligación de realizar el proceso de consulta.

Finalmente, cabe precisar que al igual que en el caso del deber de notificar, el proceso de consulta requiere de un acuerdo internacional que establezca una guía clara sobre cómo darle cumplimiento.

\subsubsection{Decisión final}

La decisión final en el ámbito internacional no está referida al acto de la administración que aprueba o desaprueba el EIA -como sucede en el caso peruano con la emisión de la certificación ambiental-, sino que está referida a la aprobación o no de ejecución de un proyecto. Esta decisión la debe tomar el Estado de origen, y si bien los distintos sistemas nacionales también varían en relación con este asunto, un aspecto consistente en la mayoría de las legislaciones es que no se puede tomar una decisión final en relación con un proyecto hasta que el proceso de EA haya culminado (Craik, 2010, p. 32). 
Ahora bien, como señala Neil Craik, "no hay ninguna obligación para los Estados de seguir las recomendaciones contenidas en el EIA finalizado ${ }^{53}$ ". «El proceso de EIA es autorregulado en cuanto que la autoridad responsable conserva la facultad discrecional de proceder con los proyectos a pesar de los resultados del EIA y los resultados de la participación pública» ${ }^{54}$.

En esta misma línea, Boyle destaca que la decisión sobre si un proyecto debe proceder o no corresponde a los funcionarios públicos, quienes tienen que ponderar la información brindada por las EA contra otros intereses, como, por ejemplo, el crecimiento económico.

En esta misma línea se encuentra enfocado el Convenio Espoo. El artículo 6 , inciso 1 , de este establece que, si bien se trata de una decisión que debe tomar el Estado de origen, ambas partes deben velar para que se tengan en cuenta los resultados de la EA, la documentación remitida, las observaciones recibidas y los resultados de las consultas realizadas. Como se aprecia, el Convenio Espoo no obliga al Estado de origen a seguir las recomendaciones contenidas en la EA, solo insta a las partes a que tengan en cuenta las recomendaciones.

De otro lado, lo que sí constituye una obligación bajo el Convenio Espoo es comunicar al Estado afectado la decisión final en relación con un proyecto, precisando las razones y consideraciones sobre las cuales la decisión final se basó (Unece, 1991, artículo 6, inciso 2).

\subsubsection{Monitoreo posterior}

Un elemento que últimamente está teniendo gran importancia en los sistemas nacionales e internacionales es el relacionado con el monitoreo de los impactos ambientales posconstrucción. El juez Weeramantry, en una opinión separada de la sentencia Gabcikovo-Nagymaros, al respecto precisó: «la evaluación de impacto ambiental significa no solo una evaluación antes del inicio de un proyecto, sino que también implica una evaluación continua del proyecto mientras este esté en operación $»^{55}$.

Si bien la inclusión del monitoreo es de cierta manera contraria al objetivo de la EA -ser una herramienta de planificación ex ante-, esta ha sido necesaria debido a las críticas existentes de que los procesos de EA ingenuamente se

\footnotetext{
${ }^{53}$ Texto original en inglés: «there is no obligation on states to follow the recommendations contained within a completed EIA report» (Craik, 2010, p. 150).

${ }^{54}$ Texto original en inglés: "The EIA process is self-regulatory in that the responsible authority retains the discretion to move ahead with projects notwithstanding the results of the EIA and the results of the public participation» (Craik, 2010, p. 32).

55 Texto original en inglés: «environmental impact assessment means not merely an assessment prior to the commencement of the Project, but a continuing assessment and evaluation as long as the Project is in operation» (C. I. J. Gabcikovo-Nagymaros Project. Separate Opinion, 1997, p. 111).
} 
basan en la idea de que los impactos pueden ser predeterminados con exactitud (Craik, 2010, p. 33).

El monitoreo posterior brinda varios beneficios al proceso de EA. En primer lugar, permite comparar los impactos ambientales reales con los impactos ambientales previstos antes del inicio del proyecto, permitiendo a la administración conocer los puntos débiles de los estudios. En segundo lugar, en los casos en que la aprobación de un determinado proyecto se encuentra sujeta a ciertos términos y condiciones, el monitoreo posterior permite solicitar a los proponentes de los proyectos, ajustes en los mismos, a fin de minimizar los impactos ambientales no previstos. Finalmente, los programas de monitoreo posterior pueden ser utilizados para identificar áreas donde faltan capacidades de predicción y pueden servir para sugerir formas de mejora en la metodología utilizada en los procesos (Craik, 2010, pp. 33-34).

En el Convenio Espoo, el análisis posterior al proyecto es un proceso optativo que solo se lleva a cabo si las partes interesadas determinan que es necesario que se realice. Si las partes determinan que ello es necesario, ambas establecen en qué medida este debe implementarse. El análisis posterior al proyecto comprende la supervisión de la actividad y la determinación de cualquier impacto transfronterizo perjudicial con miras a lograr los siguientes objetivos:

\section{APÉNDICE V}

\section{Análisis de proyectos a posteriori}

a) Supervisar el cumplimiento de las condiciones establecidas en la autorización o aprobación de la actividad, así como la eficacia de las medidas paliativas;

b) Examinar los efectos del proyecto para conseguir una gestión adecuada y resolver dudas;

c) Comprobar las predicciones anteriores para trasladar la experiencia a futuras actividades del mismo tipo.

Bajo el Convenio Espoo, uno de los beneficios más importantes del análisis posterior al proyecto es que si como resultado de este:

[...] la Parte de origen o la Parte afectada tenga motivos razonables para llegar a la conclusión de que existe un impacto transfronterizo de carácter perjudicial y magnitud apreciable o que se han descubierto factores que pudieran causar ese impacto, informará inmediatamente de ello a la otra Parte. Las Partes interesadas celebrarán entonces consultas sobre las me- 
didas necesarias para reducir o suprimir el impacto. (Unece, 1991, artículo 7, inciso 2)

Esto último impone una obligación en los Estados que aceptan llevar a cabo un análisis posterior de notificarse y consultarse en relación con los posibles impactos reales derivados de los proyectos aprobados (Craik, 2010, p. 154).

\subsubsection{Obligación de medios}

Habiendo establecido cómo se regula el procedimiento y el contenido de la obligación de realizar EA transfronterizas en los distintos instrumentos internacionales, cabe destacar que un punto de singular relevancia en torno a la obligación de realizar EA transfronterizas es analizar si se trata de una obligación de medios o una obligación de resultados. Esta distinción es de suma relevancia pues permite identificar cuándo se ha incumplido la obligación, ergo permite determinar cuándo se incurre en responsabilidad internacional (Plakokefalos, 2013, p. 36).

$\mathrm{Al}$ respecto, es importante recordar que las obligaciones de medios son aquellas que imponen a los Estados la obligación de hacer su mayor esfuerzo para cumplir una meta específica, pero sin requerirles que deban alcanzar dicha meta necesariamente; mientras que, de otro lado, las obligaciones de resultados son aquellas que necesariamente requieren que los Estados lleguen a un resultado determinado (Economides, 2010, p. 372) ${ }^{56}$.

Como se señaló en el capítulo 1, la obligación de realizar EA transfronterizas es una obligación que deriva de la obligación de prevención, y las obligaciones de prevención en el ámbito del DAI son catalogadas como obligaciones de medios. Hafner y Buffard, al respecto, destacan: «las obligaciones de tomar medidas de prevención en el ámbito de las actividades no prohibidas por el derecho internacional son sin duda normas principales del derecho internacional que imponen una obligación de conducta» ${ }^{57}$.

Al tratarse de una obligación de medios, los Estados pueden dar cumplimiento a su obligación simplemente implementando un sistema de EA transfronterizas. Sin embargo, siguiendo nuevamente a Hafner y Buffard y, justamente por tratarse de obligaciones de medios, «el incumplimiento de las obligaciones de tomar medidas de prevención para la protección del medio

\footnotetext{
${ }^{56}$ Para un análisis más detallado de las diferencias entre las obligaciones de medios y las obligaciones de resultados, revise Economides (2010).

${ }^{57}$ Texto original en inglés: «the obligations to take measures of prevention in the field of activities not prohibited by international law are without doubt primary rules of international law, imposing an obligation of conduct» (Hafner \& Buffard, 2010, pp. 523-524).
} 
ambiente también puede darse a pesar de que no se haya producido un daño al medio ambiente» ${ }^{58}$.

\subsection{Conclusión}

El presente capítulo tenía como primer objetivo demostrar la existencia de una obligación consuetudinaria internacional de llevar a cabo EA transfronterizas. $\mathrm{Y}$, en segundo lugar, buscaba presentar la estructura procedimental y el contenido de esta.

Con respecto al primer objetivo, para comprobar la existencia de tal obligación, se demostró tanto la existencia del elemento objetivo, como la existencia del elemento subjetivo -opinio juris-. Como se señaló en la primera parte del capítulo, es necesario que estos elementos coexistan para que una obligación consuetudinaria pueda surgir.

En relación con el elemento material, se demostró que las referencias a la realización de EA transfronterizas datan del ańo 1971 -con el Acta de Santiago sobre Cuencas Hidrológicas-. Desde esa fecha, se han aprobado una serie de tratados sobre el tema, de los que el más relevante es el Convenio Espoo de 1991, así como una serie de instrumentos del soft law, entre los que resalta el proyecto de artículos sobre «Prevención del daño transfronterizo resultante de actividades peligrosas» del año 2001. De otro lado, países como Colombia, Bolivia, Guatemala, Costa Rica, Paraguay y Brasil han adoptado en sus legislaciones internas la obligatoriedad de llevar a cabo EA transfronterizas, en los casos en los que sea posible la generación de estos impactos.

De igual manera, se resaltó que el desarrollo de las EA transfronterizas no solo se ha dado en el ámbito normativo, sino también en el plano de los hechos. A la fecha, en Europa, en el marco del Convenio Espoo, se han realizado más de 200 EA transfronterizas. De igual manera, en el año 2006, Uruguay realizó una EA transfronteriza para los dos proyectos de papeleras que se iban a llevar a cabo sobre el río Uruguay.

De otro lado, para demostrar la existencia de la opinio juris, adicionalmente a los tratados e instrumentos de soft law, se mostró que tanto la CIJ como distintas ONG y expertos en la materia han emitido pronunciamientos sobre el hecho de que realizar EA transfronterizas constituye, actualmente, una obligación consuetudinaria del derecho internacional. La sentencia de la CIJ más relevante sobre el tema, en la cual señala explícitamente que realizar EA

\footnotetext{
${ }^{58}$ Texto original en inglés: «the breach of obligations to take measures of prevention for the protection of the environment may also occur in the absence of any damage to the environment» (Hafner \& Buffard, 2010, p. 524).
} 
transfronterizas es una costumbre del derecho internacional, es la sentencia sobre las Plantas de Celulosa sobre el río Uruguay del año 2010.

El primer objetivo del capítulo demostró que el desarrollo de esta práctica no es reciente, ni tampoco se trata de una práctica regional o local. Realizar EA transfronterizas es una práctica que ya se ha llevado a cabo por un período de tiempo, de manera uniforme y generalizada. Esto, junto al hecho de que los Estados en más de una ocasión han mostrado encontrarse frente a una obligación internacional, y el reciente pronunciamiento de la CIJ en el caso de las Plantas de Celulosa, confirman que este proceso es ya una costumbre del derecho internacional.

De otra parte, en relación con el segundo objetivo del capítulo, se demostró que: (i) aún no existe claridad sobre cuál debería ser la estructura procedimental del proceso, y (ii) tampoco existe claridad sobre qué deberían evaluar las EA. Es decir, se demostró que si bien existe una obligación consuetudinaria de realizar EA transfronterizas, aún no se puede afirmar que existe una norma consuetudinaria que regule los diferentes aspectos procedimentales y el contenido de la obligación. Sin embargo, lo que sí se precisó es que la EA transfronteriza se tiene que realizar antes de que se tome una decisión en relación con la viabilidad de un proyecto.

Adicionalmente y sin perjuicio de lo anterior, en el presente capítulo se presentó una estructura general del proceso y se aseveró que la obligación de realizar EA transfronterizas no está limitada únicamente a la evaluación de los impactos, sino que también incluye otros aspectos, como el deber de notificar, de llevar a cabo procesos de consulta y de realizar seguimientos posteriores.

Finalmente, en cuanto al contenido de la obligación, se señaló que la CIJ, en el caso de las Plantas de Celulosa, determinó que el contenido de la obligación debe ser relegado al derecho interno de los Estados. Es decir, cuando no exista un tratado de por medio, cada Estado debe precisar, a través de su legislación, qué es lo que se debe evaluar en los procedimientos de EA. 


\section{El contexto nacional sobre la regulación de las EA y los impactos transfronterizos}

Habiendo precisado que existe una obligación internacional de realizar EA transfronterizas, el presente capítulo busca analizar si el Perú está cumpliendo esta obligación o no. En ese sentido, en primer lugar, se analizará si esta norma se encuentra incorporada en el sistema jurídico peruano; y, en segundo lugar, se estudiará si esta se encuentra implementada tanto a nivel legislativo como a nivel administrativo.

\subsection{La incorporación e implementación del derecho consuetudinario en el sistema jurídico peruano}

\subsubsection{La incorporación}

Entendemos por incorporación la manera en que la norma internacional ingresa a los ordenamientos de los Estados (Salmón, 2003, p. 151) y se vuelve vinculante para sus respectivos funcionarios públicos, personas naturales y personas jurídicas. Como veremos a continuación, la manera en que la norma internacional se incorpora al ordenamiento jurídico interno es un aspecto sometido a la soberanía de los Estados. Para determinar cómo ingresarán dichas normas a sus respectivos ordenamientos, los Estados se basan en la teoría dualista o monista.

En simple, la teoría dualista - propugnada por Triepel, Anzilotti, Duguit y Krabbe- plantea que el derecho internacional y el derecho interno son órdenes diversos, separados e independientes. Esto debido a que, en primer lugar, el derecho internacional y el derecho interno de los Estados tienen distintas 
fuentes (Pastor, 2010, p. 168); y, en segundo lugar, debido a que ambos derechos regulan relaciones diversas: el primero regula relaciones básicamente entre Estados y el segundo entre individuos o entre el Estado y sus súbditos (p. 168). En consecuencia, «la conclusión primordial que de estas premisas obtiene el dualismo es que las normas internacionales son irrelevantes en los ordenamientos internos, necesitando para su aplicación en ellos de un acto especial de recepción» (p. 168).

Por el contrario, la concepción monista -propugnada principalmente por Kelsen- sostiene que el derecho internacional y el derecho interno no están «separados» sino que forman un solo sistema jurídico (Mariño, 2005, p. 585). De ahí que «la norma internacional no necesitaría de ninguna especie de acto de recepción para ser aplicada en los ordenamientos internos y prevalecería sobre éstos en caso de conflicto» (Pastor, 2010, p. 169).

Dicho lo anterior, es importante destacar que el Derecho Internacional Positivo no ha tomado partido por alguna de las dos teorías, sino que esta ha sido una cuestión relegada al derecho interno de los Estados (Pastor, 2010, p. 169). Los Estados, con base en sus distintos compromisos históricos, políticos y constitucionales, han adoptado, en sus constituciones, distintas variaciones de estas teorías (Damrosch, 2009, p. 653).

No obstante, en la mayoría de los Estados latinoamericanos se ha evidenciado una preferencia por la doctrina monista, tanto en relación con las normas internacionales que derivan de tratados, como de las reglas del derecho internacional consuetudinario (Jiménez, 1986, p. 26). En relación con la incorporación del derecho consuetudinario en los derechos internos, Cassese ha indicado:

Todos los sistemas nacionales adoptan la misma modalidad básica de implementación: la incorporación automática. Las constituciones nacionales o estatutos o las decisiones judiciales de la mayoría de los Estados, estipulan que las normas de derecho internacional consuetudinario, se vuelven vinculantes ipso facto para los sistemas jurídicos nacionales, por el mero hecho de su evolución en la comunidad internacional. Tan pronto comienzan a existir en el derecho internacional, las normas consuetudinarias se vuelven vinculantes para los sistemas nacionales. Estas normas, además, tienen el mismo contenido a nivel nacional que a nivel internacional ${ }^{1}$.

\footnotetext{
${ }^{1}$ Texto original en inglés: «All national systems adopt the same basic modality of implementation: auto-
} 
En esta misma línea, Salmón establece:

Como se sabe, la costumbre internacional, de manera general, se aplica de forma inmediata en los ordenamientos estatales, lo que significa que no requiere de ningún acto de incorporación por parte de estos. Por lo que, desde el momento mismo de formación de la norma consuetudinaria, esta sería plenamente aplicable en el ordenamiento jurídico peruano sujetándose únicamente a los cauces de creación de la costumbre internacional, es decir, a la confluencia de los dos elementos constitutivos de la misma: la práctica material de los Estados y la opinio iuris que la acompaña. (Salmón, 2002, pp. 59-81)

La explicación de por qué la concepción monista es la adecuada para incorporar la costumbre la explica Cassese de la siguiente manera:

La explicación de la elección de este sistema de implementación es evidente: es el único sistema que se puede acomodar a las normas que surgen de manera gradual en la comunidad internacional y cuyos contenidos no pueden ser definidos de manera inmediata. Si para que una norma consuetudinaria internacional se aplique a los funcionarios e individuos de un Estado, se necesitara previamente la promulgación de una ley que exponga el contenido de esta obligación, el congreso tendría un rol bastante complejo, pues tendría que analizar si se ha constituido una norma consuetudinaria y determinar el contenido de esta. En consecuencia, dadas las características de las normas consuetudinarias, es mucho más conveniente y práctico dejar que los jueces y/u otros funcionarios establezcan si una norma consuetudinaria es vinculante y en qué medida esta lo es dentro del sistema jurídico del Estado².

\footnotetext{
matic standing incorporation. National constitutions or statutes or judicial decisions of most States stipulate that customary international rules become domestically binding ipso facto, that is, by the mere fact of their evolving in the international community. As soon as they come into being in the world community international customary rules become binding within national legal systems; in addition, they have, at the national level, the same content as that of the corresponding international rules» (Cassese, 2005, p. 224). ${ }^{2}$ Texto original en inglés: «The reason for the choice of this implementation system is self-evident: it is the only suitable one for the rules that emerge gradually in the world community and whose content is not immediately definable. Were states to decide that a customary rule only becomes binding upon State officials and individuals after the enactment of a statute setting out the contents of such a rule, the parliamentary assembly would have to play a very difficult role, namely, to decide whether the customary rule has taken shape, and with what contents. Given the characteristics of customary law, it is far more fitting and practical to leave it to judges and other State officials to establish whether and to what extent a customary rule is binding within the legal system of a State» (Cassese, 2005, p. 224).
} 
Ahora bien, haciendo referencia al caso peruano, si bien el artículo 55 de la Constitución del Perú hace referencia a la recepción inmediata de los tratados internacionales en el derecho nacional, no podemos encontrar una referencia así para el caso de las normas consuetudinarias. En relación con esta situación, la profesora Salmón señala lo siguiente:

[...] resultaría del todo alejado a la práctica y reiterada jurisprudencia internacional concluir que la no alusión [en la Constitución] a esta fuente del Derecho Internacional tenga como efecto inaplicar la costumbre internacional en el Perú. De esta forma, el silencio constitucional, al que se ha adscrito nuestro país, no resulta óbice para el carácter obligatorio de la costumbre internacional ni podría servir de excusa para su incumplimiento [...]. (Salmón, 2002, p. 76)

Debemos mencionar además que existen $\operatorname{casos}^{3}$ en los cuales los tribunales peruanos han aplicado las normas de derecho internacional consuetudinario, al considerarlas automáticamente incorporadas al derecho nacional (Novak \& García-Corrochano, 2000, p. 119).

Como resultado de lo expuesto hasta el momento y debido a lo indicado en relación con la incorporación automática de las normas consuetudinarias en los ordenamientos internos, sin necesidad de que existan actos de transformación de por medio, podemos concluir que la obligación de realizar EA transfronterizos ya se encuentra incorporada en el sistema jurídico peruano. Debemos mencionar además que esta norma consuetudinaria no solo ya se encuentra incorporada en el derecho interno peruano, sino que, también, ya es vinculante para las diferentes autoridades públicas y sus administrados.

\subsubsection{La implementación}

De conformidad con el derecho internacional, no basta con que una norma se incorpore al derecho interno de los Estados, sino que, además, existe una obligación internacional de implementar la obligación internacional asumida. Dicho de otra manera, los Estados tienen la obligación de adoptar y/o derogar todas las medidas legislativas y/o no legislativas que consideren necesarias para dar cabal cumplimiento a sus obligaciones asumidas en el plano internacional.

\footnotetext{
3 «Entre las normas aplicadas por nuestras resoluciones judiciales podemos mencionar las relativas a la inviolabilidad de los agentes diplomáticos, la inmunidad de la jurisdicción civil de estos, la personalidad e inmunidad de los Estados extranjeros, los deberes del Estado en materia de derechos humanos y derecho internacional humanitario, entre otros» (Novak \& Corrochano, 2000, p. 119).
} 
Dicho lo anterior, es también importante hacer referencia a lo indicado por la profesora Salmón:

La existencia de esta obligación no debe confundirse con el dualismo, pues no se postula la necesidad de transformación de la norma internacional en Derecho interno, sino que [...] apunta a la eventual necesidad de adoptar normas internas adicionales que sirvan para que la norma internacional sea una disposición plenamente operativa en el ordenamiento interno. (Salmón, 2007, p. 61).

\subsubsection{La obligación de implementar}

Los Estados están obligados a que las normas internacionales tengan plena vigencia en los ordenamientos internos, es decir, los Estados deben adoptar todas «las medidas legislativas, ejecutivas y de otra naturaleza -administrativas, culturales, educativas, económicas, sociales, etc.- que permitan que su orden interno resulte conforme con los compromisos internacionales que asumieron» (Salmón, 2007, p. 61). En esto consiste la obligación de implementar.

En esta misma línea, los «Lineamientos sobre cumplimiento e implementación de tratados ambientales multilaterales», emitidos en el ańo 2002 por el PNUMA, definen a la implementación como todas las normas, regulaciones, políticas, medidas en general e iniciativas relevantes, que las partes contratantes adoptan o toman para cumplir sus obligaciones asumidas bajo los acuerdos ambientales multilaterales.

Debemos agregar también que esta obligación de implementar es considerada, actualmente, una norma consuetudinaria autónoma, como lo ha señalado la Corte Interamericana de Derechos Humanos (CIDH) en más de una ocasión ${ }^{4}$ :

En el Derecho de gentes, una norma consuetudinaria prescribe que un Estado que ha celebrado un convenio internacional, debe introducir en su Derecho interno las modificaciones necesarias para asegurar la ejecución de las obligaciones asumidas. Esta norma aparece como válida universalmente y ha sido calificada por la jurisprudencia como un principio evidente [...].

\footnotetext{
${ }^{4}$ Corte IDH. Caso Garrido y Baigorria vs. Argentina, 1998, párr. 68-69; Corte IDH. Caso Durand y Ugarte vs. Perú, 2000, párr. 136; Corte IDH. Caso Baena Ricardo y otros (270 trabajadores) vs. Panamá, 2001, párr. 179.; Corte IDH. Caso Almonacid Arellano y otros vs. Chile, 2006, párr. 117.
} 
$\mathrm{Al}$ respecto, el hecho de que la obligación de implementar sea una norma consuetudinaria acarrea que esta obligación no esté únicamente vinculada a la obligación de implementar obligaciones convencionales, sino que, además, esté referida a las obligaciones consuetudinarias. En ese sentido, podemos afirmar que existe una obligación consuetudinaria de implementar normas consuetudinarias internacionales en los ordenamientos internos de los Estados.

Debemos destacar además que distintos instrumentos del soft law hacen referencia a la importancia de implementar en los derechos internos las obligaciones ambientales internacionales asumidas (Redgwell, 2007, p. 938). Ejemplo de esto son los principios 11 y 18 de la Declaración de Estocolmo de 1972, la Resolución 37/7 del ańo 1982 de la Asamblea General de la ONU y el principio 11 de la Declaración de Río de 1992.

\subsubsection{La importancia de implementar}

Ahora bien, más allá de que exista una obligación para los Estados de implementar, es importante resaltar por qué es importante implementar las normas dentro del derecho interno de los Estados.

En primer lugar, la implementación es importante, pues la mayoría de las normas internacionales no pueden rendir sus efectos sin la ayuda, cooperación y apoyo constante de los sistemas nacionales (Cassese, 2005, p. 9). Decimos la mayoría de las normas, pues esto está vinculado con el carácter «autoejecutivo» de las normas internacionales. Las normas «autoejecutivas» son aquellas que son «autosuficientes», es decir, que pueden ser aplicadas directamente por los particulares y el Estado mismo (Marińo, 2005, p. 601). Por el contrario, las normas no «autoejecutivas» son aquellas que aparte de su incorporación en el derecho interno necesitan que adicionalmente el Estado ponga en práctica diferentes medidas legislativas, ejecutivas o judiciales (Salmón, 2007, pp. 77-78).

$\mathrm{Al}$ respecto, cabe destacar que «el carácter autoejecutivo o no de la norma se define en la propia norma internacional [...]» (Salmón, 2007, p. 89). Existen normas consuetudinarias que pueden ser ejecutadas por sí mismas, como por ejemplo las referidas a la inmunidad de jurisdicción y ejecución de los Estados extranjeros, al derecho de los espacios marinos y a la protección de la propiedad privada de los extranjeros (Marińo, 2005, p. 601). Y, por el contrario, también existen normas consuetudinarias internacionales que no son «autoejecutivas». Ejemplo de esto son las que hacen referencia a una conducta esperada de un Estado respecto de otros Estados o de otros actores relevantes (Jiménez, 1986, p. 31), como, por ejemplo, la obligación consuetudinaria de llevar a cabo EA transfronterizas. 
En relación con esta idea, es importante señalar «que las normas no autoejecutivas son obligatorias y producen efectos jurídicos, por lo que contar o no con medidas de implementación adecuadas determinará el cumplimiento o incumplimiento de la obligación internacional» (Salmón, 2007, p. 92). En ese sentido, es de suma relevancia que los Estados adopten las medidas nacionales de implementación correspondientes, para dar cumplimiento a sus obligaciones internacionales.

Un segundo punto en relación con la importancia de la implementación de las normas internacionales radica en que la implementación permite que los distintos actores no estatales puedan involucrarse con ellas (Redgwell, 2007, p. 923). En otras palabras, la implementación permite llevar a cabo procesos participativos públicos y privados efectivos, generando así que los distintos actores puedan tener la posibilidad de cuestionar la manera en que se implementan las obligaciones internacionales en el país (Redgwell, 2007, p. 923).

Finalmente, si los Estados no desarrollan las normas necesarias para llevar a cabo las EA transfronterizas, las personas jurídicas que tengan a cargo proyectos que ameriten la realización de este proceso no las podrán realizar, pues no tendrán lineamientos claros que seguir, ni instituciones a las cuales dirigirse.

\subsubsection{Técnicas de implementación}

En el DIP no existe ninguna regulación específica sobre el proceso que se debe seguir para proceder a la implementación de las normas internacionales en los ordenamientos nacionales (Salmón, 2007, pp. 74-76). Dicho esto, los Estados tienen completa libertad para decidir cómo y cuándo implementar, estando limitados únicamente a no restringir el contenido o alcance de las obligaciones asumidas (Tomuschat, 2003, p. 93).

\subsection{Plazo}

Si bien los Estados tienen libertad para decidir cuándo implementar sus obligaciones internacionales, cabe destacar que «la obligación de implementar es inmediata, es decir, surge desde el momento mismo en que un Estado queda obligado por la norma internacional» (Salmón, 2007, p. 110). Al respecto, «el carácter inmediato de la implementación significa, por tanto, que ésta debe iniciarse sin demora o dilaciones, aunque su cumplimiento pueda ciertamente requerir un plazo razonable» (Salmón, 2007, p. 111). El proceso de implementación bajo ninguna circunstancia puede prolongarse en el tiempo sin límites razonables (Salmón, 2007, p. 113). 


\subsection{Forma}

La implementación de las obligaciones internacionales en los ordenamientos internos está dividida en tres partes relacionadas íntimamente entre sí: la implementación a nivel legislativo, administrativo y judicial (Sands, Peel, Fabra, \& Mackenzie, 2012, pp. 135-159).

El primer paso que los Estados deben llevar a cabo para cumplir con la obligación de implementar es desarrollar, adoptar, derogar y/o modificar su legislación nacional, políticas, programas y/o estrategias con referencia a la obligación internacional ambiental asumida (Sands et al., 2012, p. 138). La implementación a nivel legislativo es la que genera una mayor transparencia y claridad a los distintos actores sobre las obligaciones asumidas a nivel internacional.

Sin una correcta implementación legislativa de las obligaciones internacionales en los ordenamientos internos, resulta bastante complejo hacer cumplir estas en los sistemas judiciales de los Estados. Claro está que esta mayor o menor dificultad está relacionada con el carácter autoejecutable, o no ejecutable, de la norma ${ }^{5}$. Sin embargo, como ya hemos señalado anteriormente, la obligación de elaborar EA transfronterizas no es autoejecutable, por lo que resultaría bastante complejo resolver una controversia judicial si no se tiene una normativa clara al respecto.

En relación con la implementación administrativa, cabe señalar que justamente recae en las autoridades administrativas el deber de poner en práctica las obligaciones asumidas (Redgwell, 2007, pp. 930-931). En el caso de la obligación materia del presente trabajo, es importante contar con instituciones y funcionarios públicos que ejecuten todos los aspectos relacionados con las EA transfronterizas.

Finalmente, cabe señalar que un poder judicial independiente es vital para la correcta implementación del DAI (PNUMA, 2002). Las Cortes cumplen un rol complementario al poder legislativo en el momento de implementar las normas ambientales internacionales, y el éxito de este rol complementario depende de diferentes factores como, por ejemplo, la experiencia y la competencia de los jueces en materia ambiental. Sin embargo, es importante precisar que existen muy pocos casos de implementación directa de obligaciones internacionales por parte de las cortes.

\footnotetext{
${ }^{5}$ Véase la sección 3.1.2.2 del capítulo 3.
} 


\subsection{La implementación del proceso de EA transfronteriza en el Perú}

Conforme a lo señalado en la sección anterior, la obligación de realizar EA transfronterizas ya se encuentra incorporada en el sistema peruano. Lo que analizaremos a continuación es si el Estado peruano ha implementado el proceso de realizar EA transfronterizas, tanto a nivel legislativo como a nivel administrativo.

\subsubsection{Implementación a nivel legislativo}

\subsubsection{Antecedentes de la EA en el Perú}

Para analizar si el Perú tiene alguna regulación relacionada con las EA transfronterizas, es necesario entender primero cómo funciona el actual sistema de EA. Y, a fin de entender este sistema, es importante primero entender cómo y cuándo apareció la obligación de realizar EA en el Perú y, además, cómo esta fue evolucionando a través de los años.

En el año 1990, el ya derogado CMARN, aprobado por el Decreto Legislativo 613, fue la primera norma peruana en hacer mención a la obligación de realizar EIA (capítulo III), mas no hizo referencia al proceso de $\mathrm{EA}^{6}$. El CMARN establecía, entre otros aspectos, que ciertos proyectos debían realizar un EIA y que estos debían ser aprobados por las respectivas autoridades competentes (artículos 9, 10, 11 y 12).

Un año después de la aprobación del CMARN, se aprobó el Decreto Legislativo 757, Ley Marco para el Crecimiento de la Inversión Privada -norma que continúa vigente en nuestro ordenamiento-, la cual introdujo criterios adicionales en relación con los EIA, sobre todo en relación con qué se entendía por autoridades sectoriales. Sin embargo, esta norma tampoco hizo referencia a la EA sino únicamente a los EIA.

Únicamente tomando como referencia dichas normas -las cuales no desarrollaban a profundidad ni el alcance, ni el contenido, ni el procedimiento relacionado con los EIA-, las distintas autoridades sectoriales comenzaron a elaborar sus respectivas normas, a fin de regular la realización de EIA en sus respectivos sectores. Es así que, en el ańo 1993, el MEM, a través del Decreto Supremo 016-93-EM, aprobó el hoy ya derogado Reglamento para la Protección Ambiental en la Actividad Minero-Metalúrgica, creándose así el primer reglamento sectorial que regulaba los distintos lineamientos en relación con los EIA, mas no en relación con las EA.

\footnotetext{
${ }^{6}$ Es importante recordar que el EIA es un documento dentro del proceso de EA.
} 
Posteriormente, en diciembre del año 1994, mediante la Ley 26410, se creó el Conam, cuya finalidad como organismo dependiente de la PCM era ser el organismo rector de la política nacional ambiental (artículos 1 y 2), ya que hasta ese momento no existía una institución equivalente. Entre sus funciones se encontraba la de establecer los criterios generales para la elaboración de EIA (artículo 4, literal e) (en el año 2004, sus funciones fueron modificadas por el artículo 9 de la Ley 28245, estableciéndosele, entre otras funciones, la de dirigir el SEIA [artículo 4, literal f]).

Casi tres años después de la creación del Conam, el 13 de mayo de 1997, se publicó la Ley de Evaluación de Impacto Ambiental para Obras y Actividades, Ley 26786 -aún vigente-, la cual modificaba el Decreto Legislativo 757 en el sentido de que establecía que las autoridades sectoriales competentes debían coordinar con el Conam todo lo relacionado con los EIA. La intención de esta norma era fortalecer el rol del Conam en relación con los EIA. Esta fue la primera norma, en la historia del Perú, en introducir el término «Evaluación de Impacto Ambiental», aunque no hizo ninguna alusión adicional a este término.

Mientras se fueron promulgando, a lo largo de los ańos, estas normas de carácter general, los distintos sectores continuaron su proceso de elaboración de sus respectivos reglamentos ambientales y también de sus respectivas guías para la elaboración de EIA sectoriales y de sus respectivos lineamientos para la elaboración de TdR.

A partir de lo anteriormente señalado, se puede apreciar que, durante la década de 1990, el desarrollo de la regulación en torno a los EIA se dio de manera desordenada, sin claros lineamientos más allá de lo establecido en el CMARN, la Ley Marco para el Crecimiento de la Inversión Privada y la Ley de Evaluación de Impacto Ambiental para Obras y Actividades. De igual manera, cabe destacar que la legislación sobre esta materia se dio sin que exista claridad sobre las diferencias entre lo que era un proceso de EA y un EIA. Y, adicionalmente a esto, los conceptos y los procedimientos, desarrollados en cada uno de los reglamentos sectoriales, tampoco fueron uniformes entre sí. Finalmente, cabe señalar que, si bien uno de los roles del Conam era ser el ente coordinador en lo relacionado con los EIA, este nunca llegó a lograr su objetivo (De la Puente, 2005, p. 143).

En este desarrollo desordenado y poco uniforme de la legislación sobre los EIA y EA, en el que además no era clara la diferencia entre estos conceptos, el Congreso de la República, en el año 2001, aprobó la Ley 27446, Ley del SEIA, vigente hasta la fecha, con la finalidad de buscar coordinar el marco regulatorio existente. 
El SEIA se estableció con la finalidad crear un sistema único y coordinado de identificación, prevención, supervisión, control y corrección anticipada de los impactos negativos que se puedan generar por los proyectos de inversión, a fin de establecer un proceso uniforme de los requerimientos, etapas y alcances de las EA.

En cuestiones de forma, esta ley establecía que todas las normas que se oponían a ella debían derogarse, que el reglamento de la ley debía aprobarse a los 45 días de haberse publicado esta, y que, además, las normas sectoriales sobre EA debían adecuarse a lo dispuesto en dicha ley.

No obstante, los hechos en la práctica sucedieron de manera diferente: (i) el reglamento de la Ley del SEIA se aprobó 8 años después, en 2009, a través del Decreto Supremo 019-2009-Minam -Reglamento del SEIA-; y (ii) a la fecha, no todos los sectores se han terminado de adecuar a la normativa, quedando aún pendiente la adecuación de los sectores de pesquería, salud, transporte y turismo ${ }^{7}$.

Adicionalmente a lo anterior, cabe destacar que entre el período de tiempo de aprobación de la Ley del SEIA, su reglamento y el proceso de adecuación de los diferentes reglamentos sectoriales, en el Perú se aprobaron una serie de normas e instrumentos vinculados al SEIA que consideramos relevante mencionar para los efectos de este estudio:

- 8/6/2004, Ley 28245, Ley Marco del Sistema Nacional de Gestión Ambiental, cuya finalidad, entre otras, es integrar las políticas, planes, programas y acciones destinados a la protección del ambiente, contribuyendo a la conservación y aprovechamiento sostenible de los recursos naturales;

- 15/8/2005, Ley 2861 1, Ley General del Ambiente, norma ordenadora del marco normativo para la gestión ambiental en el Perú;

- 14/5/2008, Decreto Legislativo 1013, Ley de Creación, Organización y Funciones del Minam, organismo del Poder Ejecutivo rector del sector ambiental, que desarrolla, dirige, supervisa y ejecuta la Política Nacional del Ambiente;

- 23/5/2009, D. S. 012-2009-Minam, Política Nacional del Ambiente; es un requisito de acuerdo a lo establecido en el artículo 67 de la Constitución del Perú. Define los objetivos prioritarios, lineamientos, contenidos principales y estándares nacionales ambientales de obligato-

\footnotetext{
${ }^{7}$ También está pendiente la adecuación a la normativa vigente de diversas guías para la elaboración de EIA sectoriales.
} 
rio cumplimiento. Es, además, el documento base para la formulación del Plan Nacional de Acción Ambiental, la Agenda Nacional de Acción Ambiental y otros instrumentos de gestión pública ambiental en el marco del Sistema Nacional de Gestión Ambiental;

- 9/7/2011, D. S. 014-2011, Plan Nacional de Acción Ambiental (Planaa) Perú 2011-2021; el Planaa presenta la visión del país en materia ambiental para el año 2021, y sus objetivos son los mismos que se proponen lograr en la Política Nacional del Ambiente;

- 20/12/2012, Ley 29968, Ley de Creación del Senace, entidad encargada de revisar y aprobar los EIA-d de los proyectos de inversión pública, privada o capital mixto;

- 25/5/2013, D. S. 060-2013-PCM, Disposiciones Especiales para la Ejecución de Procedimientos Administrativos y Otras Medidas para Impulsar Proyectos de Inversión Pública y Privada. Tal como lo dice el título de la norma, esta tenía por objetivo agilizar la ejecución de proyectos de inversión pública y privada. Para lograr esto, se establecieron entre otras las siguientes medidas: (i) la obligación para las entidades de aprobar términos de referencia con características comunes, y (ii) que las diversas entidades que intervienen en el procedimiento emitiendo opiniones vinculantes o no vinculantes, solo pueden pronunciarse sobre aspectos de su competencia.

- 12/7/2014, Ley 30230, Ley que Establece Medidas Tributarias, Simplificación de Procedimientos y Permisos para la Promoción y Dinamización de la Inversión en el País, que en su artículo 21 regula el proceso para la emisión de opiniones vinculantes y no vinculantes;

- 28/11/2014, D. S. 015-2014-DE, Aprueban Reglamento del Decreto Legislativo 1147, que regula el fortalecimiento de las Fuerzas Armadas en las competencias de la Autoridad Marítima Nacional - Dirección General de Capitanías y Guardacostas, que, entre otros, regula la participación de la Autoridad Marítima Nacional en el SEIA;

- 5/12/2014, Resolución Ministerial 398-2014-Minam, Lineamientos para la compensación ambiental en el marco del SEIA, que regula la elaboración del Plan de Compensación Ambiental de los EIA-d.

- 21/5/2015, Ley 30327, Ley de Promoción de las Inversiones para el Crecimiento Económico y Desarrollo Sostenible. Los aspectos más 
resaltantes de esta norma en materia ambiental son que (i) el titular de un proyecto puede optar por el uso compartido gratuito de la información de la línea base de un EIA-d o EIA-s/d aprobado previamente por la autoridad competente, ya sea a su favor o a favor de terceros para la elaboración de un nuevo instrumento de gestión ambiental; y (ii) la creación del procedimiento de Certificación Ambiental Global con la finalidad de incorporar en un solo procedimiento los distintos títulos habilitantes relacionados con la Certificación Ambiental Global.

A modo de resumen, a través de la línea de tiempo que aparece en la Figura 3.1 procederemos a graficar todas las normas e instrumentos vinculados al SEIA que se encuentran vigentes actualmente.

Como se puede apreciar, existe un gran número de normas vinculadas a las EA y no todas se encuentran alineadas a la Ley del SEIA y su reglamento. En ese sentido, para analizar si en nuestro marco normativo existen referencias a las EA transfronterizas, no solo nos podemos remitir a la Ley del SEIA y su reglamento, sino que es necesario hacer referencia a un mayor número de normas. 


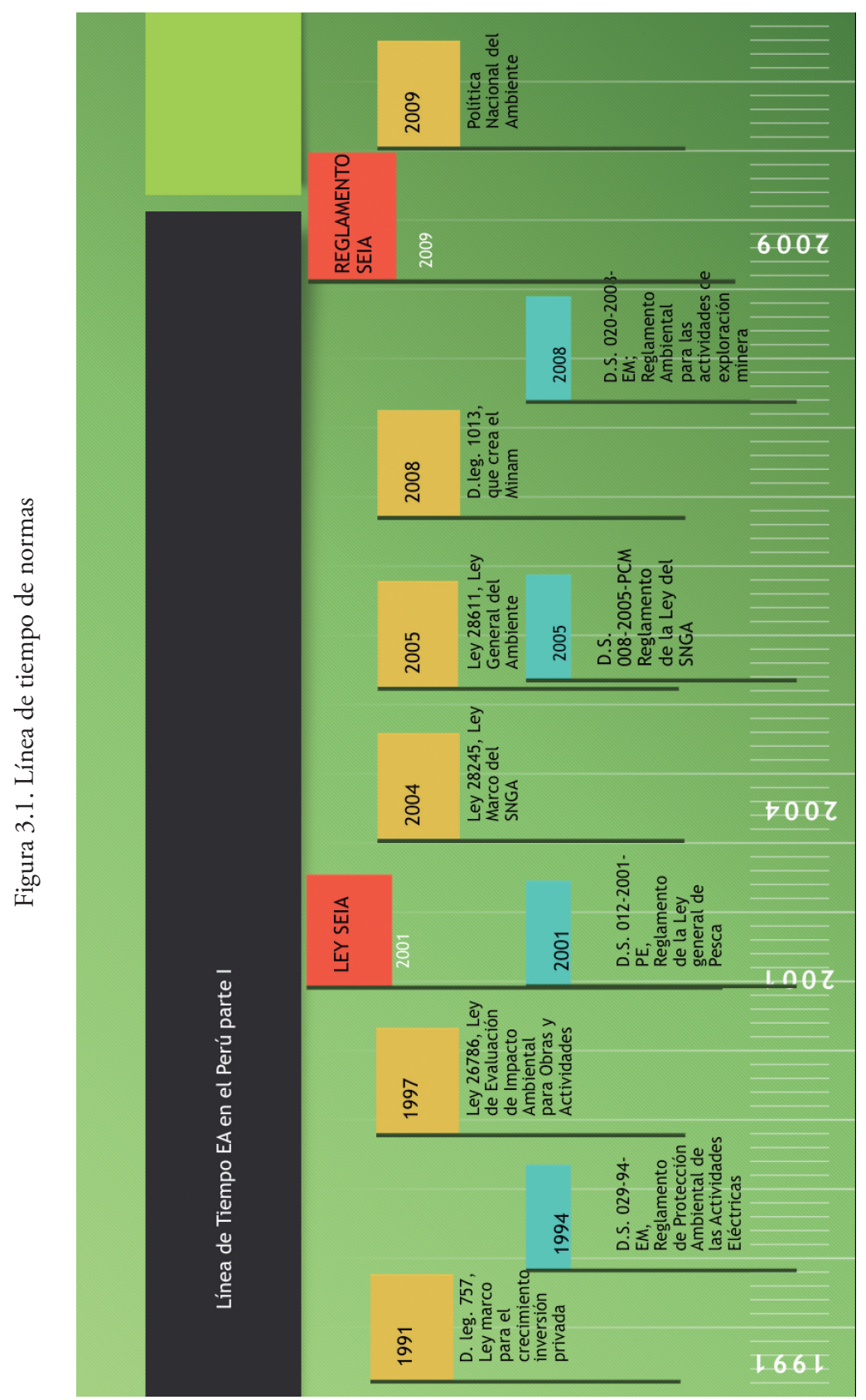




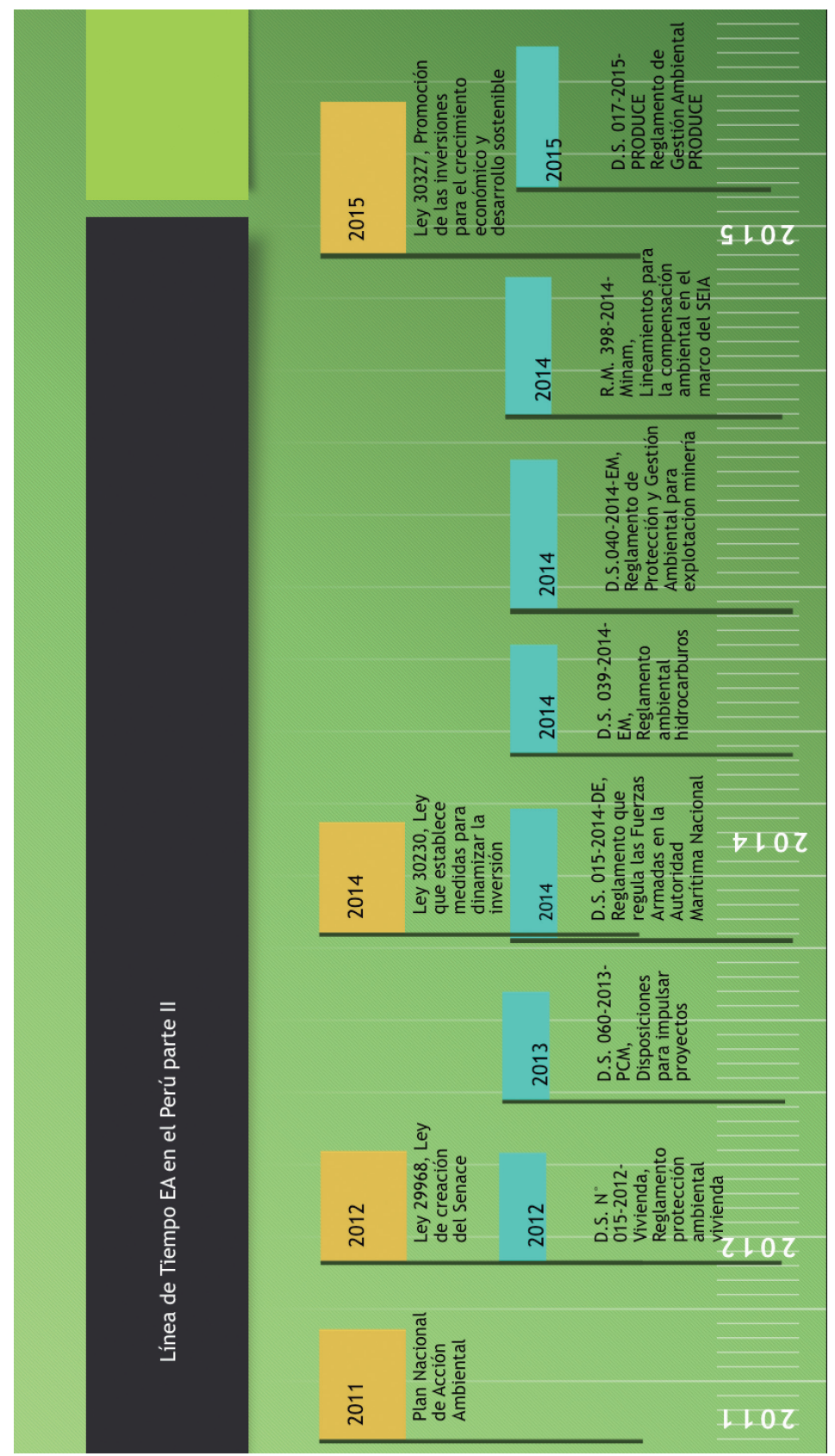

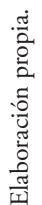




\subsubsection{Análisis de la normativa vigente}

Para comenzar, como ya hemos seńalado, tanto el Decreto Legislativo 757, Ley Marco para el Crecimiento de la Inversión Privada, como la Ley de Evaluación de Impacto Ambiental para Obras y Actividades, Ley 26786, fueron de las primeras normas de carácter general en regular los Estudios de Impacto Ambiental, mas no el proceso de EA.

La primera norma de carácter general que hizo referencia al proceso de EA fue la Ley del SEIA. Dicha ley y su reglamento constituyen las normas generales en materia de EA en el territorio nacional (D. S. 019-2009-Minam, artículo 2).

De acuerdo con estas normas:

La evaluación de impacto ambiental es un proceso participativo, técnico-administrativo, destinado a prevenir, minimizar, corregir y/o mitigar e informar acerca de los potenciales impactos ambientales negativos que pudieran derivarse de las políticas, planes, programas y proyectos de inversión, y, asimismo, intensificar sus impactos positivos.

[...] Los resultados de la evaluación de impacto ambiental deben ser utilizados por la Autoridad Competente para la toma de decisiones respecto de la viabilidad ambiental del proyecto, contribuyendo a su mayor eficiencia [...]. (D. S. 019-2009-Minam, artículo 14).

Como se puede apreciar, bajo la normativa peruana, no solo los proyectos deben ser sometidos a un proceso de EA, sino también los planes y programas. $\mathrm{Al}$ respecto, cabe señalar que el presente trabajo está centrado únicamente en los proyectos.

Bajo la legislación peruana, no todos los proyectos deben ser sometidos al proceso de EA, sino únicamente aquellos que sean susceptibles de generar impactos ambientales negativos leves, moderados o significativos. Al respecto, dependiendo de la magnitud del impacto, la rigurosidad del proceso de evaluación varía. En aquellos casos en que los impactos ambientales no tienen carácter significativo, se solicita una DIA; los proyectos que generan impactos negativos moderados y cuyos efectos negativos pueden ser eliminados o minimizados a través de medidas fácilmente aplicables, deben realizar EIAs/d: $y$, para aquellos proyectos que generan impactos ambientales negativos significativos, se requiere EIA-d. 
Ahora bien, el reglamento define qué se entiende por «impacto ambiental negativo significativo» en su anexo I, pero no específica qué se entiende por «impacto ambiental negativo no significativo», ni «impacto ambiental negativo moderado». Sin embargo, esta falta de especificación no es un problema, pues la legislación peruana, en el anexo II del Reglamento del SEIA, hace un listado de los proyectos que deben ser sometidos a un proceso de EA, independientemente del tipo de impacto que generen ${ }^{8}$. Y, con base en esta lista, las autoridades sectoriales, indican a qué tipo de evaluación -DIA, EIA-s/d, o EIA-d- deben ser sometidos los proyectos.

Ya hemos señalado los proyectos que la legislación peruana indica que deben ser sometidos a un proceso de EA. Lo que analizaremos a continuación es si a lo largo de las diferentes etapas del proceso general de EA, las distintas normas vinculadas al SEIA efectúan alguna referencia a la necesidad de identificar posibles impactos ambientales transfronterizos.

Para proceder con este análisis, es importante precisar que en nuestra legislación el procedimiento genera de EA consta de cinco etapas (Ley 27446, artículo 6): (a) presentación de la solicitud, (b) clasificación de la acción, (c) evaluación del instrumento de gestión ambiental, (d) resolución y (e) seguimiento y control'.

\footnotetext{
${ }^{8}$ Es importante precisar que, de acuerdo a los artículos 20 y 21 del Reglamento SEIA, este listado es revisado y actualizado periódicamente por el Minam en coordinación con las entidades que conforman el SEIA. Hasta la fecha, dicha lista solo ha sido actualizada una vez, en el ańo 2011, mediante la R. M. 157-2011-Minam.

${ }^{9}$ Como se puede apreciar, este proceso no es idéntico al señalado en el capítulo II. Esta estructura regula la realización de EA nacionales peruanas e incluye las obligaciones para los particulares. Sin embargo, el hecho de que la estructura procedimental sea diferente y más específica que la analizada en el capítulo II, no impide que se pruebe si el Perú está cumpliendo con la obligación o no.
} 
Figura 3.2. Flujograma del proceso nacional de EA

\section{Procedimiento Nacional de EA}

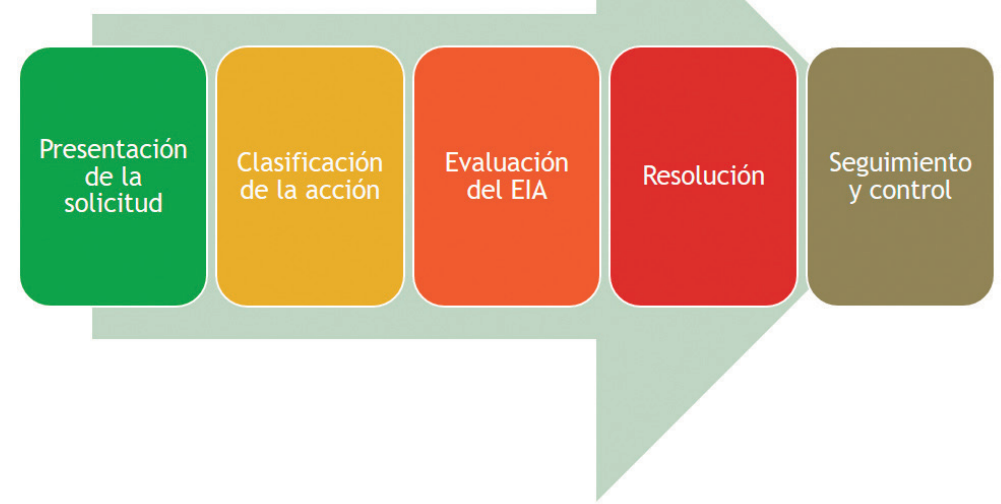

Elaboración propia.

a) Presentación de la solicitud

La presentación de la solicitud la debe hacer el titular del proyecto y debe incluir, de acuerdo a la Ley y al Reglamento del SEIA: (i) una evaluación preliminar que indique las características de la acción que se proyecta ejecutar, los antecedentes de los aspectos ambientales que conforman el área de influencia de la misma, el plan de participación ciudadana, los posibles impactos ambientales que pudieran producirse y las medidas de prevención, mitigación o corrección previstas, el plan de seguimiento y control, el plan de cierre o abandono, el cronograma de ejecución y el presupuesto de implementación; además, debe incluir (ii) una propuesta de clasificación del proyecto, (iii) una propuesta de términos de referencia para el estudio de impacto ambiental correspondiente, y (iv) una descripción de la naturaleza de las actividades de investigación, extracción o colecta de recursos forestales y de fauna silvestre o recursos hidrobiológicos que sean necesarios para elaborar la línea base ambiental, así como información de las especies, el área o zona donde se desarrollarán las acciones, el personal involucrado en el levantamiento de la información, información 
de convenios, permisos o autorizaciones para el proceso de levantamiento de información, y un compromiso de conservación y/o rehabilitación de la zona intervenida (Ley 27446, artículo 7; D. S. 019-2009-Minam, artículos 40 y 41 y anexo VI).

Adicionalmente a lo anterior, es importante resaltar que de acuerdo al artículo 40 del Reglamento del SEIA, las autoridades competentes para la presentación de la solicitud pueden solicitar información adicional a la establecida en la ley, el reglamento y sus anexos. Y, a su vez, las autoridades se encuentran en la obligación de elaborar o actualizar guías específicas para la formulación de TdR.

Como consecuencia de lo anterior, realizamos un análisis de las normas sectoriales relacionadas con esta fase de los sectores minero (D. S. 040-2014EM, D. S. 020-2008-EM); energético (D. S. 029-94-EM); industria (D. S. 017-2015-Produce); agrícola (D. S. 019-2012-AG); pesquero (D. S. 0122001-PE, D. S. 003-2016-PE); hidrocarburos (D. S. 039-2014-EM); vivienda, construcción y saneamiento (D. S. 015-2012-Vivienda); y transportes (Resolución Directoral 068-2005-MTC); y confirmamos que ninguna de estas normas solicita, de manera expresa, que se remita información relacionada con posibles impactos transfronterizos. Únicamente se podría decir que el sector minero, a través del Decreto Supremo 040-2014-EM, Reglamento de Protección y Gestión Ambiental para las Actividades de Explotación, Beneficio, Labor General, Transporte y Almacenamiento Minero, hace una referencia indirecta, en su artículo 28, a la necesidad de evaluar posibles impactos transfronterizos.

Dicho artículo precisa la necesidad de llevar a cabo una evaluación y previa aprobación de los TdR, cuando los proyectos se encuentren dentro de los 50 $\mathrm{km}$ de la frontera. Esto podría indicar que cuando un proyecto se desarrolla en la frontera, no se aplican los $\mathrm{TdR}$ generales, sino que deben elaborarse TdR especiales. Y, como consecuencia de esto, las autoridades podrían solicitar al administrado que considere los posibles impactos transfronterizos que podrían generarse.

b) Clasificación de la acción

Siguiendo con el proceso, una vez que se recibe la solicitud, la autoridad competente debe dar difusión a la evaluación preliminar a fin de que las partes interesadas puedan dar sus observaciones y comentarios (D. S. 019-2009-Minam, artículo 42). Luego, la autoridad competente procede a evaluar el contenido de la solicitud y, cuando estime conveniente, puede solicitar también opinión técnica a otras autoridades. Las opiniones emitidas deben ser recogidas en la Resolución de Clasificación que emite la autoridad. 
Otro de los aspectos por evaluar en esta etapa es si el proyecto ha sido correctamente clasificado por el titular del proyecto. Como ya hemos indicado previamente, todo proyecto que es sometido a un proceso de EA debe ser clasificado en una de las tres categorías establecidas por la Ley: (a) Categoría I- DIA; (b) Categoría II- EIA-s/d; y (c) Categoría III- EIA-d (Ley 27446, artículo 4). Los proyectos se clasifican en alguna de dichas categorías con base en los criterios establecidos en el artículo $5^{10}{ }^{11}$ de la Ley y el anexo V del Reglamento. Ninguno de estos criterios hace alusión a tomar en cuenta los impactos transfronterizos.

Finalmente, cabe destacar que de acuerdo al numeral 4.2 de la Ley del SEIA, modificado por el artículo 1 del Decreto Legislativo 1078, las autoridades competentes pueden establecer criterios complementarios adicionales para clasificar un proyecto. En ese sentido, realizamos un análisis de las normas relacionadas con esta fase de los sectores minero; energético; industrial; agrícola; pesquero; hidrocarburos; vivienda, construcción y saneamiento; y transportes, y confirmamos que ninguna de estas normas establece como criterio adicional para clasificar un proyecto los posibles impactos transfronterizos que este pueda generar.

\section{c) Evaluación del EIA}

En caso de tratarse de proyectos de la Categoría II y la Categoría III, y una vez que la autoridad competente efectúa la clasificación, el titular del proyecto debe llevar a cabo un EIA-s/d o un EIA-d, respectivamente, tomando como referencia sus TdR aprobados, la Ley y el Reglamento SEIA y las normas emitidas por las autoridades sectoriales (D. S. 010-2009-Minam, artículo 47).

De acuerdo a la Ley y al Reglamento, tanto el EIA-s/d como el EIA-d deben contener: (i) una descripción de la acción propuesta y los antecedentes de su área de influencia; (ii) la identificación y caracterización de las implicaciones y los impactos ambientales negativos, según corresponda, en todas las fases y durante todo el período de duración del proyecto, para lo cual se deberá tener en cuenta el ciclo de vida del producto o actividad, el riesgo ambiental en los casos aplicables y otros instrumentos de gestión ambiental conexos;

\footnotetext{
${ }^{10}$ Los criterios a los cuales deben ceñirse las autoridades de acuerdo al artículo 5 de la Ley y el anexo V del Reglamento son: protección de la salud de las personas; protección de la calidad ambiental; protección de la diversidad biológica y sus componentes; protección de los sistemas y estilos de vida de las comunidades; protección de los espacios urbanos; protección del patrimonio arqueológico, histórico, arquitectónico y monumentos nacionales; y los demás que surjan de la política nacional ambiental.

${ }^{11}$ De acuerdo al artículo 37 del Reglamento, las autoridades sectoriales pueden aprobar criterios especiales en el ámbito de sus respectivas competencias.
} 
(iii) la estrategia de manejo ambiental o la definición de metas ambientales incluyendo, según el caso, el plan de manejo, el plan de contingencias, el plan de compensación y el plan de abandono o cierre; (iv) el plan de participación ciudadana; (v) los planes de seguimiento, vigilancia y control; (vi) la valorización económica del impacto ambiental; (vii) un resumen ejecutivo de fácil comprensión; y (viii) otros que determine la autoridad.

Como en las etapas anteriores, la Ley y el Reglamento del SEIA hacen referencia a los impactos de manera muy general y no precisan si se deben medir los impactos únicamente dentro del territorio o si también deben considerarse los posibles impactos transfronterizos. De igual manera, cuando se hace referencia a los planes de mitigación, no se solicita que se realice un análisis de las acciones de mitigación en caso de impactos transfronterizos.

En relación con las normas sectoriales, realizamos un análisis de las normas relacionadas con esta fase de los sectores minero (D. S. 040-2014EM, D. S. 020-2008-EM); energético (D. S. 029-94-EM); industria (D. S. 017-2015-Produce); agrícola (D. S. 019-2012-AG); pesquero (D. S. 012-2001-PE, D. S. 003-2016-PE); hidrocarburos (D. S. 039-2014-EM); vivienda, construcción y saneamiento (D. S. 015-2012-Vivienda); y transportes (Resolución Directoral 068-2005-MTC), y confirmamos, que ninguna de estas normas indica de manera expresa que los EIA deben analizar los posibles impactos transfronterizos de un proyecto, ni tampoco hacen referencia a la necesidad de un análisis de las acciones de mitigación en caso de posibles impactos transfronterizos. La mayoría de las normas únicamente hacen referencia a la necesidad de evaluar los impactos sobre el ambiente, en las distintas fases del proyecto, sin especificar el alcance territorial de la evaluación.

Una vez elaborado el EIA, este debe ser presentado a la autoridad competente. Durante esta etapa, la autoridad debe evaluar el estudio, se deben llevar a cabo las audiencias públicas u otros mecanismos de participación ciudadana, así como también se deben solicitar las opiniones previas a las diversas autoridades que puedan tener interés en la aprobación del EIA. De acuerdo al reglamento del SEIA, el proceso de evaluación de los EIA-d debe llevarse a cabo en un plazo máximo de 120 días.

d) Resolución

Concluida la revisión y evaluación del EIA, la autoridad competente debe emitir la resolución acompańada de un informe que sustente lo resuelto (D. S. 019-2009-Minam, artículo 54). El informe debe comprender, entre otros aspectos, un resumen de las opiniones técnicas emitidas por las autoridades competentes, un resumen del proceso de participación ciudadana, la descrip- 
ción de los impactos ambientales significativos y las medidas por adoptar, y un resumen de las principales obligaciones que debe cumplir el titular (D. S. 019-2009-Minam, artículo 54). De la revisión de la Ley del SEIA y su respectivo reglamento, se comprobó que, para esta fase, tampoco se hace alusión a tomar en cuenta los impactos transfronterizos. Sin embargo, sí se menciona que debe hacerse un resumen de las opiniones técnicas recibidas. En ese sentido, de recibirse opiniones de la Cancillería, o de alguna otra autoridad, en relación con posibles impactos transfronterizos, estas deberían incluirse en la resolución.

En lo que respecta a las normas sectoriales, realizamos un análisis de las relacionadas con esta fase de los sectores minero (D. S. 040-2014-EM, D. S. 0202008-EM); energético (D. S. 029-94-EM); industria (D. S. 017-2015-Produce); agrícola (D. S. 019-2012-AG); pesquero (D. S. 012-2001-PE, D. S. 003-2016-PE); hidrocarburos (D. S. 039-2014-EM); vivienda, construcción y saneamiento (D. S. 015-2012-Vivienda); y transportes (Resolución Directoral 068-2005-MTC), y confirmamos que ninguna de estas normas establece de manera explícita que las autoridades deben tomar en consideración la posible ocurrencia de impactos transfronterizos en el momento de evaluar los EIA presentados.

e) Seguimiento y control

Las acciones de seguimiento y control comprenden las funciones de supervisión, fiscalización, sanción y vigilancia, y estas se originan desde el inicio de las obras. Al respecto, de acuerdo al artículo 75 del Reglamento, la acción de supervisión implica la verificación de las acciones llevadas a cabo en el marco de los EIA aprobados por la autoridad competente; la fiscalización está referida a la calificación de los resultados de la supervisión tomando como referencia los mandatos legales establecidos; la sanción se refiere a la medida correctiva impuesta por el incumplimiento de las obligaciones; y, finalmente, la vigilancia se refiere a la verificación de los efectos generados en el aire, agua, suelos, recursos naturales, salud pública y otros bienes bajo tutela del SEIA, por las acciones desarrolladas en el marco de proyectos sujetos al SEIA y otras normas especiales complementarias.

$\mathrm{Ni}$ en la Ley del SEIA ni en su respectivo reglamento se efectúa referencia al hecho de llevar acciones de seguimiento y control sobre los impactos transfronterizos que un proyecto pudiera estar generando. Adicionalmente a estas normas de carácter general, realizamos un análisis de las normas sectoriales relacionadas con las acciones de seguimiento y control de los sectores minero, energético, industrial, agrícola, pesquero; del sector hidrocarburos; del sector 
vivienda, construcción y saneamiento; y del sector transportes, y confirmamos que ninguna de estas normas efectúa referencia al hecho de realizar acciones de seguimiento y control sobre los posibles impactos transfronterizos que los proyectos pudieran generar.

De igual manera, debido a que el Organismo de Evaluación y Fiscalización Ambiental (OEFA) es, a la fecha, el encargado de la fiscalización ambiental de los sectores minero, hidrocarburos, electricidad, pesca e industria, se analizó la Segunda Disposición Complementaria Final del Decreto Legislativo 1013, la cual creó el OEFA, y la Ley 29325, Ley del Sinefa, y se apreció que en estas normas tampoco se hace referencia a un rol fiscalizador sobre los impactos transfronterizos de un proyecto.

Como conclusión del presente acápite, podemos señalar que las diferentes normas vinculadas al SEIA no hacen referencia de manera explícita a que los posibles impactos transfronterizos que un proyecto pudiera generar deben ser tomados en cuenta. De igual manera, en la normativa vigente tampoco existen guías sobre cómo elaborar un EIA transfronterizo. Sin embargo, cabe destacar que el SEIA tampoco indica que el análisis de los impactos deba circunscribirse únicamente al territorio nacional, ni tampoco prohíbe que los titulares de los proyectos realicen una EA transfronteriza para sus actividades.

\subsubsection{Normas que hacen referencia a aspectos transfronterizos}

Como hemos señalado en la sección anterior, en el sistema jurídico peruano no existen normas que hagan referencia explícita a la obligación de llevar a cabo EA transfronterizas. Sin embargo, sí existen normas que hacen referencia a la necesidad de prevenir posibles impactos transfronterizos, como, por ejemplo, la LGA.

Para comenzar, el artículo 12 de la LGA establece que la política exterior del Estado en materia ambiental se rige, entre otros, por el siguiente lineamiento:

h. La cooperación internacional destinada al manejo sostenible de los recursos naturales y a mantener las condiciones de los ecosistemas y del ambiente a nivel transfronterizo y más allá de las zonas donde el Estado ejerce soberanía y jurisdicción, de conformidad con el derecho internacional. Los recursos naturales transfronterizos se rigen por los tratados sobre la materia o en su defecto por la legislación especial. El Estado promueve la gestión integrada de estos recursos y la realización de alianzas estratégicas en tanto supongan el mejoramiento de las condiciones de sostenibilidad y el respeto de las normas ambientales nacionales. 
En esta misma línea, el artículo 97 de la LGA precisa los lineamientos para políticas sobre diversidad biológica, entre los cuales destaca el siguiente:

n. La cooperación en la conservación y uso sostenible de la diversidad biológica marina en zonas más allá de los límites de la jurisdicción nacional, conforme al Derecho Internacional.

Como se puede apreciar, la LGA sí establece la necesidad de velar por el ambiente más allá de las fronteras del Estado peruano, a fin de estar conformes con las normas emanadas del derecho internacional, sin embargo, no efectúa referencia explícita a la norma procedimental de realizar EA transfronterizas. Al respecto, es importante notar que si bien la LGA se aprobó después de la Ley del SEIA y por eso se podría entender por qué este aspecto no está regulado en la Ley del SEIA, no se logra comprender por qué el reglamento del SEIA y los reglamentos sectoriales no acogieron también estos lineamientos sobre la prevención de impactos transfronterizos.

Ahora bien, esta preocupación por el ambiente más allá de las fronteras se establece más expresamente en la Política Ambiental del Sector Turismo, aprobada por la Resolución Ministerial 195-2006-Mincetur-DM. En los principios y lineamientos de dicha política ambiental se establece lo siguiente:

El estado como estimulador, guía-orientador, facilitador y promotor del cambio ambiental en las actividades turísticas, brinda a continuación los lineamientos de la Política Ambiental del Sector Turismo:

\section{$[\ldots]$}

13. El Sector Turismo compromete a velar por que sus operaciones no afecten el ambiente de otros países o zonas de jurisdicción internacional.

En consecuencia, como se puede apreciar, la legislación peruana y algunos instrumentos de gestión ambiental sí reconocen la necesidad de prevenir la ocurrencia de impactos transfronterizos. El siguiente paso por realizar es que se regule específicamente la necesidad de llevar a cabo EA transfronterizas, obligación que, como se ha podido desprender del análisis, no se encuentra regulada de manera explícita en ninguna norma vinculada al SEIA.

\subsubsection{La implementación a nivel administrativo}

Si bien se ha demostrado que en la normativa nacional no existen referencias explícitas a la necesidad de llevar a cabo EA transfronterizas, en la presente 
sección se hará referencia al caso de la mina Pucamarca, para la cual sí hubo que llevar a cabo algunas acciones con el fin de analizar los posibles impactos que se pudieran generar sobre el territorio chileno ${ }^{12}$.

La mina de oro Pucamarca, propiedad de la empresa Minsur, es un yacimiento aurífero a tajo abierto ubicado en Cerro Checocollo, distrito de Palca, en la región Tacna, a 200 metros de la frontera con Chile (AMEC, 2007, p. 1). El EIA del proyecto fue aprobado por Resolución Directorial 256-2009MEM/AMM, el 21 de agosto de 2009.

El EIA aprobado por la Resolución Directorial 256-2009-MEM/AMM no hacía referencia a los impactos transfronterizos que pudieran ocasionarse sobre el territorio chileno; sin embargo, Minsur efectuó dos estudios para tener en cuenta las posibles afectaciones que podían generarse sobre el territorio del país vecino: una Línea de Base del Proyecto Pucamarca sobre el territorio chileno y una Evaluación Ambiental del Proyecto Pucamarca sobre territorio chileno. Ambos documentos fueron entregados por la empresa, en noviembre del año 2007, a la Embajada de la República de Chile en Lima, y también fueron enviados al Ministerio de Energía y Minas del Perú.

La línea de base fue elaborada por la consultora chilena SRK consultores en 2004, con el objetivo de desarrollar un diagnóstico inicial de los componentes ambientales presentes en la potencial área de influencia del proyecto Pucamarca en territorio chileno, de acuerdo a los contenidos exigidos por la legislación ambiental chilena (SRK, 2004, p. 1). Para alcanzar este objetivo, el documento (i) delimitó el área de influencia del proyecto en el territorio chileno para los componentes del medio físico, biológico, humano y construido, susceptibles de ser afectados por el proyecto; y (ii) desarrolló una línea de base de los componentes ambientales del medio físico, biológico, humano y construido, presentes en el área de influencia del proyecto, tomando en cuenta la legislación ambiental chilena, bibliografía pertinente y resultados de investigaciones de terreno (SRK, 2004, p. 1).

En relación con la línea de base realizada es importante hacer referencia a una de las conclusiones y recomendaciones que se hicieron, en la que se indicó lo siguiente: «Dado que se trataría de un proyecto aparentemente sin precedentes, en el sentido de ejercer potenciales impactos en territorio chileno, ocurriendo sus actividades en territorio extranjero, será preciso sostener conversaciones con autoridades fronterizas y ambientales de ambos países, para

\footnotetext{
${ }^{12} \mathrm{El}$ análisis presentado en esta sección se ha efectuado únicamente con base en la información proveída por el Ministerio de Energía y Minas, a través del procedimiento administrativo de acceso a la información pública del EIA del proyecto Pucamarca.
} 
indagar acerca de las condiciones en que debieran llevarse a cabo las instancias legal-ambientales del proyecto» (SRK, 2004, p. 192).

De otro lado, el EIA sobre el territorio chileno fue elaborado por AMEC en el año 2007 -la misma consultora que realizó el EIA sobre territorio peruano-. Este instrumento tuvo como objetivo identificar y evaluar los impactos ambientales potenciales del Proyecto Pucamarca sobre territorio chileno (AMEC, 2007, p. 1). Para esto, se analizó el marco legal aplicable, efectuándose comparaciones entre el marco legal chileno y el peruano; se desarrolló un análisis del clima, suelos, hidrografías, formaciones vegetales y fauna terrestre, de los aspectos socioeconómicos y de los aspectos arqueológicos. Asimismo, se identificaron y evaluaron los impactos potenciales, tanto ambientales como sociales; se propuso un Plan de Manejo Ambiental; $y$, finalmente, se hicieron recomendaciones en materia de calidad ambiental, biológica y socioeconómica.

Si bien Minsur dio un gran paso en llevar a cabo estos estudios, del análisis de la información proveída por el MEM no se pudo observar si los órganos especializados chilenos revisaron estos documentos, si tuvieron observaciones o no, ni si hubo o no respuestas oficiales o consultas oficiales enviadas posteriormente por el gobierno chileno a Minsur o al Estado peruano. Tampoco se pudo apreciar si se realizaron audiencias con la población chilena ${ }^{13}$, por más que en el EIA se indicó que la distancia entre el proyecto y las poblaciones en el territorio chileno era menor que la de los proyectos ubicados en el territorio peruano (AMEC, 2007, pp. 1-4) y se recomendó «Informar, por diversos medios a las potenciales comunidades afectadas en el territorio chileno, los procedimientos, características y detalles del proyecto en las que se enfatice en el manejo responsable de los recursos, como el agua» (AMEC, 2007, pp. 8-12).

Es importante destacar que el hecho de que se hayan llevado a cabo estos estudios demuestra que por más que la legislación peruana no regule ni exija de manera expresa la necesidad de llevar a cabo estas EA transfronterizas, actualmente existen proyectos que necesitan de estos estudios y, por ende, de lineamientos para elaborarlos. Esto demuestra que no solo se tiene una obligación internacional de llevar a cabo estos estudios, sino que, además, existe una real necesidad de los proyectos y de los países de elaborar estos estudios. La interacción con diversas autoridades, los tiempos, los procesos de notificación y consulta, entre otros, son aspectos que deben contar con regulación

\footnotetext{
${ }^{13}$ En el EIA se indicó que no se realizaron rondas de talleres informativos en territorio chileno, por cuestión de competencia (AMEC, 2007, pp. 3-11).
} 
específica al respecto, y en el siguiente capítulo se procederá a esbozar una propuesta para esto.

\subsection{Conclusión}

Como primer punto, el presente capítulo demostró que la obligación consuetudinaria de llevar a cabo EA transfronterizas ya se encuentra incorporada en nuestro ordenamiento, debido a que el proceso de incorporación se da de manera automática. Esto quiere decir que, actualmente, esta obligación ya ha ingresado a nuestro ordenamiento y, por ende, ya es vinculante.

Sin embargo, también se indicó que si bien esta norma ya está incorporada, esta aún no se ha implementado plenamente en el sistema legislativo peruano. Esto se traduce en que aún es necesario que se aprueben y/o modifiquen las normas vinculadas al SEIA, a fin de que se regule de manera explícita la necesidad de llevar a cabo EA transfronterizas. Si no se realizan estas modificaciones, será muy difícil que los funcionarios puedan exigir la realización de estos estudios. Asimismo, cabe resaltar que el hecho de que el Perú aún no haya implementado esta obligación, se podría interpretar como un incumplimiento, lo que podría generarle consecuencias en el campo del derecho internacional.

Para llegar a la conclusión anterior, se analizaron diversas normas e instrumentos del sector ambiental, pero sobre todo diversas normas que conforman el SEIA, incluyéndose en el análisis a aquellas relativas a los EIA que se dieron antes de la creación de este sistema y que aún se encuentran vigentes en el sistema jurídico peruano.

Si bien la LGA y la Política Ambiental del Sector Turismo, aprobada por Resolución Ministerial 195-2006-Mincetur-DM, efectúan unas vagas referencias a la importancia de velar por el ambiente más allá de las fronteras del Estado peruano; y si bien las diversas normas vinculadas al SEIA no señalan que la EA deba circunscribirse únicamente al territorio peruano, lo cierto es que no existe ninguna norma en el Perú que haga referencia a la necesidad de llevar a cabo EA transfronterizas ni, menos aún, existen normas que regulen este proceso.

Sin perjuicio de lo anterior, el presente capítulo demostró que si bien en el Perú no existe una norma que regule de manera expresa la realización de EA transfronterizas, ya existe registro de un caso de evaluación de impactos sobre el territorio chileno por la ejecución de una actividad sobre territorio peruano. La mina Pucamarca, propiedad de la empresa Minsur, ubicada en Tacna, a 200 metros de la frontera con Chile, tuvo que elaborar una EIA del proyecto sobre el territorio chileno, debido, básicamente, a la presión de la población chilena. Este estudio fue compartido con las autoridades chilenas y también 
con el MEM; sin embargo, no se pudo comprobar si los órganos especializados chilenos revisaron estos documentos ni si tuvieron observaciones o no.

Lo anterior demuestra que la realidad de los diversos proyectos de inversión demanda que el Perú cuente con lineamientos para elaborar estudios de EA transfronteriza. La siguiente sección presenta una propuesta de cómo se podrían regular estos procesos en el Perú. 


\section{Propuesta de implementación de las EA transfronterizas en el Perú}

Como hemos señalado a lo largo de este trabajo, existe una obligación de realizar EA transfronterizas. Sin embargo, la estructura procedimental y el contenido de esta obligación aún no se han determinado en el marco internacional. Asimismo, en el capítulo anterior, hemos precisado que existe una obligación para el Perú de incorporar e implementar dicha obligación en su sistema nacional. Al tratarse de una norma consuetudinaria, esta se encuentra automáticamente incorporada en el sistema legal peruano. Sin embargo, esta aún no ha sido implementada.

De igual manera, se precisó que, en el derecho internacional, no existe ninguna regulación específica sobre cómo debería ser el proceso de implementación, dejándose al derecho interno de los Estados completa libertad para decidir cómo y cuándo implementar la obligación, con la única limitación de no restringir el contenido o el alcance de la obligación internacional asumida.

En consecuencia, al tratarse de una obligación consuetudinaria, el escenario ideal de implementación de esta obligación sería, primero, formar parte de un tratado con los países limítrofes. Esto permitiría establecer estándares mínimos en cuanto a la estructura del procedimiento y el contenido de la obligación. El siguiente paso, con base en dicho tratado, sería proceder a desarrollar la obligación en la legislación nacional. Al respecto, este ha sido el procedimiento que se ha seguido en Europa, a raíz de la firma del Convenio Espoo.

Sin embargo, pareciera que el proceso de implementación en Sudamérica se está dando de manera inversa al proceso seguido en Europa. Países como Colombia, Bolivia, Brasil y Paraguay han implementado en sus legislaciones 
esta obligación internacional, sin ser miembros de algún tratado sobre la materia. Al respecto, este es el procedimiento que consideramos que el Perú debería seguir, al no existir hasta la fecha ningún intento concreto de elaborar o adherirse a un tratado sobre la materia, con los países vecinos.

Sin perjuicio de esta última idea, a continuación desarrollaremos las dos posibles formas de implementación de esta obligación. La primera forma hace referencia al escenario ideal, que consiste en la idea de primero formar parte de un tratado y, luego, desarrollar las normas nacionales; y la segunda forma se refiere al escenario real, que consiste en implementar directamente la obligación en el sistema nacional.

\subsection{Escenario ideal: primero tratado, luego desarrollo de legislación nacional}

\subsubsection{La importancia del tratado}

Los procesos de EA transfronterizas buscan, en los casos en que es posible la ocurrencia de impactos transfronterizos, integrar dichos impactos y a las poblaciones transfronterizas en el funcionamiento de los procesos nacionales de EA (Marsden \& Koivurova, 2011, pp. 15-16). Es decir, lo que se busca, a través de estos procesos, es incluir los aspectos transfronterizos dentro de los procesos internos de EA de los Estados (Marsden \& Koivurova, 2011, pp. 15-16).

De igual manera, cabe destacar que las EA transfronterizas no las realiza un organismo independiente creado por los Estados de origen y los Estados afectados, sino que se trata de un procedimiento internacional, que se analiza y se lleva a cabo en el mismo Estado que genera la necesidad de la existencia de dicho procedimiento. Ergo, al tratarse de una relación entre como mínimo dos Estados, donde se imponen derechos y deberes tanto al Estado de origen como a los Estados afectados, la mejor manera de regularla es a través de la existencia de un tratado (Marsden \& Koivurova, 2011, pp. 15-16).

En relación con esta idea, es importante precisar lo señalado en el principio 12 de la Declaración de Río:

PRINCIPIO 12

[...] Se debería evitar tomar medidas unilaterales para solucionar los problemas ambientales que se producen fuera de la jurisdicción del país importador. Las medidas destinadas a tratar los problemas ambientales transfronterizos o mundiales 
deberían, en la medida de lo posible, basarse en un consenso internacional.

$\mathrm{Al}$ respecto, desde un punto de vista funcional, el tratado más exitoso sería aquel que lograse que todos los Estados contratantes tengan un proceso de EA transfronterizo idéntico (Marsden \& Koivurova, 2011, p. 16). Sin embargo, tratar de homogenizar todos los procedimientos de EA de los Estados resulta una tarea bastante compleja, si no imposible de realizar, puesto que la mayoría de los países ya cuentan con procedimientos de EA debidamente implementados e institucionalizados.

En consecuencia, si bien un tratado no puede llevar a cabo la tarea de homogenizar todos los procedimientos, lo que sí puede lograr es establecer mínimos, tanto en relación con la estructura procedimental como con el contenido de la obligación. Esto no implicaría la realización de cambios sustanciales en los sistemas nacionales de los Estados y, además, permitiría que los procesos de EA transfronteriza se den con menores costos de transacción.

Haciendo hincapié en la estructura procedimental, el tratado también permitiría estandarizar los aspectos más generales de esta, sobre todo los relacionados con el proceso de notificación y consulta, los cuales requieren una gran interacción entre los Estados y, por ende, necesitan de lineamientos claros por seguir.

En relación con las actividades por ser sometidas a los procesos de EA transfronteriza, un tratado permitiría que, a través de este, los Estados se pongan de acuerdo sobre qué actividades deben ser sometidas necesariamente a esta evaluación, y también permitiría establecer los procesos por seguir para incluir o excluir actividades.

En consecuencia, todo lo anteriormente señalado permitiría generar seguridad entre los Estados contratantes, entre los titulares de proyectos y en las poblaciones afectadas, así como reducir conflictos, como el sucedido entre Argentina y Uruguay en relación con las Plantas de Celulosa, en el que uno de los puntos que cuestionó Argentina fue, justamente, la manera como se llevó a cabo la EA. De igual manera, como señalan Marsden y Koivurova, con la previa existencia de un tratado, «el Estado potencialmente afectado y su población sabrían cuándo y cómo participar en el procedimiento de EA realizado de conformidad con el procedimiento de EA del estado de origen ${ }^{1}$.

\footnotetext{
${ }^{1}$ Texto original en inglés: «the potentially affected state and its public would know when and how to participate in the EIA procedure taking place in accordance with the EIA procedure of the origin state» (Marsden \& Koivurova, 2011, p. 3).
} 
Habiendo establecido la importancia de la existencia de un tratado sobre la materia, a continuación pasaremos analizar la conveniencia de (i) adherirse al Convenio Espoo o (ii) impulsar la elaboración de un acuerdo regional. Una vez señaladas ambas opciones, procederemos a precisar los beneficios de proceder a legislar en los sistemas nacionales con base en la existencia previa de un tratado.

\subsubsection{Adhesión al Convenio Espoo o elaboración de un nuevo convenio}

\subsubsection{Convenio Espoo}

Una vez identificados los beneficios que supone la previa existencia de un tratado, la siguiente cuestión por analizar es la conveniencia de adherirse a un convenio ya existente, específicamente al Convenio Espoo, o proceder a la elaboración de un nuevo tratado regional sobre la materia.

En esta sección, analizaremos la conveniencia de adherirse al Convenio Espoo y también evaluaremos de qué manera este logra estandarizar los aspectos vinculados a las EA transfronterizas entre sus países miembros.

Para comenzar, es importante recordar que el Convenio Espoo fue adoptado en el año 1991 en Espoo, Finlandia, y entró en vigor el 10 de septiembre de 1997. Posteriormente, en el año 2001, en Sofía, Bulgaria, a través de la Decisión II/14, se modificó el Convenio Espoo con la finalidad de que cualquier Estado que sea miembro de la ONU pueda formar parte del mismo, con la previa aprobación de la Conferencia de las Partes. Esta adenda aún no ha surtido efectos, debido a que no ha sido ratificada por todos los países que formaron parte de la Convención del año 2001. Es decir, a la fecha de elaboración del presente trabajo, los países que no forman parte de la Unece aún no pueden adherirse al Convenio Espoo.

Sin perjuicio de lo anteriormente señalado, es un hecho que esta modificación al Convenio Espoo surtirá efectos y, en consecuencia, cualquier Estado miembro de la ONU podrá aherirse, incluido el Perú.

La adhesión al Convenio Espoo presenta una serie de ventajas. Para comenzar, es el instrumento vinculante líder en EA transfronterizas (Marsden $\&$ Koivurova, 2011, p. 10). Ha sido ratificado por 45 países no solo de Europa, sino también de Norteamérica y Asia Central (Marsden \& Koivurova, 2011, p. 10), por lo que cuenta con una gran cantidad de miembros que ya utilizan los estándares establecidos por él. En relación con esto, Marsden y Koivurova destacan:

Si los Estados realmente desean hacer cumplir sus obligaciones consuetudinarias de EAT, parece bastante obvio que 
deberían hacer uso de las normas para EAT reguladas en el Convenio Espoo. Este cumplimiento también se aplica a los bancos multilaterales de desarrollo y comercio cuando realizan préstamos para proyectos que puedan generar impactos negativos significativos transfronterizos ${ }^{2}$.

En segundo lugar, el Convenio Espoo es un convenio marco que establece mínimos y que no impide la regulación de medidas más rigurosas a través de acuerdos bilaterales u otros acuerdos multilaterales entre los Estados Parte (1991, artículo 2, inciso 9).

Ahora bien, en relación con la importancia de que los tratados identifiquen previamente las actividades por ser sometidas a los procesos de EA transfronterizos, el Convenio Espoo resuelve esta situación de dos maneras. En primer lugar, define qué se entiende por «actividad propuesta» e «impacto transfronterizo"; y, en segundo lugar, establece una lista, en su apéndice I, de las actividades susceptibles de causar impactos transfronterizos significativos. De esta manera, todas las partes contratantes tienen claridad sobre cuáles son las actividades que necesariamente deberán ser sometidas al proceso.

Haciendo referencia a la estandarización del procedimiento, una característica de gran relevancia del Convenio Espoo es que no solo ha logrado estandarizar el procedimiento de EA transfronteriza para todos sus países miembros, sino que, además, ha desarrollado de una manera muy detallada los aspectos procedimentales de notificación, evaluación, consulta y monitoreo posterior (Knox, 2003 p. 162). Al respecto, es importante precisar que estos aspectos procedimentales se elaboraron tomando como referencia las normas de los sistemas nacionales de los países signatarios más desarrollados -los países miembros de la UE, Canadá y los EE. UU.- (Knox, 2003 p. 162), por lo que se trata de estándares procedimentales bastante altos.

En relación con el contenido de la obligación, el Convenio Espoo, en su apéndice II, establece la documentación mínima que la EA deberá incluir, es decir, las cuestiones mínimas que los Estados deben evaluar. $\mathrm{Al}$ respecto, es importante notar que si bien se establecen -entre otras cuestiones- la obligación de describir las actividades que se realizarán y las alternativas y los posibles impactos que se generarán, no se estable cómo se tiene que realizar

\footnotetext{
2 Texto original en inglés: «If states are serious about observing their customary law TEIA obligations, it seems fairly obvious that they should make use of the standards of the Espoo Convention for TEIA - an observation that applies also to multilateral development and commercial banks when they grant loans for projects likely to have significant adverse transboundary impacts» (Marsden \& Koivurova, 2011, p. 30-31).
} 
esto, ni la metodología que se debe seguir, dejándose estos aspectos a los sistemas nacionales de los Estados.

Como se puede apreciar, el Convenio Espoo reúne varios aspectos positivos que permiten considerarlo como el posible tratado encargado de regular la relación del Perú con sus países vecinos. Ahora bien, es importante notar que no sería de gran utilidad para el Perú adherirse al Convenio Espoo si sus países vecinos no lo hacen. Asimismo, es importante resaltar que la adhesión del Perú a este instrumento no acarrea necesariamente la adhesión a este por parte de sus países vecinos. En ese sentido, de encontrarse el Perú interesado en formar parte del Convenio Espoo, un primer paso importante por efectuar sería evaluar el interés de los países vecinos en formar parte de dicho instrumento.

Respecto a esta última idea, cabe precisar el hecho de que posiblemente Brasil sea uno de los primeros países en mostrarse interesados en ratificar el Convenio Espoo, debido a que comparte frontera con la Guayana Francesa, una región de Francia constituida en departamento de ultramar. En consecuencia, al tratarse de un departamento que pertenece a Francia y al ser este un país que ha ratificado el Convenio Espoo, Francia podría aplicar el Convenio a algún proyecto que se realice en la frontera entre Brasil y la Guayana Francesa.

De otro lado, también es importante resaltar el hecho de que para el Perú ${ }^{3}$ y sus países vecinos, los estándares de este procedimiento de EA transfronteriza serían más altos que los estándares de EA para su ámbito nacional. En relación con esto, los Estados tendrían dos caminos por seguir: «(a) adoptar requisitos de EA más estrictos para aquellos proyectos que tengan efectos transfronterizos que para aquellos con efectos únicamente nacionales, lo cual es bastante difícil o imposible en términos políticos; o (b) elevar los estándares para las EA nacionales, lo cual podría ser extremadamente caro» ${ }^{4}$.

$\mathrm{Al}$ respecto, es importante notar que en Europa los países miembros del Convenio Espoo optaron por la segunda alternativa. Como señala Knox: «al facilitar la capacidad para utilizar el Convenio Espoo como un modelo por seguir para mejorar los sistemas nacionales de EA, los países miembros del Convenio Espoo han alentado a los países europeos, con economías en transición, a elegir

\footnotetext{
${ }^{3}$ Es importante resaltar que en el Perú existe el principio de jerarquía de la mitigación, lo que significa que en primer lugar se deben adoptar medidas para eliminar los impactos, después para prevenir los impactos, luego para controlarlos, después para mitigarlos, luego para rehabilitarnos y finalmente para compensarlos. El Convenio Espoo no establece medidas de rehabilitación ni compensación, por lo que, si se optara por firmarlo, la rehabilitación y la compensación tendrían que ser eliminadas de la legislación nacional, al ser estándares menores que los establecidos en el Convenio.

${ }^{4}$ Texto original en inglés: «(a) to adopt stricter EIA requirements for transboundary effects than for domestic effects, which might be difficult or impossible politically; or (b) to raise their domestic EIA standards, which might be prohibitively expensive» (Knox, 2003, p. 165).
} 
la segunda opción " ${ }^{5}$. En consecuencia, así como sucedió con los países europeos menos desarrollados, dicho Convenio también "podría cumplir un rol similar con respecto a otros países que buscan mejorar sus sistemas nacionales de EA ${ }^{6}$.

\subsubsection{Elaboración de un nuevo convenio}

Si bien existen varios puntos a favor de la opción de ratificación del Convenio Espoo, soy de la opinión que existen dos razones de singular peso por las que se debería considerar proceder a la elaboración de un nuevo tratado.

La primera está referida a que el Convenio Espoo no regula la realización de proyectos complejos en los que existan más de un Estado de origen o más de un Estado afectado (situación que se evidenció con la construcción del gaseoducto en el mar Báltico, donde había cuatro Estados de origen y nueve Estados afectados); y la segunda está referida a que todavía no se tiene certeza de cuándo los países no miembros de la Unece podrían formar parte del Convenio Espoo. A 14 años de la enmienda de Sofía, solo 26 de los 45 países la han ratificado, quedando pendiente la ratificación por parte de 19 Estados.

Adicionalmente a lo anterior, con base en la experiencia sobre cómo se está procediendo en la región para el desarrollo de la Convención Internacional sobre Democracia Ambiental, se podría deducir que los Estados latinoamericanos preferirían elaborar su propio tratado sobre la materia. Al respecto, los países tenían la opción de ratificar el Convenio Aarhus, pero prefirieron elaborar uno nuevo, pues consideraron que las características de la región sudamericana diferían de las de la europea, al ser más necesarios los recursos naturales para el desarrollo de las economías en América Latina que en Europa (Huerta, 2013).

Como consecuencia de lo anterior, otra de las posibles opciones por seguir sería impulsar la elaboración de un tratado regional. Al respecto, una primera opción sería analizar la posibilidad de impulsar este nuevo Convenio desde la Organización de los Estados Americanos (OEA). La OEA está conformada por 35 Estados independientes, entre los que se encuentran el Perú y todos sus países vecinos. La elaboración de un tratado sobre EA transfronterizas en el marco de la OEA tendría como sustento la Declaración de Panamá sobre la Contribución Interamericana al Desarrollo y Codificación del Derecho Internacional [AG/DEC. 12 (XXVI-O/96)], así como el Programa Interamericano

\footnotetext{
${ }^{5}$ Texto original en inglés: «By facilitating their ability to use the Espoo Convention as a model for improving their domestic EIA systems, the Espoo Parties have encouraged European countries with transitional economies to choose the second option" (Knox, 2003, p. 165).

${ }^{6}$ Texto original en inglés: « [...] could play a similar role with respect to other countries looking to improve their domestic EIA systems» (Knox, 2003, p. 165).
} 
para el Desarrollo del Derecho Internacional [AG/RES. 1471 (XXVII-O/97)]. Ambos instrumentos hacen referencia a las facultades codificadoras de la OEA.

Una segunda opción sería impulsar la elaboración de un Convenio desde la Oficina Regional para América Latina y el Caribe (Orpalc) del PNUMA. El PNUMA fue establecido en el ańo 1972 y es el principal órgano de la ONU en la esfera del medio ambiente (Declaración de Nairobi, 1997, artículo 1). El artículo 3 b) de la Declaración de Nairobi de 1997, que hace referencia al fomento del desarrollo del régimen jurídico ambiental internacional, podría servir como sustento para la elaboración de este Convenio.

Otra opción de carácter más regional sería buscar impulsar un tratado desde la Unión de Naciones Suramericanas (Unasur). Este organismo internacional está conformado por 12 países de la región suramericana, entre los que se encuentran el Perú y sus vecinos. El artículo 3, inciso g), del Tratado Constitutivo de la Unasur establece que uno de los objetivos de esta organización es «La protección de la biodiversidad, los recursos hídricos y los ecosistemas [...]», por lo que en el marco de este artículo se podría impulsar la elaboración de un tratado sobre la materia.

Una cuarta opción se podría lograr a través de la Asociación Latinoamericana de Integración (Aladi). De acuerdo con el Tratado de Montevideo de 1980, marco jurídico global constitutivo y regulador de la Aladi, tanto los acuerdos regionales como los de alcance parcial que se promuevan pueden abarcar, entre otras materias, la preservación del medio ambiente (Aladi, 1980, artículos 6-9). En consecuencia, este convenio podría ser el sustento para la elaboración de un tratado sobre EA transfronterizas.

Otro sistema de integración regional que podría utilizarse es el Sistema Económico Latinoamericano y del Caribe (SELA), un organismo regional intergubernamental creado en 1975 mediante el Convenio Constitutivo de Panamá. El artículo 5, inciso 1.k, de dicho convenio establece que uno de los objetivos del SELA es estimular la cooperación para la protección, conservación y mejoramiento del medio ambiente, con lo cual la elaboración de un tratado sobre EA transfronterizas calzaría dentro de los objetivos del organismo. Ahora bien, cabe indicar que, en comparación con la Aladi, la negociación para un tratado sobre EA transfronterizas en el SELA podría ser más complicada, al existir en este sistema un mayor número de Estados Parte que no comparten fronteras entre sí.

Una opción adicional sería analizar la posibilidad de impulsar este instrumento desde la Comunidad Andina; sin embargo, a través de esta OI solo se estaría logrando tener un acuerdo con Bolivia, Colombia y Ecuador, mas no 
con Brasil ni Chile, países con los que el Perú también comparte frontera. Sin perjuicio de lo anterior, es importante resaltar que en la Comunidad Andina, si bien la idea de elaboración de un acuerdo transfronterizo aún no se ha materializado, en el año 2006, en la Agenda Ambiental Andina, se consideró como tema que ameritaba mayor análisis y debate, antes de pasar a ser parte de la Agenda Operativa, la acción de desarrollar «Lineamientos de política para decisión andina sobre evaluación de impacto ambiental transfronteriza en actividades y proyectos que comprendan dos o más países andinos» (CAN, 2007).

Finalmente, también podría considerarse la posibilidad de impulsar este tratado a través de la Organización del Tratado de Cooperación Amazónica (OTCA). Sin embargo, a través de esta organización no se podría llegar a involucrar a Chile, y únicamente se podrían considerar los proyectos que se realicen en la Amazonía.

De otro lado, más allá de lo anteriormente señalado, es importante analizar cómo se debería regular la estructura procedimental y el contenido de la obligación de llevar a cabo EA transfronterizas. En relación con esto, lo que debería buscar el acuerdo es estandarizar lo más que se pueda dichos aspectos -como ya se ha señalado con anterioridad- tomando como referencia al Convenio Espoo. De igual manera, es importante precisar que la UICN elaboró una posible estructura para un acuerdo en materia de EA transfronteriza para Centroamérica, la cual sin lugar a dudas también podría servir como referencia para la elaboración de un tratado en Sudamérica ${ }^{7}$.

Adicionalmente a todo lo anteriormente señalado, es importante destacar que la elaboración de un nuevo acuerdo podría, incluso, ser más beneficiosa para la región que buscar la adhesión al Convenio Espoo. Hago esta precisión debido a que existe la posibilidad de que los estándares establecidos por el Convenio Espoo resulten muy elevados para los países sudamericanos, haciendo que en algunos casos sea incluso imposible cumplir con ellos. En contraposición, un nuevo acuerdo podría establecer estándares más adecuados para la región.

\footnotetext{
${ }^{7}$ Dicha estructura de acuerdo se encuentra contenida en el siguiente documento de trabajo: Evaluación de impacto ambiental transfronteriza en Centroamérica: lineamientos generales (UICN, 2006).

${ }^{8}$ Como se señaló en la nota al pie de página 3, el Convenio Espoo no establece medidas de rehabilitación ni compensación -la legislación peruana sí lo hace- por lo que, si se optara por firmar este convenio, la rehabilitación y la compensación tendrían que ser eliminadas de la legislación nacional, al ser estándares menores que los establecidos por dicho convenio.
} 


\subsubsection{Desarrollo de legislación a partir de un tratado}

Como ya hemos expresado, el procedimiento de EA transfronteriza es un proceso que busca incluir los impactos transfronterizos en los sistemas nacionales de los Estados, por lo que, si bien la existencia de los tratados es relevante, si esta obligación no es implementada en las legislaciones nacionales, no es posible que esta se pueda cumplir. Este es un aspecto adicional que el Convenio Espoo no deja de lado, y al respecto Marsden y Koivurova destacan lo siguiente: «para que este procedimiento funcione de manera eficaz, el Convenio Espoo obliga a los estados miembros a establecer procedimientos nacionales y/o subnacionales de EA que permitan la integración de los impactos transfronterizos y los actores extranjeros»?.

Al existir un tratado marco que regula la relación entre los Estados de origen y los Estados afectados, el desarrollo de la legislación interna se pueda dar con mayor facilidad, pues existen claros parámetros sobre los cuales guiarse.

\subsection{Escenario real: implementación directa}

Si bien hemos expuesto que el escenario óptimo es aquel en el que primero existe un tratado que establece los lineamientos claros que deben seguir los países y luego se desarrolla la legislación nacional, también es posible que se implemente la obligación sin la previa existencia de un tratado, como está sucediendo en ciertos países sudamericanos. Al respecto, Marsden y Koivurova señalan: «en las zonas donde no se aplican dichos acuerdos, las EAT se han ido implementando a través de la aplicación de la legislación nacional de EA a las actividades con posibilidad de generar impactos significativos transfronterizos importantes ${ }^{10}$.

Como consecuencia de lo anterior, los mismos autores indican:

Los Estados que actualmente están aplicando su legislación nacional de EA a las actividades con potencial de generar impactos transfronterizos en una región determinada pueden, en un momento determinado en el tiempo, decidir armonizar sus prácticas a través de la adopción de un acuerdo de EAT con lineamientos para esa región en particular, o, en todo

\footnotetext{
${ }^{9}$ Texto original en inglés: «In order for this procedure to function effectively, the Espoo Convention requires the states parties to establish national and/or sub-national EIA procedures that allow for the integration of foreign impacts and foreign actors» (Marsden \& Koivurova, 2011, p. 19).

${ }^{10}$ Texto original en inglés: «In areas where such agreements do not apply, TEIA has increasingly been implemented through the application of national EIA legislation to activities with potential significant transboundary impacts» (Marsden \& Koivurova, 2011, p. 29).
} 
caso, pueden optar por adherirse a un acuerdo sobre EAT ya existente, como por ejemplo el Convenio Espoo ${ }^{11}$.

En Sudamérica, todo indica que el proceso de regulación de EA transfronterizas se dará a la inversa de Europa, pues los países están comenzando a desarrollar en sus legislaciones nacionales los procedimientos de EA transfronteriza para luego, al parecer, buscar homogenizar sus prácticas a través de un tratado.

Neil Craik, en relación con la posibilidad de afrontar los problemas ambientales directamente por medio de los sistemas nacionales, ha señalado lo siguiente: «[...] para los casos en los cuales los temas ambientales pueden ser abordados exitosamente de manera unilateral, existe menos justificación para impulsar el desarrollo de normas internacionales» ${ }^{12}$. Y, en esta misma línea, Peter Sand ha señalado:

En lugar de internacionalizar un asunto local [...], en la mayoría de los casos, una solución más económica sería adaptar los procesos de toma de decisiones locales para que estos puedan manejar los problemas transfronterizos como si fuesen problemas locales ordinarios de tamańo similar ${ }^{13}$.

\subsubsection{Países con implementación directa}

En Sudamérica, Colombia, Bolivia, Brasil, Paraguay y Surinam ${ }^{14}$ han implementado en sus sistemas nacionales, de distintas maneras y con diferentes niveles de precisión, la obligación de evaluar los posibles impactos transfronterizos.

Colombia fue el primer país en Sudamérica en hacer referencia a la necesidad de adoptar medidas para que no se causen perjuicios a otros países, así como también medidas referentes a la necesidad de notificar sobre los posibles impactos transfronterizos que un proyecto pudiera generar. Estos aspectos se

\footnotetext{
${ }^{11}$ Texto original en inglés: «States that are currently applying national EIA law to activities with potential transboundary impact in a certain region may, at a certain moment in time, decide to harmonize their practices by the adoption of a TEIA agreement of guidelines for that particular region, or to become part of an already existing TEIA agreement, such as the Espoo Convention» (Marsden \& Koivurova, 2011, p. 30). ${ }^{12}$ Texto original en inglés: «[...] where environmental issues can be successfully addressed unilaterally, there is less justification for the development of international rules» (Craik, 2010, p. 45).

${ }^{13}$ Texto original en inglés: «Instead of internationalizing a local issue [...], a more economic solution in most cases would be to adapt local decision-making processes so that they can handle transfrontier problems like ordinary local ones of comparable size» (Sand, 1977, pp. 146-159).

${ }^{14}$ Para llegar a esta conclusión se analizó la legislación de todos los países sudamericanos. Chile: Ley 19300, D. S. 40, Ley 20417; Bolivia: Ley 1333, Reglamento General de Gestión Ambiental, Reglamento de Prevención y Control Ambiental; Colombia: Ley 99, Decreto 2041-2014, Decreto 2811; Ecuador: R. O. 418, Decreto Ejecutivo 3399; Argentina: Ley Nacional 25.675; Uruguay: Ley 16.466, Ley 17.283, Decreto 349/05; Paraguay: Ley 294/1993, Decreto 453/2013; Venezuela: Ley Orgánica del Ambiente, Decreto 1257; Guyana: Environmental Protection Act Chapter 20:05; Surinam: Environmental Assessment Guidelines Volume I; Guayana Francesa: Loi 76-629, Décret 77-1141; Brasil: Resolución Conama 237/97.
} 
encuentran regulados por la parte II del Decreto 2811 de 1974, norma que dicta el Código Nacional de Recursos Naturales Renovables y de Protección al Medio Ambiente. $\mathrm{Al}$ respecto, en dicha sección se establece lo siguiente:

PARTE II

\section{DE LOS ASUNTOS AMBIENTALES DE ÁMBITO O IN- FLUENCIA INTERNACIONALES}

Artículo $10^{\circ}$.- Para prevenir o solucionar los problemas ambientales y regular la utilización de recursos naturales renovables compartidos con países limítrofes y sin perjuicio de los tratados vigentes, el Gobierno procurará complementar las estipulaciones existentes o negociar otros que prevean:

a) El recíproco y permanente intercambio de informaciones necesarias para el planeamiento del desarrollo y el uso óptimo de dichos recursos y elementos;

b) La recíproca y previa comunicación de las alteraciones o desequilibrios ambientales que puedan originar obras o trabajos proyectados por los Gobiernos o los habitantes de los respectivos países, con antelación suficiente para que dichos Gobiernos puedan emprender las acciones pertinentes cuando consideren que sus derechos e intereses ambientales pueden sufrir menoscabo;

c) La administración conjunta de los Gobiernos en los recursos naturales renovables cuya explotación o aprovechamiento no pueda ser físicamente divisible entre los países interesados, o que del punto de vista técnico o económico no resulte conveniente dividir;

d) La adopción de medidas para que no cause perjuicios sensibles a otros países el uso puramente interno de los recursos naturales no renovables u otros elementos ambientales, hecho en Colombia, o en naciones vecinas.

Artículo $11^{\circ}$.- Los recursos naturales materia de las previsiones a que se refiere el artículo precedente son, entre otros, los siguientes:

a) Las cuencas hidrográficas de ríos que sirvan de límite o que atraviesan las fronteras de Colombia, incluidas las aguas 
superficiales y subterráneas y los demás cursos naturales conexos;

b) Los bosques de ambos lados de una frontera;

c) Las especies de la fauna en que tengan interés común Colombia y los países vecinos;

d) Las aguas marítimas Nacionales y los elementos que ellas contienen;

e) La atmósfera, en cuanto los actos ya verificados o los proyectados en un país puedan producir efectos nocivos en el vecino o alteraciones climáticas perjudiciales;

f) Los yacimientos geotérmicos que se extienden a ambos lados de una frontera.

Artículo $12^{\circ}$

El Gobierno procurará evitar o prohibirá la utilización de elementos ambientales y recursos naturales renovables que puedan producir deterioro ambiental en países no vecinos, en alta mar o en su lecho, o en la atmósfera o espacio aéreo más allá de la jurisdicción territorial.

El Gobierno también procurará realizar gestiones para obtener que, en circunstancias similares, otros países adopten actitud semejante.

Como se puede apreciar, si bien Colombia no hace una referencia directa a las EA transfronterizas, establece claramente una obligación para el gobierno colombiano de no afectar a otros países con sus actividades, indicando la necesidad de adoptar medidas para prevenir dichos impactos y de llevar a cabo procesos de intercambio de información.

Como se verá a continuación, en línea con la regulación colombiana se encuentran la paraguaya, la brasileña y la de Surinam.

En Paraguay, las EA están reguladas a través de la Ley 294/1993, Ley de Evaluación de Impacto Ambiental, y su reglamento el Decreto 453/2013 ${ }^{15}$.

\footnotetext{
${ }^{15}$ El Decreto 453/2013 derogó el Decreto 14.281/1996, el cual, en su capítulo VIII, compuesto por tres artículos, regulaba las evaluaciones de impactos ambientales con efectos transfronterizos. El nuevo reglamento no hace ninguna referencia a las EA transfronterizas. No se ha podido encontrar una explicación a por qué se eliminó la regulación a las EA transfronterizas en el nuevo reglamento. En el artículo 14 de las disposiciones finales y transitorias, se estableció que la Secretaría del Ambiente-SEAM- queda facultada a reglamentar todos los aspectos de evaluación de impacto ambiental que no se hayan contemplado expresamente en el Decreto; sin embargo, a la fecha de presentación del presente trabajo de investigación no se había publicado ninguna norma en relación con las EA transfronterizas.
} 
$\mathrm{Al}$ respecto, las referencias a las EA transfronterizas únicamente se encuentran en la ley, mas no en el reglamento. En ese sentido, el artículo 8 de la ley sanciona lo siguiente:

\section{Artículo 8.}

La Autoridad Administrativa pondrá a disposición del público y de los organismos afectados en el ámbito nacional, departamental y municipal, la Evaluación de Impacto Ambiental por los medios y el término a establecerse en las reglamentaciones de esta Ley. Se protegerán los derechos del secreto industrial y se asegurará un procedimiento que permita la consideración de las observaciones, denuncias e impugnaciones de datos efectuadas por los interesados. Cuando los Impactos negativos fueran susceptibles de producir efectos transfronterizos, la Autoridad Administrativa deberá informar al Ministerio de Relaciones Exteriores.

Como se puede apreciar, la referencia a las EA transfronterizas no es directa, pero se reconoce que estas pueden existir, y se busca regular este procedimiento transfronterizo a través del Ministerio de Relaciones Exteriores.

En Brasil, el Licenciamiento Ambiental está regulado, entre otras normas, por la Resolución Conama 237/97. El artículo 4 señala que una de las competencias del Ibama es el licenciamiento ambiental de, entre otras actividades, aquellas cuyos impactos ambientales traspasen los límites territoriales del país.

Art. $4^{\circ}$ - Compete ao Instituto Brasileiro do Meio Ambiente e dos Recursos Naturais Renováveis - IBAMA, órgão executor do SISNAMA, o licenciamento ambiental, a que se refere o artigo 10 da Lei $n^{\circ}$ 6.938, de 31 de agosto de 1981, de empreendimentos e atividades com significativo impacto ambiental de âmbito nacional ou regional, a saber:

\section{$[\ldots]$}

III - cujos impactos ambientais diretos ultrapassem os limites territoriais do País ou de um ou mais Estados;

$[\ldots]$.

Como se puede apreciar, en Brasil la referencia a la realización de EA transfronterizas tampoco se efectúa de manera directa. Sin embargo, si bien 
la referencia no es directa, esta igual ha sido utilizada como base legal para solicitar que en los EIA se incluya el análisis de los impactos transfronterizos. Ejemplo de esto es que, en marzo de 2007, ocho especialistas del Ibama emitieron una opinión técnica sobre el EIA del Complejo Hidroeléctrico de Río Madeira, en la cual, entre otros aspectos, recomendaban que se incluyeran los posibles impactos transfronterizos que dicho complejo tendría sobre el territorio boliviano (Hora 25, 2014).

Finalmente, en relación con Surinam, cabe destacar que hasta la fecha no existe un marco regulatorio específico en torno a las EA, sino lineamientos para la evaluación ambiental y social elaborados por el Nimos, cuya última versión data del año 2009. En el anexo 1 de este documento se regulan los lineamientos para la fase de screening y se establece un checklist de las preguntas para esta etapa. Una de las preguntas por considerar para esta etapa está relacionada con los impactos transfronterizos: «¿Existen impactos que transciendan la frontera o sean transfronterizos, que necesiten ser considerados? ${ }^{36}$ ". Como se puede observar, las referencias realizadas en Surinam sobre las EA transfronterizas son aún mucho menores que las realizadas en Colombia, Paraguay y Brasil. Sin embargo, lo que es importante de rescatar es que el concepto de evaluar impactos transfronterizos se encuentra presente en dicho país.

Ahora bien, a diferencia de Colombia, Paraguay, Brasil y Surinam, Bolivia sí hace referencia explícita a la necesidad de llevar a cabo EA que incluyan el análisis de los impactos transfronterizos. En dicho país, el marco regulatorio de las EA está conformado por la Ley 1333, Ley del Medio Ambiente del año 1992, el Reglamento General de Gestión Ambiental y el Reglamento de Prevención y Control Ambiental. Al respecto, el Reglamento General de Gestión Ambiental hace referencia a los impactos transfronterizos, como se puede apreciar a continuación:

ARTÍCULO 7o En el marco de lo establecido por la Ley del Medio Ambiente, Ley de Ministerios del Poder Ejecutivo y su Decreto Reglamentario, son atribuciones, funciones y competencias del Ministro de Desarrollo Sostenible y Medio Ambiente, a través de la SNRNMA, entre otras, las siguientes:

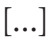

\footnotetext{
${ }^{16}$ Texto original en inglés: «Are there cross border or transboundary impacts, which need to be considered?».
} 
m) emitir criterio técnico cuando se susciten problemas transfronterizos internacionales en materia de medio ambiente y recursos naturales

$[\ldots]$

Por otro lado, el Reglamento de Prevención y Control Ambiental desarrolla la obligación de llevar a cabo EA transfronterizas. Para comenzar, en su artículo 4 se precisa lo siguiente:

ARTÍCULO 4o El Ministerio de Desarrollo Sostenible y Medio Ambiente (MDSMA), como autoridad nacional, tendrá competencia en todos los proyectos, obras o actividades que tengan impactos internacionales transfronterizos. Esta autoridad llevará a cabo los respectivos procedimientos técnico-administrativos, en caso de que surjan discrepancias respecto a procesos de Evaluación de Impacto Ambiental y de Control de Calidad Ambiental, sobre proyectos, obras o actividades, públicos o privados que estén a cargo de las Instancias Ambientales dependientes de los prefectos y que tengan por lo menos una de las siguientes características:

a) Estén ubicados geográficamente en más de un departamento.

b) La zona de posibles impactos pueda afectar a más de un departamento.

c) Se ubiquen o afecten áreas protegidas que integren el Sistema Nacional de Áreas Protegidas (SNAP) y sus zonas de influencia.

d) Igualmente será de competencia de la Autoridad Nacional la formulación de políticas, planes y programas que involucren a más de un departamento.

La sección más importante del reglamento es el título VIII, compuesto por un único capítulo y dos artículos, ya que es la sección que realmente regula el procedimiento de EA de los impactos transfronterizos:

TÍTULO VIII

DE LOS IMPACTOS TRANSFRONTERIZOS

CAPÍTULO ÚNICO 
ARTÍCULO 1670 Si un proyecto, obra o actividad se localiza en las zonas fronterizas del país y ocasione o pudiera ocasionar impactos o riesgo inminente sobre el ambiente de un Estado vecino, así como sobre recursos naturales compartidos con otros Estados, el REPRESENTANTE LEGAL debe considerar esas circunstancias en el EEIA.

Conforme a los principios del Derecho Internacional, cuando exista Convenio de Reciprocidad, el MDSMA, a través del Ministerio de Relaciones Exteriores y Culto, informará al o los Estados que puedan ser afectados por la implementación, operación o abandono de proyectos, obras o actividades, de los resultados de EEIA's y AA's que se efectúen con el fin de conocer los impactos potenciales y efectos actuales que los afecten o puedan afectar.

Toda transmisión de información al respecto entre países vecinos o fronterizos, debe guardar la confidencialidad correspondiente.

ARTÍCULO $168^{\circ}$ En ausencia de tratados de cooperación sobre el control de la calidad ambiental en áreas fronterizas, deberá mantenerse el principio de la comunidad para el aprovechamiento de áreas forestales, áreas protegidas, áreas de desarrollo y otros.

Como se puede apreciar, Bolivia sí realiza una referencia directa a la necesidad de llevar a cabo EA transfronterizas y, al respecto, prácticamente ha implementado su obligación a través de dos artículos de su reglamento.

Si bien todos los países anteriormente señalados han desarrollado en sus legislaciones de alguna u otra manera la implementación de la obligación de realizar EA transfronterizas, y si bien Bolivia es el país que posee la legislación más avanzada, consideramos que las referencias realizadas en las legislaciones a las EA transfronterizas son insuficientes. Realizar EA transfronterizas es una tarea de gran complejidad que no puede ser resuelta a través de la existencia de tres o cuatro artículos en una sola norma.

En ese sentido, tomando como referencia la legislación de los mencionados países, a continuación desarrollaremos nuestra recomendaciones de modificación a la legislación peruana, a fin de que se pueda considerar que esta sí implementa la realización de EA transfronterizas. 


\subsubsection{Recomendaciones para adecuar la legislación peruana a la obligación internacional de realizar EA transfronterizas}

Esta sección plantea las adecuaciones que se sugiere deberían realizarse tanto a la Ley como al Reglamento del SEIA, a fin de que se pueda considerar que el Perú ha implementado en su sistema la obligación de llevar a cabo EA transfronterizas. Con base en las modificaciones que se proponen en la presente sección, los distintos ministerios deberían proceder a adecuar sus respectivos reglamentos.

Para desarrollar esta sección, lo que haremos será tomar como referencia la estructura de las EA transfronterizas desarrollada en el capítulo 2 y compararla con la estructura del proceso de EA regulado en las normas peruanas, descrito en el capítulo 3.

\subsubsection{Screening}

En los capítulos 1 y 2 concluimos que el requisito general para llevar a cabo EA transfronterizas es que existan actividades que: (i) generen impactos negativos; (ii) sean generadas por actividades humanas; (iii) exista causalidad entre la actividad y los impactos; (iv) sean de carácter significativo; y (v) exista un Estado transfronterizo afectado.

De otro lado, en el capítulo 3 se indicó que en el Perú se solicitaban EA para los impactos leves, moderados y significativos. Sin embargo, el nivel de detalle de la EA dependía del nivel de los impactos; es así que cuando se estaba frente a impactos significativos, se solicitaba la realización de un EIA detallado.

En consecuencia, a fin de estar alineados con el marco internacional en la fase de screening, únicamente se tendrían que modificar aquellos artículos que hacen referencia a los impactos «significativos» y a los EIA-d. Lo que se debe buscar con la modificación es regular que para aquellos casos en los que se puedan generar impactos ambientales negativos significativos y exista la posibilidad de que se puedan generar impactos transfronterizos, se establezca la necesidad de llevar a cabo EA transfronterizas.

En ese sentido, para cumplir con esta parte de la obligación, se deberían modificar los artículos 2 y 4c de la Ley del SEIA y los artículos 2, 18, 20, 36, del Reglamento. Asimismo, se debería indicar que las actividades señaladas en el anexo II del reglamento del SEIA, en caso puedan generar impactos ambientales transfronterizos, deberían ser sometidas a las EA transfronterizas.

Se debe agregar que habría que determinar cuándo se está ante la posible ocurrencia de un impacto transfronterizo. Una posible solución a esto sería indicar que cuando se está cerca de la frontera, por ejemplo, a unos $50 \mathrm{~km}$, o cuando exista la posibilidad de afectar un recurso natural compartido, y/o 
cuando el proyecto esté ubicado en ciertas zonas de la Amazonía, automáticamente se debería realizar una EA transfronteriza. Como consecuencia de lo anterior, se tendrían que modificar el artículo 5 de la Ley del SEIA y el artículo 37 y el anexo V del Reglamento del SEIA, a fin de que establezcan criterios de cuándo se está frente a la posible ocurrencia de impactos transfronterizos.

Por otro lado, haciendo referencia a la parte procedimental, cuando los proyectos estén ubicados en zonas como las descritas anteriormente, el titular del proyecto, en los diferentes documentos que se tienen que presentar en la solicitud, como la evaluación preliminar y la propuesta de términos de referencia, debería hacer mención a los posibles impactos transfronterizos que considere que se puedan generar.

Consecuentemente, la autoridad competente, en la clasificación de la acción de proyectos con impactos transfronterizos, debería solicitar opiniones vinculantes a las diferentes instituciones que puedan tener competencias sobre estos temas, como, por ejemplo, la Cancillería, la Dirección General de Capitanías y Guardacostas (Dicapi) y la Autoridad Nacional del Agua (ANA), por mencionar algunos. Asimismo, en la resolución de clasificación se debería indicar si el administrado debería evaluar los impactos transfronterizos que se pudieran generar sobre los países vecinos, precisando sobre cuáles se debería realizar la evaluación.

Las señaladas modificaciones del aspecto procedimental deberían verse reflejadas con la modificación de los artículos 7 y 8 de la Ley y los artículos 40, 41, 42, 43, 44 y 45 del Reglamento.

Finalmente, también se deberían modificar los artículos 2 y 5 de la Ley del SEIA y los artículos 2, 4, 14, 18 y 20 del Reglamento del SEIA, para que de manera general quede plasmado que el SEIA es un sistema que promueve la realización de evaluaciones de impactos que se puedan generar dentro del territorio nacional, así como fuera de este.

\subsubsection{Alcance y contenido de las EA transfronterizas}

Como hemos señalado con anterioridad, a nivel internacional no se ha establecido cuál debería ser el contenido de la obligación de realizar EA transfronterizas. Al respecto, la CIJ, en el caso de las Plantas de Celulosa, estableció que este era un aspecto relegado a la legislación nacional de los Estados. Y, con base en esta sentencia, Boyle precisó que al menos se deberían evaluar los posibles impactos que se pudieran generar sobre los seres humanos, bienes y el medio ambiente de los Estados de origen y de los Estados afectados.

En ese sentido, partiendo de los requisitos mínimos indicados por Boyle, la legislación peruana debería regular los impactos significativos que se pudieran 
generar sobre los seres humanos, los bienes y el medio ambiente no solo del Estado peruano, sino también de los otros Estados que potencialmente se puedan ver afectados.

En consecuencia, esta evaluación se debería poder apreciar en las etapas de (i) la presentación de la solicitud; (ii) la clasificación de la acción; y (iii) la evaluación del instrumento de gestión ambiental. Todas estas etapas -descritas en el capítulo anterior- están vinculadas al contenido del proceso de EA y, por eso, en cada una de ellas se debería hacer referencia al contenido mínimo señalado por Boyle.

En ese sentido, las adecuaciones por realizarse en la Ley del SEIA serían: para (i) la fase de presentación de la solicitud, el artículo 7; para (ii) la fase de clasificación de la acción, el artículo 5 y el artículo 8; y para (iii) la fase de evaluación de instrumento de gestión ambiental, el artículo 10.

En el Reglamento, las adecuaciones por realizarse serían: para (i) la fase de presentación de la solicitud, el artículo 41; para (ii) la fase de clasificación de la acción, los anexos V y VI; y para (iii) la fase de evaluación de instrumento de gestión ambiental, el artículo 49 y los anexos III y IV.

\subsubsection{Notificación}

El proceso de notificación no se encuentra regulado en la legislación del SEIA. $\mathrm{Al}$ respecto, si bien es posible regular este proceso únicamente en la legislación nacional-como lo ha hecho Bolivia-, la recomendación general es que exista un tratado de por medio que permita reducir los costos de transacción de esta operación. Sin perjuicio de esto último, a continuación procederemos a indicar recomendaciones de modificaciones a la legislación nacional para regular este procedimiento de notificación.

Para comenzar, es importante recordar lo indicado por la legislación boliviana. En esta se ha regulado la notificación únicamente señalando que en caso se identifique la existencia de posibles impactos transfronterizos, el Ministerio del Exterior debe ser notificado. Sin embargo, en la legislación no se precisa en qué momento o cómo debe darse esta acción.

En relación con esto, consideramos que la legislación peruana debería regular este aspecto más detenidamente, y para lograrlo se deberían realizar las siguientes adecuaciones en la Ley del SEIA:

- Artículo 6.- Procedimiento para la certificación ambiental. Este artículo regula las etapas que componen el procedimiento para la certificación ambiental. A fin de que la notificación se realice lo antes posible, la recomendación sería que después de la etapa de clasificación de la acción, se incluya la etapa de notificación. En ese sentido, el paso 
3 del procedimiento para la certificación ambiental podría denominarse «notificación de la acción a los posibles Estados afectados».

- Artículo 8.- Clasificación de la acción propuesta. Este artículo, aparte de regular la clasificación que debe realizar la autoridad una vez recibida la propuesta de clasificación presentada por el titular del proyecto, también establece los siguientes pasos que debe realizar dicha autoridad. En relación con esto, se debería agregar un tercer inciso al artículo 8.2, el cual establezca:

Para el caso de la categoría III, en caso exista la probabilidad de que se generen impactos transfronterizos, se deberá notificar al Ministerio de Relaciones Exteriores, a fin de que este, a través de sus pares, informe al o los Estados que puedan verse afectados por el proyecto. Esto con la finalidad de que los posibles países afectados indiquen si tienen la intención de participar en el procedimiento de EA.

De igual manera, se deberían efectuar las siguientes adecuaciones al Reglamento de la Ley del SEIA:

- Artículo 5.- Entidades que conforman el SEIA. Debido a que el proceso de notificación implica que se involucre al Ministerio de RR. EE., se debería incluir a este organismo como entidad que conforma el SEIA.

- Artículo 8.- Funciones de las autoridades competentes. Adicionalmente a las funciones establecidas en este artículo para las autoridades competentes, se debe incluir como función adicional el deber de notificar al Ministerio de RR. EE., en los casos en que los proyectos puedan generar impactos transfronterizos.

- Artículo 45.- Resolución de clasificación. En relación con el contenido de la resolución, es necesario agregar un inciso adicional a este artículo. En este, se debe indicar que en caso se asigne la categoría III al proyecto, la autoridad competente deberá notificar al Ministerio de RR. EE., a fin de que este, a través de sus pares, informe a los Estados que puedan verse afectados por el proyecto.

- Título II, capítulo 2-A. Notificación de la acción a los posibles Estados afectados. En el título II del Reglamento, se debería agregar un capítulo adicional denominado capítulo 2-A, cuya finalidad sería regular, en detalle, el proceso de notificación. 
Un primer aspecto por regular sería el referido al momento en que la autoridad competente debería notificar al Ministerio de RR. EE. y, asimismo, el momento en que este ministerio debería notificar a los posibles Estados afectados.

De igual manera, se debería precisar cuál debería ser el contenido de la notificación, es decir, qué información debería ser notificada a los Estados. Al respecto, se recomienda que: (i) se incluya toda la información presentada en la solicitud de clasificación, (ii) se establezca el plazo de respuesta de los Estados y (iii) se consulte a los Estados si se encuentran interesados en participar en el procedimiento de EA.

Asimismo, este capítulo debería regular el proceso por seguir en caso los Estados afectados decidan participar, y el proceso por seguir en caso no se encuentren interesados. En caso el Estado afectado decida no participar del proceso, se deberá notificar al titular del proyecto para que este no incluya el análisis transfronterizo en el EIA-d que se realizará. Y en caso el Estado afectado decida participar del proceso, la notificación deberá precisar que dichos impactos y medidas de mitigación sí deben ser incluidas.

Finalmente, un aspecto importante por regular es el referido a si el procedimiento de EA debería suspenderse hasta obtener la respuesta de los Estados afectados. Es de nuestra opinión que solo debería efectuarse una suspensión parcial, es decir, únicamente en relación con el análisis de los efectos transfronterizos.

\subsubsection{Consulta}

Como ya hemos señalado, el Estado de origen también tiene la obligación de consultar con los Estados afectados sobre el proyecto planificado. Y, al igual que para el deber de notificar, la mejor manera de regular este aspecto sería a través de un tratado ${ }^{17}$. De igual manera, es importante recordar que, debido al concepto de soberanía de los Estados, es singularmente complicado regular este

\footnotetext{
${ }^{17}$ Actualmente se está negociando un tratado sobre participación ciudadana en el sector ambiental, denominado Convención Internacional sobre «democracia ambiental». Este tiene como objetivo establecer un estándar mínimo sobre acceso a información, participación ciudadana y derecho a justicia en materia medioambiental.
} 
aspecto unilateralmente, ya que no es posible normar en la legislación peruana cómo los Estados afectados deberían llevar a cabo sus procesos de consulta.

La idea anterior se refuerza con el hecho de que ninguno de los países antes señalados -Colombia, Brasil, Bolivia, Paraguay- ha regulado el aspecto de la consulta con los posibles Estados afectados. En consecuencia, el Perú sería el primer país en hacer referencia a este aspecto en su legislación.

Para comenzar, es importante precisar que el proceso de consulta dentro del territorio peruano se denomina participación ciudadana y se encuentra regulado en el artículo 14 de la Ley del SEIA y en el título IV del Reglamento de la Ley del SEIA. Los aspectos más específicos de este procedimiento se encuentran regulados en el Decreto Supremo 002-2009-Minam, Reglamento sobre Transparencia, Acceso a la Información Pública y Participación y Consulta Ciudadana en Asuntos Ambientales, y en la legislación sectorial, regional y local correspondiente.

De manera general, se puede describir la participación ciudadana como un proceso aplicable a todas las etapas del proceso de EA, que se lleva a cabo a través de múltiples modalidades y mecanismos, con la finalidad de generar un intercambio amplio de información entre los distintos actores involucrados (D. S. 019-2009-Minam, art. 68). Asimismo, cuenta con instancias formales e instancias no formales de participación. Las formales son establecidas por las autoridades competentes, mientras que las no formales son impulsadas por el titular o proponente a través del Plan de Participación Ciudadana.

$\mathrm{Al}$ respecto, la situación óptima sería aquella en que los mismos procedimientos de participación ciudadana llevados a cabo en el Perú se apliquen a las poblaciones de los Estados afectados. Sin embargo, como ya se ha seńalado, la uniformación de este proceso no se puede dar de manera unilateral, es decir, no se puede efectuar únicamente a través de la legislación peruana.

En consecuencia, la propuesta legislativa para este aspecto sería que tanto en el artículo 14 de la Ley del SEIA como en el título IV del Reglamento del SEIA se precise que, en los casos de EA transfronterizas, los procesos de participación se lleven a cabo de acuerdo a las regulaciones de cada Estado afectado. Asimismo, se debería precisar que no se podrá tomar una decisión en relación con la viabilidad ambiental de un proyecto si no se cuenta con la información proveniente de los procesos de consulta llevados a cabo en los posibles países afectados.

De igual manera, se debería indicar el deber del Estado peruano de procurar brindar igual peso a las observaciones efectuadas por los ciudadanos de los Estados afectados y a las observaciones efectuadas por los ciudadanos perua- 
nos. Y, finalmente, se debe dejar en claro que, bajo ninguna circunstancia, el proceso de consulta transfronteriza podría incluir un derecho de veto para los Estados afectados.

\subsubsection{Decisión final}

$\mathrm{Al}$ igual que en el caso anterior, en la legislación comparada sudamericana no se ha regulado ningún aspecto vinculado a las decisiones finales sobre las EA transfronterizas, con lo cual, nuevamente, no existe algún modelo al cual se pueda hacer referencia para la implementación de este aspecto en el Perú.

De igual manera, resulta complicado hacer referencias al Convenio Espoo para este punto, pues, como hemos señalado antes, la decisión final bajo dicho Convenio está referida a si el proyecto debe llevarse a cabo o no, mientras que, en el Perú, este proceso está dirigido a aprobar, o no, el EIA presentado.

En relación con la decisión final sobre el proceso de EA en el Perú, actualmente es el Senace la autoridad encargada de revisar y aprobar los EIA-d regulados en la Ley del SEIA ${ }^{18}$. En consecuencia, uno de los aspectos básicos que deberían ser tomados en cuenta por el Senace en el momento de aprobar un EIA-d, y, por ende, que debería regularse en la legislación peruana, es que para tomar una decisión sobre la aprobación o no del EIA se deberían tomar en cuenta la documentación remitida, las observaciones recibidas y los resultados de las consultas realizadas tanto en el territorio peruano como en los países afectados. Asimismo, es importante que en el momento de la evaluación del EIA se soliciten las opiniones técnicas a las autoridades peruanas que puedan tener competencias sobre el tema.

Adicionalmente a lo anterior, un aspecto muy importante por regular es el relacionado con la comunicación al Estado afectado sobre el resultado final del proceso de EA. En esta comunicación se deberían precisar las razones y consideraciones sobre las cuales la decisión final es tomada. A su vez, es importante regular que no solo se debería notificar a los Estados afectados la decisión respecto a los EIA-d, sino también el momento en que se da inicio a las actividades que entrañan el riesgo de causar impactos transfronterizos.

Como consecuencia de lo anterior, estas adecuaciones deberían poder observarse en el artículo 12 de la Ley del SEIA, modificado por el artículo 1

\footnotetext{
${ }^{18}$ Es importante tener en cuenta que el Senace fue creado en el año 2012 mediante la Ley 29968 y, a la fecha de elaboración de la presente publicación, no todas las funciones de los distintos ministerios le han sido transferidas. De acuerdo con el D. S. 006-2015-Minam, todas las transferencias de funciones de las autoridades sectoriales a este organismo público culminarán en el cuarto trimestre de 2020.
} 
del Decreto Legislativo 1078 y los artículos 54, 55 y 56 del Reglamento de la Ley del SEIA.

\subsubsection{Monitoreo posterior}

En las legislaciones colombiana, paraguaya, brasileña y boliviana no existe referencia al monitoreo posterior de las EA transfronterizas.

Por otro lado, bajo el Convenio Espoo, el análisis posterior al proyecto es un proceso optativo que solo se lleva a cabo si los Estados determinan que es necesario que este se implemente. Al respecto, en caso los Estados establezcan su necesidad, estos deben determinar en qué medida se debe llevar a cabo el monitoreo posterior. Asimismo, este convenio busca que los Estados se notifiquen y se consulten en relación con los impactos transfronterizos que emerjan y no hayan sido considerados en el EIA aprobado.

En la legislación peruana, el monitoreo posterior -denominado seguimiento y control- está compuesto por las acciones de supervisión, fiscalización, sanción y vigilancia. Se trata de un proceso obligatorio de realizar y el organismo público encargado de llevarlo a cabo es el OEFA.

Con base en el concepto de soberanía de los Estados, el Estado peruano, a través del OEFA, no podría supervisar los impactos generados en los Estados afectados. Sin embargo, en la regulación peruana se podría establecer que en los casos de EA transfronterizas el OEFA busque, a través de sus organismos pares en los Estados afectados, tener conocimiento sobre los impactos que se están generando en dichos territorios. A partir de lo anterior, el OEFA podría tomar los informes de dichas organizaciones pares como información adicional para cumplir con sus obligaciones de supervisión, fiscalización, sanción y vigilancia. Estas recomendaciones de regulación deberían reflejarse tanto en el capítulo IV de la Ley del SEIA, como en título VI del Reglamento de la Ley del SEIA.

Con base en todo lo expuesto en esta sección, a continuación, a modo de resumen, el proceso nacional de EA transfronterizas propuesto se podría graficar de la siguiente manera: 
Figura 4.1. Propuesta de proceso de EA transfronterizas

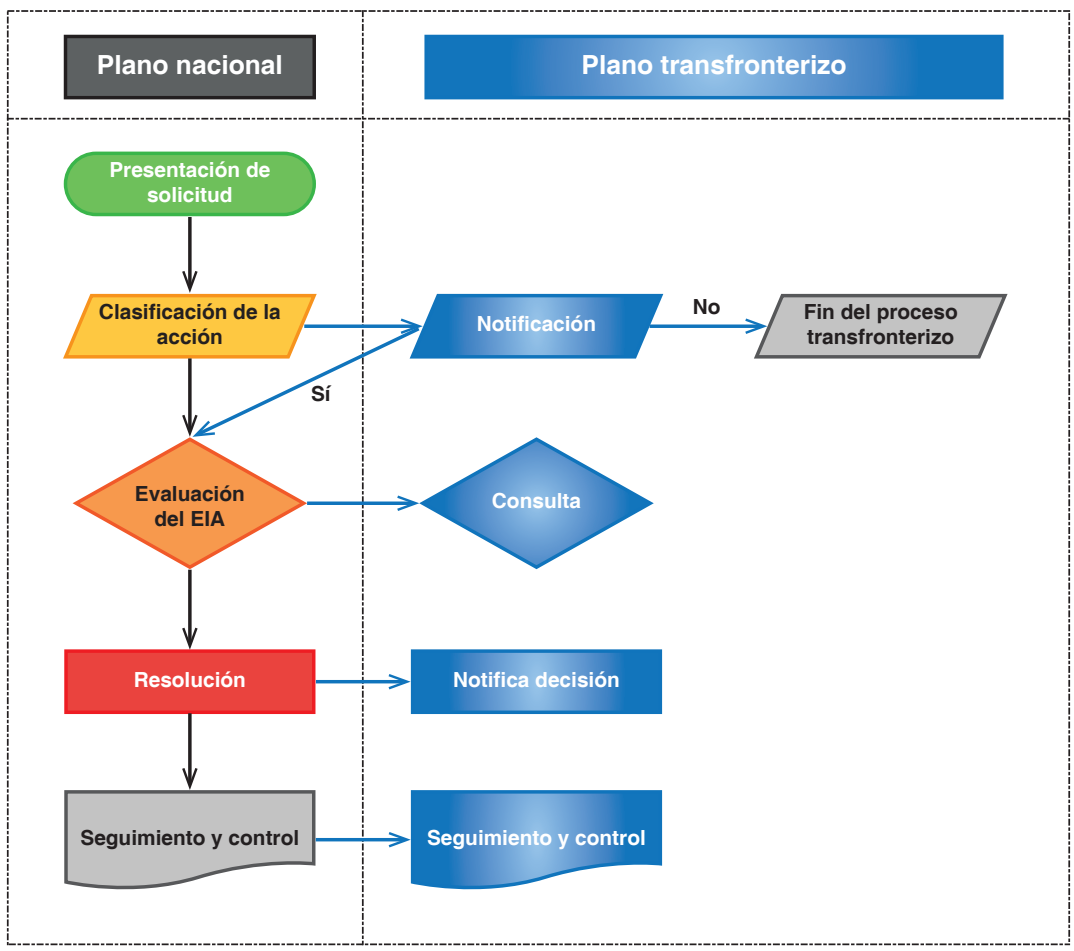

Elaboración propia.

\subsection{Conclusión}

Como consecuencia de la ausencia de regulación en la legislación peruana sobre la obligación de llevar a cabo EA transfronterizas, el objetivo de este capítulo fue presentar las alternativas de regulación para esta.

$\mathrm{Al}$ respecto, en primer lugar, se indicó que, debido al carácter consuetudinario de la obligación, lo ideal sería que antes de implementar la obligación en la legislación nacional, se busque formar parte de un tratado con los países vecinos. De esta manera se lograría establecer estándares mínimos en cuanto a la estructura y el contenido de la obligación.

Como consecuencia de lo anterior, se presentaron dos posibles escenarios para el Perú, a fin de que este pueda formar parte de un tratado. La primera opción propuso la adhesión del Perú al Convenio Espoo; y la segunda, fomentó la elaboración de un nuevo tratado para la región. 
En relación con la adhesión al Convenio Espoo, se demostró que si bien este presentaba varios aspectos positivos, como el hecho de ser considerado el instrumento legal líder en la materia, también tenía dos inconvenientes. En primer lugar, la enmienda de Sofía -que permite que cualquier país pueda ratificar este Convenio- aún no surte efecto, por lo que aún no se tiene certeza de cuándo los países que no son miembros de la Unece podrían formar parte de este. Y, en segundo lugar, el Convenio Espoo no regula con claridad cómo hacer frente a proyectos con más de un Estado de origen y más de un Estado afectado.

A partir de lo anterior, se propuso como segunda opción impulsar la elaboración de un tratado regional sobre el tema. Y, al respecto, se sugirió que lo óptimo sería impulsar el acuerdo desde un sistema integración regional del que formen parte el Perú y sus países vecinos, como, por ejemplo, la OEA, la Orpalc del PNUMA, Aladi, SELA, la OTCA o la CAN.

De igual manera, se determinó que lo principal en cualquier opción que se decida seguir era buscar que tanto el Perú como sus países vecinos formen parte del instrumento. La idea de formar parte de un tratado es que tanto los Estados de origen como los Estados afectados tengan claridad sobre cuál es el procedimiento por seguir en caso surjan proyectos con posibilidades de generar impactos transfronterizos, evitando así controversias posteriores.

Teniendo como marco un tratado, el siguiente paso por seguir sería proceder a implementar la obligación en la legislación nacional.

La situación antes descrita sería la manera ideal de implementación de la obligación en el Perú. Sin embargo, este capítulo demostró que, en Sudamérica, el proceso no se estaba dando de esta manera. Colombia, Brasil, Paraguay, Surinam y Bolivia, de diferentes maneras, han implementado esta obligación sin la previa existencia de un tratado que regule la materia. En ese sentido, se precisó que el escenario real de implementación de esta obligación para el Perú sería aquel en el cual se implemente la obligación directamente en la legislación nacional, sin la previa existencia de un tratado.

Como consecuencia de lo anterior, en la sección 4.2.2 se presentaron las propuestas de modificación a la legislación peruana, a fin de que esta regule el proceso de EA transfronteriza. Se buscó que la estructura procedimental, descrita en el capítulo 2 , sea incluida en el SEIA. Es decir, las recomendaciones se enfocaron, básicamente, en que se adecue la legislación nacional a fin de que en las fases de screening, contenido, consulta, decisión final y monitoreo posterior, se haga referencia a las EA transfronterizas, y, además, en que se incluya la fase de notificación, la cual no está regulada en la legislación peruana. 
Finalmente, se determinó que si bien no existe mayor complejidad en hacer adecuaciones a la legislación nacional para que se incluya la evaluación de impactos transfronterizos en las fases de screening, contenido, toma de decisión y monitoreo posterior, sí es de singular complejidad regular el proceso de notificación y consulta sin un tratado de por medio. Esto debido al gran nivel de interacción que debe de existir entre los Estados para estas fases. 


\section{Conclusiones y recomendaciones}

En presente documento de investigación tuvo cuatro objetivos. El primero estuvo enfocado en desarrollar qué son las EA transfronterizas y cuál es la relevancia de estas para el Perú. El segundo probó que existe una obligación consuetudinaria internacional de realizar EA transfronterizas. El tercero demostró que el Perú no estaba cumpliendo con llevar a cabo dicha obligación internacional. Y el cuarto se enfocó en brindar recomendaciones de adecuación a la legislación peruana, a fin de que el Perú pueda dar cumplimiento a su obligación. En consecuencia, con base en estos cuatro objetivos, procederemos a presentar las conclusiones finales del trabajo.

\section{Objetivo 1: Qué son las EA transfronterizas y cuál es la relevancia de estas para el Perú}

1. Si bien existen diversos instrumentos del hard law y soft law que buscan esbozar una definición sobre las EA transfronterizas, no existe aún un tratado general que establezca una definición al respecto.

2. Con base en el análisis de diversos instrumentos, el presente trabajo definió a las EA transfronterizas como un proceso de toma de decisiones llevado a cabo por los Estados para evaluar de manera científica, y con la participación de los ciudadanos, los impactos que se podrían producir sobre su medio ambiente, y el de otros Estados, a causa del desarrollo de una determinada actividad, con la finalidad de identificar las medidas para prevenir, reducir y controlar dichos impactos. 
3. Se propuso que los impactos que deberían ser sometidos a las EA transfronterizas deberían ser aquellos compuestos por los siguientes elementos: (i) carácter negativo; (ii) generado por una actividad humana; (iii) causalidad entre la actividad y el impacto; (iv) carácter significativo; y (v) Estado transfronterizo afectado.

4. Se señaló la existencia de diversas actividades - principalmente de los sectores minero, energético y saneamiento- que se desarrollan cerca a zonas de frontera y sobre recursos naturales compartidos, que podrían poner al Perú en una posición de generar impactos transfronterizos negativos significativos.

\section{Objetivo 2: La obligación consuetudinaria internacional de realizar EA transfronterizas}

5. Es posible afirmar que se ha generado una obligación consuetudinaria internacional de realizar EA transfronterizas debido a que se probó tanto la existencia del elemento objetivo como de la opinio juris.

6. En relación con el elemento material, se demostró que realizar EA transfronterizas es una práctica que se ha efectuado por un período mayor de 30 ańos, de manera intensa, coherente y generalizada.

7. Para probar lo anterior, se resaltaron los distintos actos que llevaron a cabo diversos Estados tanto en el ámbito normativo como en el plano de los hechos.

8. En el plano normativo, se demostró que las primeras referencias a la realización de EA transfronterizas se pueden encontrar en el Acta de Santiago sobre Cuencas Hidrológicas del año 1971. Asimismo, se señaló que, a partir de esa fecha, se aprobaron al menos 14 tratados que establecen la necesidad de llevar a cabo EA transfronterizas. De igual manera, en más de una ocasión, distintos Estados realizaron declaraciones sobre la obligatoriedad de llevar a cabo EA. Adicionalmente, países como Guatemala, Costa Rica, Colombia, Bolivia, Paraguay y Brasil incluyeron en sus legislaciones referencias a estos procedimientos; e, igualmente, distintas OI emitieron al menos 7 instrumentos de soft law sobre la materia.

9. En el plano de los hechos, se destacó que en el marco del Convenio Espoo, en Europa, se han llevado a cabo más de 200 EA transfronterizas. Al respecto, se desarrollaron los casos de (i) la EA transfronteriza 
de la planta de energía hidráulica del río Neman entre Bielorrusia y Lituania, (ii) la EA transfronteriza de la carretera Thonon-Annemasse en la frontera francesa y suiza, y (iii) la EA transfronteriza de la Planta de Energía Nuclear Olkiluoto 3 en Finlandia.

10. En relación con la opinio juris, se observó que los Estados han llevado a cabo las EA transfronterizas con la convicción de que estas son obligatorias de acuerdo al derecho internacional. Para probar esto, se hizo referencia a todos los actos del plano normativo señalados anteriormente, pero, además, se mostró que tanto la CIJ como distintas ONG y expertos en la materia, han emitido pronunciamientos sobre el hecho de que realizar EA transfronterizas constituye, actualmente, una obligación consuetudinaria del derecho internacional.

11. A nivel internacional, es posible afirmar que existe una obligación consuetudinaria de realizar EA transfronterizas. Sin embargo, lo que aún no es del todo claro es cuál es el procedimiento que se debe seguir y qué es exactamente lo que se debe evaluar a través de este proceso. Es decir, se demostró que si bien existe una obligación consuetudinaria de realizar EA transfronterizas, aún no se puede afirmar que existe una norma consuetudinaria que regule los diferentes aspectos procedimentales y el contenido de la obligación.

12. Sin perjuicio de lo anterior, este trabajo presentó una estructura procedimental general, tomando como principal referencia lo establecido en el Convenio Espoo. Y, además, se aseveró que llevar a cabo EA transfronterizas no implica únicamente realizar evaluaciones de los impactos. La propuesta del presente trabajo es que esta incluye, además, el deber de notificar, de realizar consultas y de realizar un monitoreo posterior.

13. En cuanto al contenido de la obligación, se señaló que la CIJ, en el caso de las Plantas de Celulosa, determinó que el contenido de la obligación debe ser relegado al derecho interno de los Estados.

14. Por último, se precisó que esta obligación es una obligación de medios. $\mathrm{Y}$, al tratarse de una obligación de medios, los Estados dan cumplimiento a su obligación simplemente implementando un sistema de EA transfronterizas, no siendo necesario asegurar que no se vayan a producir impactos transfronterizos. 


\section{Objetivo 3: El contexto nacional sobre la regulación de las EA y los dańos transfronterizos}

15. El Perú no está cumpliendo con su obligación internacional de llevar a cabo EA transfronterizas, pues si bien esta norma ya se encuentra incorporada en el sistema, aún no se ha implementado.

16. Al respecto, la incorporación es la manera en que la norma internacional ingresa a los ordenamientos de los Estados y se vuelve vinculante para sus respectivos funcionarios públicos, personas naturales y personas jurídicas. En el caso de obligaciones consuetudinarias, la incorporación se da de manera automática, sin la necesidad de que existan actos de transformación de por medio. Ergo, la obligación de llevar a cabo EA transfronterizas ya se encuentra incorporada en el derecho interno peruano y, además, ya es vinculante para las diferentes autoridades públicas y sus administrados.

17. Sin embargo, de conformidad con el derecho internacional, no basta con que una norma se incorpore al derecho interno de los Estados, sino que, además, existe una obligación internacional de implementar la obligación internacional asumida. Es decir, los Estados tienen la obligación de adoptar y/o derogar todas las medidas legislativas y/o no legislativas que consideren necesarias para dar cabal cumplimiento a sus obligaciones asumidas en el plano internacional.

18. Como consecuencia de lo anterior, se analizaron diversas normas e instrumentos del sector ambiental, poniendo un especial énfasis en las diversas normas que conforman el SEIA.

19. Si bien la LGA y la Política Ambiental del Sector Turismo, aprobada por Resolución Ministerial 195-2006-Mincetur-DM, efectúan unas vagas referencias a la importancia de velar por el ambiente más allá de las fronteras del Estado peruano, y si bien las diversas normas vinculadas al SEIA no seńalan que la EA deba circunscribirse únicamente al territorio peruano, lo cierto es que no existe ninguna norma en el Perú que haga referencia a la necesidad de llevar a cabo EA transfronterizas ni, menos aún, existen normas que regulen este proceso.

20. En el plano administrativo, se demostró que si bien en el Perú no existe una norma que regule de manera expresa la realización de EA transfronterizas, ya existe registro de un caso de evaluación de impactos sobre 
el territorio chileno por la ejecución de una actividad sobre territorio peruano. La mina Pucamarca, propiedad de la empresa Minsur, ubicada en Tacna, a 200 metros de la frontera con Chile, tuvo que elaborar un EIA del proyecto sobre el territorio chileno.

21. En el Perú no solo se desarrollan actividades que tienen un potencial de generar impactos transfronterizos, sino que esta situación ya es una realidad. En consecuencia, urge que el Perú cuente con lineamientos para elaborar estudios de EA transfronterizas.

\section{Objetivo 4: Propuesta de implementación de EA transfronterizas en el} Perú

22. En el derecho internacional no existe ninguna regulación específica sobre cómo debería ser el proceso de implementación, dejándose al derecho interno de los Estados completa libertad para decidir cómo y cuándo implementar la obligación, con la única limitación de no restringir el contenido o el alcance de la obligación internacional asumida.

23. Debido al carácter consuetudinario de la obligación, lo mejor para el Perú sería, primero, formar parte de un tratado sobre la materia, el cual establezca los estándares mínimos en cuanto a la estructura y el contenido de la obligación, y, luego, con base en este tratado, proceder a realizar las adecuaciones respectivas en la legislación nacional.

24. Las opciones identificadas para formar parte de un tratado, fueron: (i) adherirse al Convenio Espoo; o (ii) impulsar la elaboración de un nuevo tratado regional sobre la materia, a través de sistemas de integración regional como la OEA, la Orpalc del PNUMA, Aladi, SELA, OTCA o la CAN. Si bien ambas opciones presentan ventajas, las mismas también presentan como desventaja el hecho de que para que cualquiera de ellas se concrete sería necesario que transcurra un largo período de tiempo.

25. Debido a lo anterior, se sugirió que el Perú siga la línea establecida por Colombia, Bolivia, Brasil y Paraguay, países que decidieron regular en sus respectivas legislaciones la obligación de llevar a cabo EA transfronterizas sin formar parte de un tratado.

26. Si bien todos los países anteriormente señalados han desarrollado en sus legislaciones de alguna u otra manera la implementación de la obligación de realizar EA transfronterizas, y si bien Bolivia es el país que posee la legislación más desarrollada, las referencias realizadas en 
las legislaciones a dicho procedimiento son insuficientes. Realizar EA transfronterizas es una tarea de gran complejidad que no puede ser resuelta a través de la existencia de 3 o 4 artículos en una sola norma.

27. Por lo tanto, en la sección 4.2.2 se presentaron las propuestas de modificación a la legislación peruana. Las recomendaciones estuvieron enfocadas a que se introduzcan, en las fases de screening, contenido, consulta, decisión final y monitoreo, de la Ley del SEIA y su reglamento, referencias a las EA transfronterizas, y, adicionalmente, que en ambas normas se introduzca un capítulo de cómo llevar a cabo el proceso de notificación.

28. Finalmente, cabe resaltar que se hizo singular hincapié en la importancia de apoyarse en la figura de opiniones consultivas en el momento de regular las EA transfronterizas en el Perú. 


\section{Referencias}

\section{Libros}

Barberis, J. (1994). Formación del derecho internacional. Buenos Aires: Editorial Ábaco de Rodolfo Depalma.

Barboza, J. (2008). Derecho internacional público. Buenos Aires: Zavalía Editor.

Bastmeijer, K., \& Koivurova, T. (2008). Theory and practice of transboundary environmental impact assessment. Leiden: Martinus Nijhoff Publishers.

Cancado Trindade, A. A. (2005). General course of public international law: International law for humankind: Towards a new jus gentium. En The Hague Academy of International Law, Collected courses of The Hague Academy of International Law (tomo 316). Leiden | Boston: Brill | Nijhoff.

Cassese, A. (2005). International law. Oxford: Oxford University Press.

Craik, N. (2010). The international law of environmental impact assessment: Process, substance and integration. Cambridge: Cambridge University Press.

Damrosch, L. F. (2009). International law: Cases and materials. Saint Paul, Minnesota: Thomson/West.

De la Puente Brünke, L. (2005). Legislación ambiental en la minería peruana. Lima: Instituto de Estudios Energético Mineros.

Dupuy, P. (2007). Customary law and general principles. En D. Bodansky, B. Jutta \& H. Ellen (Eds.). The Oxford handbook of international environmental law. Oxford: Oxford University Press.

Economides, C. (2010). Content of the obligation: Obligations of means and obligations of result. En J. Crawford, P. Alain, O. Simon y P. Kate (Eds.), The law of international responsibility. Oxford: Oxford University Press. 
Fitzmaurice, M. (2001). International protection of the environment. En The Hague Academy of International Law, Collected courses of The Hague Academy of International Law (tomo 293). Leiden | Boston: Brill | Nijhoff.

Gómez-Robledo Verduzco, A. (2003). Jurisprudencia internacional por daños transfronterizos. En Temas selectos del derecho internacional (pp. 349-374). 4. ${ }^{\text {a }}$ ed. Universidad Nacional Autónoma de México, Instituto de Investigaciones Jurídicas. Recuperado de https://archivos.juridicas.unam.mx/www/bjv/libros/2/831/16.pdf

Gonzales Campos, J. et al. (2008). Curso de derecho internacional público. Cuarta edición revisada. España: Editorial Aranzadi.

Hafner, G., \& Buffard, I. (2010). Obligations of prevention and precautory principle. En J. Crawford, A. Pellet, S. Olleson \& Kate Parlett (Eds.), The law of international responsibility. Oxford: Oxford University Press.

Handl, G. (2007). Transboundary impacts. En D. Bodansky, B. Jutta \& E. Hey (Eds.), The Oxford handbook of international environmental law. Oxford: Oxford University Press.

Hanqin, X. (2003). Transboundary damage in international law. Cambridge: Cambridge University Press.

Lepard, D. B. (2010). Customary international law: A new theory with practical applications. Cambridge: Cambridge University Press.

Mariño Menéndez, F. (2005) Derecho Internacional Público: Parte general (4. a ed.). Madrid: Editoral Trotta.

Marsden, S., \& Koivurova, T. (2011). Transboundary environmental impact assessment in the European Union: The Espoo Convention and its Kiev Protocol on Strategic Environmental Assessment. Abingdon: Earthscan.

Meron, T. (1991). Human rights and humanitarian norms as customary law. Clarendon Press.

Novak Talavera, F., \& García-Corrochano Moyano, L. (2000). Derecho internacional público. Introducción y fuentes (tomo 1). Lima: Fondo Editorial de la PUCP.

Oppenheim, L. F. L. (1961). Tratado de derecho internacional público. (J. López Olivan y J. M. Castro Rial, trads.). Barcelona: Bosh.

Pastor Ridruejo, J. (2010). Curso de derecho internacional público y organizaciones internacionales (14. ${ }^{\mathrm{a}}$ ed.). Madrid: Editorial Tecnos.

Pastorino, L. (2005). El daño al ambiente (1.a ed.). Buenos Aires: Lexis Nexis.

Redgwell, C. (2007). National implementation. En D. Bodansky, B. Jutta \& E. Hey, The Oxford handbook of international environmental law. Oxford: Oxford University Press.

Rosenne, S. (2001). General course of public international law: The perplexities of modern international law. En The Hague Academy of International Law, Collected courses of The Hague Academy of International Law (tomo 291). Leiden | Boston: Brill | Nijhoff.

Salmón, E. (2007). El derecho internacional humanitario y su relación con el derecho interno de los estados. Lima: Palestra.

Sands, P., Peel, J., Fabra Aguilar, A., \& Mackenzie, R. (2012). Principles of international environmental law (3. ${ }^{\mathrm{a}}$ ed.). Cambridge: Cambridge University Press. 
Smets, H. (2006). Por un derecho efectivo al agua potable. Bogotá: Universidad del Rosario. Recuperado de https://books.google.com.pe/books?id=fYux9Z-CcuMC\&pg $=$ PA6\&lpg=PA6\&dq=Por + un + Derecho + Efectivo + al + Agua + Potable + Bogot $\%$ C3\% A1,+Colombia:+Universidad +del+Rosario. \&source=bl\&ots $=$ PPg13hoX8J\&sig= Q7aqTkXb08dtr8TZOwBANiKJpns\&hl=en\&sa=X\&ved=0ahUKEwjO3ob-3s PSAhWGKyYKHWsaCC0Q6AEIOTAC\#v=onepage\&q=Por\%20un\%20Derecho \%20Efectivo\%20al\%20Agua\%20Potable.\%20Bogot\%C3\%A1\%2C\%20Colom bia\%3A\%20Universidad\%20del\%20Rosario. \&f=false

Thirlway, H. (2014). The sources of international law. Oxford: Oxford University Press.

Tomuschat, C. (2003). Human rights between idealism and realism. Nueva York: Oxford University Press. Recuperado de https://books.google.com.pe/books?id=wmEzxW2UBgc C\&printsec=frontcover\&source=gbs_ge_summary_r\&cad $=0 \# \mathrm{v}=$ onepage\&q\&f =false

\section{Artículos de revistas}

Jiménez de Aréchaga, E. (enero-marzo de 1986). La Convención Interamericana de Derechos Humanos como derecho interno. Revista del IIDH.

Knox, J. H. (2003). Assessing the candidates for a global treaty on transboundary environmental impact assessment. New York University Environmental Law Journal, XII, 153-168. Recuperado de https:/wakespace.lib.wfu.edu/bitstream/ handle/10339/26077/Knox\%20Assessing\%20the\%20Candidates\%20for\%20 a\%20Global\%20Treaty\%20on\%20Transboundary\%20Environmental\%20 Impact $\% 20$ Assessment $\% 20 \mathrm{New} \% 20$ Approaches $\% 20$ to $\% 20$ Environmental $\% 20$ Review\%20-\%20Colloquium\%20Article.pdf

López Escárcena, S. (2012). El asunto de las plantas de celulosa sobre el río Uruguay: Comentario de la sentencia de la Corte Internacional de Justicia de fecha 20 de abril de 2010. Revista Chilena de Derecho, 39(3), 849-860. Recuperado de http://www. scielo.cl/scielo.php?script=sci_arttext $\&$ pid=S0718-34372012000300012\#n42

Salmón, E. (2002). Las normas internacionales en la propuesta de la Comisión de Estudio de las Bases de la Reforma Constitucional del Perú. Agenda Internacional, VII, (16), 59-81.

Salmón, E. (2003). Los aspectos internacionales en la reforma de la Constitución. Pensamiento Constitucional, IX, (9), 149-184.

\section{Documentos de trabajo}

AMEC (julio de 2007). Evaluación ambiental del proyecto Pucamarca en territorio chileno. preparado para Minsur $S$. A.

ANA (12 de mayo de 2015). Modelo hidrológico de gestión integrada de recursos hidricos del río Maure-Mauri. Recuperado de http://www.ana.gob.pe/sites/default/files/ normatividad/files/rd_004-2015-ana-dcprh_estudio_completo.pdf 
Bonvoisin, N. (marzo de 2011). National seminar on the way to the International Year of Eater Cooperation: The role of international law, including Unece Water Convention, in strengthening cooperation on water resources management. Recuperado de http://www. unece.org/fileadmin/DAM/env/water/cadialogue/docs/Dushanbe_March2011/ Bonvoisin_Eng.pdf

Boyle, A. (s. f). Developments in international law of EIA and their relation to the Espoo Convention. Recuperado de http://www.unece.org/fileadmin/DAM/env/eia/docu ments/mop5/Seminar_Boyle.pdf

CAN. (2007). Agenda ambiental andina 2006-2010. 2. a versión. Recuperado de http:// www.comunidadandina.org/Upload/201166172430libro_agenda_ambiental2.pdf

Dourojeanni, M. (3 de octubre de 2010). Hidrovías en la Amazonía. Recuperado de http:// www.actualidadambiental.pe/?p=7168

Dourojeanni, M., Barandiarán, A., \& Dourojeanni, D. (11 de septiembre de 2009). Amazonía peruana en 2021 Explotación de recursos naturales e infraestructuras: ¿Qué está pasando? ¿Qué es lo que significan para el futuro? SDPA. Recuperado de http://www.spda.org.pe/wpfb-file/20120216164858_amazonia-peruana-pdf/

Duvic-Paoli, L.-A. (2014). Sovereignty over natural resources vs. prevention of environmental harm? Examining the application of the prevention principle within domestic borders. Recuperado de http://graduateinstitute.ch/files/live/sites/iheid/files/sites/inter national_law/shared/international_law/doctoral_seminar/2014/Leslie-Anne\%20 Duvic-Paoli_Abstract.pdf

Espinoza, G. (2007). Gestión y fundamentos de evaluación de impacto ambiental. BID/CED. Recuperado de http://cdam.minam.gob.pe/publielectro/impacto\%20ambiental/ Evaluacionimpactoambienta1.pdf

Finer, M., \& y Jenkins, C. (18 de abril de 2012). Proliferation of hydroelectric dams in the Andean Amazon and implications for Andes-Amazon connectivity. PLoS ONE, 7(4): e35126. https://doi.org/10.1371/journal.pone.0035126

Jervan, M. (2014). The prohibition of transboundary environmental harm. An analysis of the contribution of the International Court of Justice to the development of the no-harm rule. University of Oslo. Recuperado de https:/www.duo.uio.no/bitstream/ handle/10852/41416/213.pdf?sequence $=1$ \&isAllowed $=y$

Little, P. E. (abril de 2014). Megaprojects in the Amazon Region: A geopolitical and socio-environmental analysis with proposals of better government for the Amazon. DAR. Recuperado de http://www.dar.org.pe/archivos/publicacion/145_megaproyectos _ingles_final.pdf

ONU. (2012). Estructura y organización: Comisión de Derecho Internacional. Recuperado de http://www.un.org/es/aboutun/structure/ilc.shtml

Plakokefalos, I. (2013). Prevention obligations in international environmental law. Yearbook of International Environmental Law (en prensa). Amsterdam Law School Research Paper 2013-37; Amsterdam Center for International Law 2013-12. SSRN: https:// ssrn.com/abstract $=2290211$ 
Sand, P. (1977). The role of domestic procedures in transnational environmental disputes. En OECD, Legal aspects of transfrontier pollution (pp. 146-159). París.

SRK Consultores. (junio de 2004). Linea de base proyecto Pucamarca, territorio chileno: Informe final. Preparado para Minsur S. A.

Summers, P. (2014). Gestión integrada y sostenible de los recursos hidricos transfronterizos en la cuenca del río Amazonas considerando la variabilidad y el cambio climático. OTCA / GEF / PNUMA.

UICN. (2006). Evaluación de impacto ambiental transfronteriza en Centroamérica: Lineamientos generales. Recuperado de https://portals.iucn.org/library/efiles/documents/ EPLP-062.pdf

Unece. (2006). Thonon-Annemasse Road, France, close to Switzerland. Recuperado de http:// www.unece.org/env/eia/pubs/factsheet3_r.html

Unece. (2009). Case study fact sheet \#5: Nuclear power plants in Finland. Recuperado de http://www.unece.org/fileadmin/DAM//env/eia/documents/factsheet/Factsheet5_ Nuclear_power_plants_Finland_Mar09.pdf

Unece. (2011). List of transboundary cases. Recuperado de http://www.unece.org/fileadmin/ DAM/env/eia/documents/database/Listing_of_transboundary_EIA_procedures_ July_2011.pdf

WCS. (mayo de 2016). Inambari: Hacia un enfoque integrado de la gestión de cuencas hidrográficas (1. ${ }^{\mathrm{a}}$ ed.). Lima: Gráfica Biblos.

Wood, C. (noviembre de 2003). Environmental impact assessment in developing countries: An overview. Conference on New Directions in Impact Assessment for Development: Methods and Practice. Recuperado de http://www.enterprise-impact.org.uk/pdf/ Wood.pdf

\section{Noticias}

ALT. (6 de septiembre de 2007). Sistema TDPS. Recuperado de http://web.archive.org/ web/20110123120042/http://www.alt-perubolivia.org/pagina/sistema-tdps.html

Angarita, P. (11 de septiembre de 2014). Colombia, a una firma de poder fumigar coca más cerca de Ecuador. El Tiempo. Recuperado de http://www.eltiempo.com/politica/ justicia/colombia-podria-fumigar-mas-cerca-de-ecuador/14522715

Bolpress. (2 de octubre de 2010). Perú desestima un proyecto de trasvase del río Mauri hacia Tacna. Recuperado de http://www.bolpress.net/art.php?Cod=2010100201

Cuadema (septiembre de 2009). El desvío de las aguas del río Mauri, una historia de muchos años. Recuperado de https://cuadema.wordpress.com/el-desvio-del-rio-mauri/

Eju. (18 de junio 2011). Perú planea desviar aguas del Mauri (Bolivia) para llevarlas a Tacna. Recuperado de http://eju.tv/2011/06/per-planea-desviar-aguas-del-mauribolivia-para-llevarlas-a-tacna/

El Morrocotudo. (19 de mayo de 2011). Concejales de Arica preocupados por proyecto minero Pucamarca emplazado a menos de un kilómetro de la frontera con Chile. Recuperado de http://www.elmorrocotudo.cl/noticia/sociedad/concejales-de-aricapreocupados-por-proyecto-minero-pucamarca-emplazado-menos-de-un 
El Nuevo Diario. (14 de julio de 2014). Costa Rica exige a Nicaragua información ambiental sobre el Gran Canal. Recuperado de http://www.elnuevodiario.com.ni/ nacionales/324784-costa-rica-exige-a-nicaragua-informacion-ambiental-gran-canal Gestión. (21 de noviembre de 2016). Renace proyecto de Río Blanco en Piura por más de US\$ 2,500 millones. Recuperado de: http://gestion.pe/empresas/renace-proyectorio-blanco-piura-mas-us-2500-millones-2175150

Greenpeace Espańa. (26 de septiembre de 2014). Greenpeace pondrá una denuncia internacional ante la intención de reabrir Garońa sin un estudio de impacto ambiental transfronterizo. Recuperado de http://www.greenpeace.org/espana/es/news/2014/ Septiembre/Greenpeace-pondra-una-denuncia-internacional-ante-la-intencion -de-reabrir-Garona-sin-un-estudio-de-impacto-ambiental-transfronterizo/

Hora 25. (24 de febrero de 2014). El impacto de las represas brasileñas en Bolivia - El origen de las inundaciones. Recuperado de http://hora25.info/content/1025

Huerta, H. (25 de agosto de 2013). Quince países de América Latina preparan convención internacional por derechos ambientales. Diario U Chile. Recuperado de http:// radio.uchile.cl/2013/08/25/quince-paises-de-america-latina-preparan-convencion -internacional-por-derechos-ambientales/

La Razón - Bolivia. (14 de septiembre de 2010). Bolivia ratifica desvío del rio Mauri, Perú lo niega. Recuperado de http://la.migalhas.com/Calientes/134, MI1 17250,101048-Bolivia+ratifica+desvio+del+rio+Mauri+Peru+lo+niega

La República. (30 de enero de 2016). Autoridades tacneńas consiguen S/. 40 millones para proyecto Vila Vilani. Recuperado de http://larepublica.pe/impresa/politica/ 737451-autoridades-tacnenas-consiguen-s-40-millones-para-proyecto-vila-vilani

Luksic, A. (28 de junio de 2010). Perú seca el río Mauri dejando desolación y muerte en varias comunidades de Bolivia. El Pais. Recuperado de http://www.elpaisonline. com/index.php/blogs/la-billetera/item/30757-peru-seca-el-rio-mauri-dejando -desolacion-y-muerte-en-varias-comunidades-de-bolivia

Ministerio de Relaciones Exteriores de Costa Rica. (14 de julio de 2014). Costa Rica recuerda a Nicaragua obligación de informar sobre construcción de obras que puedan afectar el territorio nacional. Recuperado de https://www.rree.go.cr/?sec= servicios\&cat=prensa\&cont $=593 \& \mathrm{id}=1801$

Página Siete. (1 de agosto de 2014). Sigue controversia con Perú por agua del río Mauri. Recuperado de http://www.paginasiete.bo/sociedad/2014/8/1/sigue-controversia -peru-agua-mauri-28255.html

Radio Uno. (16 de enero de 2012). Proyecto Pucamarca está contaminando el altiplano chileno. Recuperado de http://www.radiouno.pe/noticias/25447/proyecto-pucamarca -esta-contaminando-altiplano-chileno

Radio Uno. (4 de abril de 2016). Málaga: «Retomaremos proyecto de trasvase del río Desaguadero». Recuperado de http://radiouno.pe/noticias/53858/malaga-retoma remos-proyecto-trasvase-rio-desaguadero 
RPP. (28 de mayo de 2009). Gobierno de Bolivia demanda a Perú por desvío de río Mauri. Recuperado de http://rpp.pe/mundo/actualidad/gobierno-de-bolivia-demanda-aperu-por-desvio-de-rio-mauri-noticia-184411

Salisbury, C. (29 de agosto de 2016). Los ocho mil kilómetros de recorrido migratorio del bagre de la Amazonía en peligro a causa de las represas. (Trad. Pedemonte, M.) Mongabay. Recuperado de https://es.mongabay.com/2016/08/los-ocho-mil-kilo metros-recorrido-migratorio-del-bagre-la-amazonia-peligro-causa-las-represas/

Tarija. (23 de septiembre de 2010). Perú desestima proyecto para desviar aguas del río Mauri. Recuperado de http://www.tarijalibre.tarijaindustrial.com/peru-desestimaproyecto-para-desviar-aguas-del-rio-mauri/

WCS. (s.f [a]). Propuesta C. H. Inambari. Recuperado de http://inambari.org/hidroelectricas/ propuesta-inambari/

WCS. (s. f. [b]). Aguas amazónicas. Recuperado de: https://peru.wcs.org/es-es/iniciativas/ aguas-amaz $\%$ C3\%B3nicas.aspx

\section{Instrumentos internacionales}

ONU. (1945). Carta de las Naciones Unidas y Estatuto de la Corte Internacional de Justicia. (1971). Acta de Santiago sobre Cuencas Hidrológicas.

ONU. (1972). Plan de Acción para el Medio Ambiente desarrollado en la Conferencia de Naciones Unidas sobre el Ambiente Humano.

(1974). Convenio Nórdico sobre la Protección del Medio Ambiente.

(1976). Convención para la Protección del Mar Mediterráneo.

PNUMA (1978). Principios sobre la Conservación y la utilización harmoniosa de los recursos naturales compartidos por dos o más Estados.

Ropme. (1978). Convenio Regional de Kuwait sobre Cooperación para la Protección del Medio Marino contra la Contaminación.

Aladi. (1980). Tratado de Montevideo.

UICN. (1982). Carta Mundial de la Naturaleza adoptada por la Asamblea General de las Naciones Unidas, por la Resolución 37/7(1982).

ONU. (1982). Convención de las Naciones Unidas sobre el Derecho del Mar.

PNUMA. (1983). Convención para la Protección y el Desarrollo del Medio Ambiente Marino de la Región del Gran Caribe.

CEE. (1985). Directiva relativa a la evaluación de las repercusiones de determinados proyectos públicos y privados sobre el medio ambiente, del Consejo de las Comunidades Europeas - Directiva 85/337/CEE.

(1986). Convención de Noumea.

PNUMA. (1987). Metas y principios de las Evaluaciones de Impacto Ambiental.

(1991). Tratado entre Chile y Argentina sobre medio ambiente.

Unece. (1991). Convenio sobre la Evaluación del Impacto Ambiental en un Contexto Transfronterizo - Convenio Espoo.

ONU. (1992a). Declaración de Río sobre el Medio Ambiente y el Desarrollo - Declaración de Río. 
ONU. (1992b). Convenio de Diversidad Biológica.

(1992). Tratado de Libre Comercio para América del Norte.

(1992). Convenio sobre la protección y uso de los cursos de agua transfronterizos y los lagos internacionales -Convenio de Helsinki.

(1992). Convención para la Protección del Medio Ambiente Marino del Océano Báltico.

(1994). Convención sobre la Cooperación para la Protección y Uso Sostenible del río Danubio.

(1995). Memorando de Entendimiento sobre los principios ambientales que gobiernan el desarrollo económico del área del río Tumen y del Noroeste Asiático, 1995.

ONU. (1997). Convención de las Naciones Unidas sobre el derecho de los usos de los cursos de agua internacionales para fines distintos de la navegación.

Unece. (1998). Decisión 1/3 de la reunión de las Partes del Convenio Espoo.

(2000). Protocolo de aplicación de la Convención Alpina de 1991.

(2000). Tratado sobre integración y complementación minera entre Chile y Argentina.

CDI. (2001a). Proyecto de artículos de «Prevención del daño transfronterizo resultante de actividades peligrosas» adoptado por la CDI en su $53 .^{\circ}$ período de sesiones.

CDI. (2001b). Comentarios generales al texto de los artículos sobre Prevención del Daño Transfronterizo Resultante de Actividades Peligrosas, aprobados por la CDI en su 53. ${ }^{\circ}$ período de sesiones.

UNEP. (2002). Governing Council Decision SS. VII/4. Compliance with and Enforcement of Multilateral Environmental Agreements.

PNUMA (2002a). Lineamientos sobre Cumplimiento e Implementación de Tratados Ambientales Multilaterales.

PNUMA (2002b). Principios de Johannesburgo sobre el papel que cumplen el Derecho y el Desarrollo Sostenible.

(2002). Convenio de Cooperación para la Protección y el Desarrollo Sostenible de las Zonas Marinas y Costeras del Pacífico Noroeste.

(2003). Convención Marco sobre la Protección y el Desarrollo Sostenible de los Cárpatos.

(2003). Convenio marco para la protección del medio marino del Mar Caspio Convenio de Teherán.

\section{Legislación diversos países}

\section{Argentina}

Ley Nacional 25675, Ley General del Ambiente. Boletín Oficial, Buenos Aires, 26 de noviembre de 2002.

Decreto 349/005, Reglamento de evaluación de impacto ambiental. Diario Oficial, Montevideo, Uruguay, 3 de octubre de 2005. 


\section{Bolivia}

Ley 1333, Ley del Medio Ambiente. Bolivia, 27 de abril de 1992.

Decreto Supremo 24176, Reglamento de Prevención y Control Ambiental - anexo 2. Bolivia, 8 de diciembre de 1995 .

\section{Brasil}

Resolución Conama 237/97. Diário Oficial da União 247, Brasil, 19 de diciembre de 1997.

\section{Chile}

Ley 19300, Ley Orgánica de la Superintendencia del Medio Ambiente. Diario Oficial, Santiago, Chile, 9 de marzo de 1994.

Ley 20417, Crea el Ministerio, el Servicio de Evaluación Ambiental y la Superintendencia del Medio Ambiente. Diario Oficial, Santiago, Chile, 26 de enero de 2010.

D. S. 40/2012, Reglamento del Sistema de Evaluación de Impacto Ambiental. Diario Oficial, Santiago, Chile.

\section{Colombia}

Decreto 2811, Código Nacional de Recursos Naturales Renovables y de Protección al Medio Ambiente. Diario Oficial 34243, Bogotá, Colombia, 18 de diciembre de 1974.

Ley 99, por la cual se crea el Ministerio del Medio Ambiente, se reordena el Sector Público encargado de la gestión y conservación del medio ambiente y los recursos naturales renovables, se organiza el Sistema Nacional Ambiental, SINA, y se dictan otras disposiciones. Diario Oficial 41146, Bogotá, 22 de diciembre de 1993.

Decreto 2041-2014, por el cual se reglamenta el título VIII de la Ley 99 de 1993 sobre licencias ambientales. Diario Oficial 19305, Bogotá, 15 de octubre de 2014.

\section{Costa Rica}

Decreto Ejecutivo 31849-Minae-S-MOPT-MAG-MEIC, Reglamento General sobre los Procedimientos de Evaluación de Impacto Ambiental de Costa Rica. La Gaceta, Costa Rica, 28 de junio de 2004.

\section{Ecuador}

Decreto Ejecutivo 3399, Texto Unificado de Legislación Secundaria del Ministerio del Ambiente. Registro Oficial 725, Quito, 16 de diciembre de 2002.

Ley de Prevención y Control de la Contaminación Ambiental. Registro Oficial 418, Quito, Ecuador, 10 de septiembre de 2004.

\section{Guatemala}

Acuerdo Gubernativo 23-2003, Reglamento de Evaluación, Control y Seguimiento Ambiental. Diario de Centro América, Guatemala, 29 de enero 2003.

\section{Guayana Francesa}

Loi 76-629, relative à la protection de la nature. Francia, 10 de julio de 1976.

Décret 77-1141, pris pour l'application de l'article 2 de la loi n ${ }^{\circ}$ 76-629 du 10 juillet 1976 relative à la protection de la nature. Francia, 12 de octubre de 1977.

\section{Guyana}

Chapter 20:05. Environmental Protection Act. Guyana, 1998. 


\section{Paraguay}

Ley 294/1993, Ley de Evaluación de Impacto Ambiental y su modificatoria Ley 345/1994. Gaceta Oficial, Asunción, Paraguay, 31 de diciembre de 1993.

Decreto Reglamentario 453/2013, Reglamenta la Ley 294/19993 de evaluación de impacto ambiental y su modificatoria, la Ley 345/1994. Gaceta Oficial, Asunción, Paraguay, 8 de octubre de 2013.

\section{Surinam}

Environmental Assessment Guidelines Volume I: Generic. Surinam, agosto de 2009.

\section{Uruguay}

Ley 16466, Declárase de interés general, la protección del mismo, contra cualquier tipo de depredación, destrucción o contaminación. Diario Oficial 23977, Montevideo, Uruguay, 26 de enero de 1994.

Ley 17283, Declarase de interés general, de conformidad con lo establecido en el artículo 47 de la Constitución de la República, que refiere a la protección del medio ambiente. Diario Oficial 25663, Montevideo, Uruguay, 12 de diciembre de 2000.

\section{Venezuela}

Decreto 1257, Ley Orgánica del Ambiente. Gaceta Oficial 35946, Caracas, Venezuela, 26 de abril de 1996.

\section{Legislación nacional peruana}

Decreto Legislativo 613, Código del Medio Ambiente y los Recursos Naturales. Diario Oficial El Peruano, Lima, Perú, 8 de septiembre de 1990.

Decreto Legislativo 757, Ley Marco para el Crecimiento de la Inversión Privada. Diario Oficial El Peruano, Lima, Perú, 13 de noviembre de 1991.

Decreto Supremo 016-93-EM, Reglamento del Título decimoquinto del Texto Único Ordenado de la Ley General de minería sobre el medio ambiente - Reglamento para la Protección Ambiental en la Actividad Minero-Metalúrgica. Diario Oficial El Peruano, Lima, Perú, 1 de mayo de 1993.

Ley 26410, Ley del Consejo Nacional del Ambiente. Diario Oficial El Peruano, Lima, Perú, 22 de diciembre de 1994.

Ley 26786, Ley de Evaluación de Impacto Ambiental para Obras y Actividades. Diario Oficial El Peruano, Lima, Perú, 13 de mayo de 1997.

Decreto Supremo 004-99-PE, Reglamento General para la Protección Ambiental en las Actividades Pesqueras y Acuícolas. Diario Oficial El Peruano, Lima, Perú, 28 de marzo de 1999.

Decreto Supremo 012-2001-PE, Reglamento de la Ley General de Pesca. Diario Oficial El Peruano, Lima, Perú, 14 de marzo de 2001.

Ley 27446, Ley del Sistema Nacional de Evaluación de Impacto Ambiental. Diario Oficial El Peruano, Lima, Perú, 21 de abril de 2001.

Ley 28245, Ley marco del Sistema Nacional de Gestión Ambiental. Diario Oficial El Peruano, Lima, Perú, 8 de junio de 2004. 
Ley 28611, Ley General del Ambiente. Diario Oficial El Peruano, Lima, Perú, 13 de octubre de 2005.

Decreto Supremo 015-2006- EM. Reglamento para la Protección Ambiental en las Actividades de Hidrocarburos. Diario Oficial El Peruano, Lima, Perú, 3 de marzo de 2006.

Decreto Supremo 020-2008-EM, Reglamento Ambiental para las Actividades de Exploración Minera. Diario Oficial El Peruano, Lima, Perú, 2 de abril de 2008.

Decreto Legislativo 1013, Ley de Creación, Organización y Funciones del Ministerio del Ambiente. Diario Oficial El Peruano, Lima, Perú, 14 de mayo de 2008.

Decreto Supremo 019-2009-Minam, Reglamento de la Ley 27446, Ley del Sistema Nacional de Evaluación de Impacto Ambiental. Diario Oficial El Peruano, Lima, Perú, 25 de septiembre de 2009.

Ley 29325, Ley del Sistema Nacional de Evaluación y Fiscalización Ambiental. Diario Oficial El Peruano, Lima, Perú, 5 de marzo de 2009.

R. M. 157-2011-Minam, Primera Actualización del Listado de Inclusión de los Proyectos de Inversión sujetos al Sistema Nacional de Evaluación de Impacto Ambiental SEIA. Diario Oficial El Peruano, Lima, Perú, 21 de julio de 2011.

Decreto Supremo 015-2012-Vivienda, Reglamento de Protección Ambiental para proyectos vinculados a las actividades de Vivienda, Urbanismo, Construcción y Saneamiento. Diario Oficial El Peruano, Lima, Perú, 14 de septiembre de 2012.

Decreto Supremo 019-2012-AG, Reglamento de Gestión Ambiental del Sector Agrario, Reglamento de Protección Ambiental para proyectos vinculados a las actividades de Vivienda, Urbanismo, Construcción y Saneamiento. Diario Oficial El Peruano, Lima, Perú, 14 de noviembre de 2012.

Ley 29968, Ley de creación del Servicio Nacional de Certificación Ambiental para las Inversiones Sostenibles - Senace. Diario Oficial El Peruano, Lima, Perú, 20 de diciembre de 2012.

Decreto Supremo 040-2014-EM, Reglamento de Protección y Gestión Ambiental para las Actividades de Explotación, Beneficio, Labor General, Transporte y Almacenamiento Minero. Diario Oficial El Peruano, Lima, Perú, 12 de noviembre de 2012.

Decreto Supremo 039-2014-EM, Reglamento para la Protección Ambiental en las Actividades de Hidrocarburos. Diario Oficial El Peruano, Lima, Perú, 12 de noviembre de 2014.

Decreto Supremo 017-2015-Produce, Reglamento de Gestión Ambiental para la Industria Manufacturera y Comercio Interno. Diario Oficial El Peruano, Lima, Perú, 6 de junio de 2015.

\section{Jurisprudencia}

\section{CIJ}

C. I. J. Corfu Channel case, Judgment of April 9"th 1949: I. C. J. Reports 1949.

C. I. J. Fisheries case, Judgment of December 18 ${ }^{\text {th }}$ 1951: I. C. J. Reports 1951.

C. I. J. North Sea Continental Shelf, Judgment, I. C. J. Reports 1969.

C. I. J. Continental Shelf (Libyan Arab Jamahiriya / Malta), Judgment, I. C. J. Reports 1985. 
C. I. J. Legality of the Threat of Use of Nuclear Weapons, Advisory Opinion, I. C. J. Reports 1996.

C. I. J. Gabcikovo- Nagymaros Project (Hungary/Slovakia), Judgment, I. C. J. Reports 1997.

C. I. J. Gabcikovo-Nagymaros Project (Hungary/Slovakia), Separate Opinion of Vice-President Weeramantry, I.C.J. Reports 1997.

C. I. J. Sovereignty over Pedra Branca / Pulau Batu Puteh, Middle Rocks and South Ledge (Malaysia vs. Singapore), Judgment, I.C.J. Reports 2008.

C. I. J. Pulp Mills on the River Uruguay (Argentina v. Uruguay), Judgement, I. C. J. Reports 2010.

C. I. J. Request for an Examination of the Situation in Accordance with Paragraph 63 of the Court S Judgment of 20 December 1974 in the Nuclear Tests (New Zealand v. France) Case, I. C. J. Reports 1995.

\section{Corte IDH}

Corte IDH. Caso Garrido y Baigorria vs. Argentina. Reparaciones y Costas. Sentencia del 27 de agosto de 1998 . Serie C N. 39.

Corte IDH. Caso Durand y Ugarte vs. Perú. Fondo. Sentencia del 16 de agosto de 2000. Serie C N. ${ }^{\circ} 68$.

Corte IDH. Caso Baena Ricardo y otros (270 trabajadores) vs. Panamá. Fondo, Reparaciones y Costas. Sentencia del 2 de febrero de 2001. Serie C N. ${ }^{\circ} 72$.

Corte IDH. Caso Almonacid Arellano y otros vs. Chile. Excepciones Preliminares, Fondo, Reparaciones y Costas. Sentencia del 26 de septiembre 2006. Serie C N. ${ }^{\circ} 154$.

\section{Tribunal Internacional del Derecho del Mar}

Responsibilities and Obligations of States Sponsoring Persons and Entities with Respect to Activities in the Area, Advisory Opinion, Itlos Case N. ${ }^{\circ}$ 17, Itlos Rep. 2011.

The MOX Plant Case (Ireland v. United Kingdom), Provisional Measures, Itlos Case N. ${ }^{\circ}$ 10, ICGJ 343 (Itlos 2001).

\section{Tribunales arbitrales}

Iron Rhine Arbitration (Belgium/Netherlands), 2005, RIAA, vol. XXVII, pp. 35-125.

Trail Smelter (EEUU v. Canada), RIAA, vol. III (1938, 1941), pp. 1905-1982.

\section{Software}

Ingemmet. Geocatmin. Recuperado de http://geocatmin.ingemmet.gob.pe/geocatmin/ index.html 